\title{
Untersuchung einer Anzahl von Muskeln von Rana esculenta in bezug auf ihren Bau und ihre Kernverhältnisse.
}

Von

\section{P. Schiefferdecker.}

In drei Muskelarbeiten ${ }^{1}$ ) habe jch bisher schon eine Anzahl von gesunden und kranken Muskeln des Menschen und eine Anzahl von gesunden Muskeln verschiedener Tiere nach einer neuen, von mir angegebenen Methode untersucht. Wegen der Resultate, welche diese Arbeiten ergeben haben, muss ich auf dieselben verweisen, ebenso wegen der Methode; eine kurze Zusammenstellung hierüber findet sich in der Einleitung zu der letzten Arbeit ${ }^{2}$ ). Es kam mir bei diesen Arbeiten darauf an, zu ergründen, in welcher Weise die Funktion eines Muskels von seinem Baue abhängig ist, und zwar speziell von dem Verhalten der Kerne und der Fasern zueinander in bezug auf ihre Massen und die Verteilung dieser. Ausserdem wurde das mikroskopische Bild des ganzen Muskels und seiner einzelnen Teile berücksichtigt und, soweit es nötig erschien; auch die Beschaffenheit der Fibrillen. Immerhin sind diese letzteren im ganzen mehr vernachlässigt worden gegenüber den anderen Bildungen, und zwar aus dem Grunde, weil mir die Kernverbältnisse zunächst als die bei weitem wichtigeren erschienen. Die Untersuchung der menschlichen Muskeln wurde dadurch erschwert, dass es einmal

1) P. Schiefferdecker, Beiträge zur Kenntnis der Myotonia congenita der Tetanie mit myotonischen Symptomen, der Paralysis agitans und einiger anderer Muskelkrankheiten, zur Kenntnis der Aktivitätshypertrophie und des normalen Muskelbaues. Mit klinischen Beiträgen von Professor Fr. Schultze. Deutsche Zeitschr. f. Nervenheilk. Bd. 25 H. 1-4 S. 1-345 m. 15 Taf. 1903. P. Schiefferdecker, Muskeln und Muskelkerne. 317 Seiten mit $20 \mathrm{Ab}$ bildungen im Text. Joh. Ambros. Barth, Leipzig 1909. - P. Schiefferdecker, Untersuchung des Zwerchfelles auf seinen Bau und seine Kernverhältnisse. Pflüger's Arch. Bd. 139 S. 337-427, 7 Textfig. u. 4 Fahnentab.

2) P. Schiefferdecker, Untersuchung des Zwerchfelles auf seinen Bau und seine Kernverhältnisse. Pfl üger's Arch. Bd. 139 S. 337-427, 7 Textfig. u. 4 Fahnentab. 
schwierig war, das nötige Material überhaupt zu erhalten, und zweitens dadurch, dass die menschlichen Muskeln, welche man erhalten konnte, sich in sehr verschiedenen Zuständen in bezug auf die Totenstarre befanden. Die hierdurch entstandenen Fehler versuchte ich auszugleichen durch Benutzung der Ha uck' schen Zahlen ${ }^{1}$ ); doch ergab es sich im Verlaufe der Untersuchung mehr und mehr, dass diese doch augenscheinlich nur ziemlich unvollkommene Korrekturen erlaubten, und dass es eigentlich nötig wäre, weitere ausgedehnte Untersuchungen über die genauen Grössen der Veränderungen auszuführen, welche durch die Totenstarre in den mensehlichen Muskeln herbeigeführt werden. Bei den Tieren lagen die Verhältnisse ja weit günstiger. Hier konnte man die Muskeln einfach dem frisch getöteten Tiere entnehmen. Indessen auch dieses war nicht so einfach; denn ein Muskel, der dem frisch getöteten Tiere entnommen und in die Fixierungsflüssigkeit eingelegt wird, verändert sich natürlich ziemlich stark und in einer gar nicht vorher zu bestimmenden Weise, da er, von seinem Ursprungs- und Endpunkte losgelöst, dem Reize und der sonstigen Einwirkung der Fixierungsflüssigkeit ausgesetzt wird. Es wurde daher auch bei den früher untersuchten tierischen Muskeln - es sind bis jetzt untersucht worden die weissen und roten Kaninehenmuskeln und die weissen und roten Karauschenmuskeln - stets so verfahren, dass das ganze Tier, von der Haut befreit, in die Fixierungsflüssigkeit (als solche diente stets Alkohol oder die Formollösung nach Jores) eingelegt wurde, eventuell, dass ausserdem vorher das Tier noch mit der betreffenden Härtungsflüssigkeit injiziert wurde. Die fixierten und gehärteten Mnskeln wurden daun zur Untersuchung herauspräpariert. Nach den Untersuchungen, die ich beim Menschen, dem Kaninchen und der Karausche sowie bei zwei Hundemuskeln ausgeführt hatte, wünschte ich uun, von einem Tiere aus einer anderen Klasse Muskeln zu untersuchen, und zwar am besten eine grössere Anzahl von solchen, um das spezifische Verhalten der einzelnen Muskeln desselben Tieres feststellen zu können. Da lag es nahe, den Wasserfrosch zu wählen, der ja ein so beliebtes Objekt für wissenschaftliche Untersuchungen seit langer Zeit darstellt. Der Frosch hat ausserdem den Vorteil,

1) L. Hauck, Untersuchungen zur normalen und pathologischen Histologie der quergestreiften Muskulatur. 18 Seiten. Inang.-Diss. Leipzig 1900. Zugleich erschienen in Deutsche Zeitschr. f. Nervenheilk. Bd. 17. 
dass bei den bei weitem meisten Muskeln Farbenunterschiede kaum festzustellen sind, so dass die Vergleithung eine einfachere war, da nicht noch die Art der Färbung als ein komplizierendes Moment hinzutrat. Ausgesprochen rötlich und dadurch von den anderen Muskeln sich deutlich unterscheidend, fand $\mathrm{Knoll}^{1}$ ) (S. 684) bei Rana nur den Submaxillaris, und Lehmann ${ }^{2}$ ) (S. 340) gibt an, dass der Gehalt an Muskelhämoglobin beim Frosche so gering ist, dass die quantitative Bestimmung nicht scharf gelang. Das Zwerchfell von Säugern und andere sehr angestrengte Muskeln hatten dagegen sehr hohe Zahlen. Der für hiesige Verhältnisse grosse männliche Froseh wurde am 7. November getötet und in Alkohol gelegt. Das Tier war in sehr gutem Ernährungszustande, die Leber gross, der Fettkörper sehr gut entwickelt, der Darm war allerdings leer, das Tier hatte also schon eine Zeitlang gehungert. Es wurde von diesem Tiere eine grössere Anzahl von Muskeln herauspräpariert und in Celloidin eingebettet. Von diesen Muskeln kamen 16 zur Untersuchung und sind hier ausgemessen worden. Die Zahl der Muskeln sollte eigentlich noch grösser sein, durch besondere Verhältnisse fielen aber im Laufe der Untersuchungen eine Anzahl von Muskeln aus, die nicht wieder ersetzt werden konnten, und da es zu dem genauen Vergleiche nötig war, dass alle hier untersuchten Muskeln von demselben Tiere berstammten, so waren diese Lücken nicht gut auszufüllen. Die hier untersuchten Präparate sind im wesentlichen in den Jahren 1904 und 1905 hergestellt worden. Immerhin stellen auch diese hier ausgemessenen 16 Muskeln schon ein Material dar, das hinreichend gross ist, um eine Anzahl von Schlüssen zu erlauben.

Ich werde, wie ich das auch in meinen früheren Arbeiten getan habe, zuerst von jedem der untersuchten Muskeln eine Beschreibung des mikroskopischen Bildes geben und dann auf die Ergebnisse der Ausmessung der Fasern und Kerne eingehen. Die Literatur werde ich dabei an geeigneter Stelle berücksichtigen.

1) Ph. Knoll, Über protoplasmaarme und protoplasmareiche Muskulatur. Denkschr. d. k. Akad. d. Wiss. zu Wien, math.-naturw. Kl. Bd. 58 S. $638-700$ m. 9 Taf. 1891 .

2) K. B. Lehmann, Untersuchungen über den Hämoglobingehalt der Muskeln. Zeitschr. f. Biol. Bd. 45 S. 324-345. 190 . 


\section{Beschreibung des mikroskopischen Bildes der Muskely.}

Die Muskeln sind im folgenden geordnet - und diese Reihenfolge wird durch die ganze Arbeit hindurch beibehalten werden nach der Länge der Kerne, so dass diejenigen Muskeln, die die kürzesten Kerne haben, zuerst kommen und dann die Reihe sich aufsteigend fortsetzt. Es ist diese Anordnung getroffen worden, nur um überhaupt ein Einteilungsprinzip zu haben, und weil die Kernlänge, die ich bisher schon als ein wichtiges spezifisches Maass kemnen gelernt hatte, sich am einfachsten dazu darbot.

\section{A. Rectus abdominis (400 Fasern, 1184 Kerne).}

\section{Celloidin-Querschnitte, Färbung mit Hämatoxylin (Ehrlich).}

Der Querschnitt zeigt eine Abteilung in Bündel nur hin und wieder angedeutet. Die Muskelfasern sind meist gut im Querschnitte getroffen, hin und wieder auch im Schrägschnitte. Die Querschnitte der Muskelfasern sind polygonal mit mehr oder weniger abgerundeten Ecken. Sie liegen dicht aneinander. Die grösseren Septa zwischen den Bündeln sind mässig kernreich. Zwischen den Muskelfaserquerschnitten hin und wieder ein Bindegewebskern. Die Faserquerschnitte erscheinen fein punktiert. Abteilung von Fibrillenbündeln nicht sichtbar. Die fast sämtlich binnenständigen Kerne zeigen vielfach dreiseitige bis polygonale Formen mit scharfen Ecken. Durchschnittliche Grösse des Faserquerschnittes $3791 q \mu$, Max. $7050 q \mu$, Min. $680 q \mu$. Durchschnittliche Kernzahl 2,96, Max. 5, Min. 1. Durchschnittliche Kerngrösse 5,52 qu, Max. 15,50 qu, Min. 2,50 qu.

\section{Celloidin-Längsschnitte, Färbung mit Hämatoxylin (E h rlich).}

Die Fasern liegen mehr oder weniger stark gewellt. Querstreifung deutlich, teilweise Ruhezustand, teilweise Kontraktion. Längsstreifung deutlich. Die lang ovalen bis stäbchenförmigen Kerne sind nicht immer ganz gerade, teilweise etwas gebogen. Kernkörperchen treten nur hin und wieder hervor, dann meist 1-2. Kernreihen nicht sichtbar. Kernlänge 20,64 $\mu$, Max. 30,00, Min. 14,00 $\mu$.

\section{Celloidin-Quer- und -Längsschnitte, Färbung nach Calleja.}

Infolge der Färbung treten die Septa hier etwas deutlicher vor als bei der Hämatoxylinfärbung, immerhin ist die Abgrenzung der Bündel nur eine unvollkommene.

\section{Celloidin-Quer- und -Längsschnitte, Färbung mit Orceill.}

Nur in den dickeren Septen sind einige feine elastische Fasern sichtbar, die teils der Länge, teils der Quere nach verlaufen, und von denen einige wenige quer verlaufende Fasern in die abtretenden Septa übergehen. Der Muskel ist also sehr arm an elastischen Fasern.

5. Celloidin-Quer- nnd -Längsschnitte, Färbung mit Karbol-Toluidinblau. Mässig viele Mastzellen, die unregelmässig verstrent liegen. 


\section{B. Transversus abdom in is (400 Fasern, 1091 Kerne).}

\section{Celloidin-Querschnitte, Färbung mit Hämatoxylin (Ehrlich).}

Es finden sich auf dem Querschnitte des Muskels nur sehr wenige richtige Faserquerschnitte, dagegen sehr viele Schrägschnitte und sogar Längsschnitte. Durch den langen schmalen Querschnitt des Muskels zieht sich ungefähr in der Mitte, etwas näher dem einen Rande, ein verhältnismässig breites Bindegewebsseptum hin, von dem mach beiden Seiten dünnere Septa abgehen und so die beiden dünnen Muskelplatten in Unterabteilungen von sehr verschiedener Grösse und Form zerlegen: die Querschnitte der Mrtskelbündel. Diese Septa ziehen bis zu dem Perimysium externum hin, welches den Querschnitt an beiden Seiten begrenzt und eine Bindegewebsschicht darstellt, die etwas dicker ist als das

mediane Septum (je nach der Dicke dieses, die ziemlich wechselnd ist, ist das Perimysium externum vielleicht doppelt bis anderthalb mal so dick). Von den Septa, welche die Bündel begrenzen, können dann mitunter wieder dünnere Septa abtreten, welche Unterabteilungen bilden. Die einzelnen Muskelfaserquerschnitte erscheinen polygonal mit im allgemeinen mehr scharfen Eicken; sie liegen dicht aneinander. Was die nähere Beschaffenheit der Muskelfaserquerschnitte aulangt, so erscheinen sie mehr oder weniger dentlich in polygonale Felder eingeteilt: Fibrillenbündel, die von kleinen Pünktchen erfüllt werden, den Fibrillenquerschnitten. Das mediane Septum enthält ziemlich zahlreiche Kerne, zwischen den Muskelfaserquerschnitten finden sich vereinzelte Kerne. In den Muskelfaserquerschnitten liegen die Kernquerschnitte meist binnenständig, sie sind ziemlich stark gefärbt, kreisförmig bis kurz oder lang oval oder polygonal. Durchschnittliche Grösse des Faserquerschnittes $2559 q \mu$, Max. $5750 q \mu$, Min. 680. qu. Durchschnittliche Kernzahl 2,73, Max. 5, Min. 1. Durchschnittliche Kerngrösse 8,81 $q \mu$, М̈ax. 24,00 $q \mu$, Min. 2,00 qu.

\section{Celloidin-Längsschnitte, Färbung mit Hämatoxylin (E h rli ch).}

Entsprechend dem Querschnitte liegen auf dem Längsschnitte die Fasern sehr unregelmässig. Querstreifung durchschnittlich nur schwach sichtbar, Ruhezustand, Längsstreifung ebenfalls nur schwach sichtbar. Die mässig stark gefärbten Kerne sind lang, stäbchenförmig, und zeigen meist deutlich ein bis zwei Kernkörperchen. Durchschnittliche Kernlänge 21,46 $\mu$, Max. 28,00 $\mu$, Min. 14,00 $\mu$.

\section{Celloidin-Quer- und -Längsschnitte, Färbung nach Calleja.}

Das Bild entspricht durchaus dem unter 1 und 2 beschriebenen.

\section{Celloidin-Quer- und -Längsschnitte, Färbung mit Orceim.}

Sowohl von den beiden Schichten des Perimysium externum wie von dem medialen Septum, welches auch auf dem Längsschnitte deutlich hervortritt, gehen zahlreiche, quer verlaufende elastische Fasern aus, welche die nächstgelegenen Muskelbündel umspinnen und mehr oder weniger weit durch die beiden Muskelschichten hin zu verfolgen sind. Diese elastischen Fasern gehen aus von solchen; die in dem Septum sowohl wie in den Schichten des Perimysium zum Teile der Länge nach, zu einem; und zwar wie es scheint zum grösseren Teile, 
aber auch der Quere nach verlaufen. Wir würden also bei diesem Muskel den seltenen Fall haben, dass die elastischen Fasern sowohl in dem Perimysium externum wie in dem Hauptseptum hauptsächlich der Quere nach verlaufen, während sie ja sonst meist der Länge nach verliefen und nur mehr oder weniger viele schräge oder quere Ästé abgaben, welche die einzelnen Muskelfasern umspannen. Dieser Muskel erscheint in Anbetracht der Armut der Froschmuskeln an elastischen Fasern sehr reich an solchen, wenngleich er absolut genommen immer nur erst ziemlich wenige elastische Fasern enthält.

5. Celloidin-Quer- und -Längsschnitte, Färbung mit Karbol-Tolnidinblau.

Hin und wieder einzelne Mastzellen.

$$
\text { C. Sartorius (400 Fasern, } 1238 \text { Kerne). }
$$

\section{Celloidin-Querschnitte, Färbung mit Hämatoxylin (E h r li ch).}

Schöne Querschnitte. Die Zerteilung in Bündel wieder sehr mangelhaft, da die Septa nur hin und wieder deutlich hervortreten. Die Muskelfaserquerschnitte sind polygonal mit bald mehr abgerundeten, bald mehr scharfen Ecken. Sie liegen dicht aneinander, nur hin und wieder siebt man zwischen ihnen Kerne. Die zahireichen Kernquerschnitte liegen fast alle binnenständig, sie sind kreisförmig bis kurz oval, mässig stark gefärbt. Durchschnittliche Grösse des Faserquerschnittes 4368 q $\mu$, Max. 10480 q $\mu$, Min. 1005 q $\mu$. Durchschnittliche Kernzahl 3,10, Max. 6, Min. 1. Durchschnittliche Kerngrösse 9,37 qu, Max. $22,00 q \mu$, Min. 3,50 q $\mu$.

\section{Celloidin-Längsschnitte, Färbung mit Hämatoxylin (Ehrlich).}

Fasern schön gestreckt, Querstreifung und Längsstreifung deutlich, meist Ruhezustand. Die Kerne lang oval und stäbchenförmig, mässig stark gefärbt, Kernkörperchen meist deutlich hervortretend, in verschiedener Menge, meist 1-4. Kernreihen fehlen. Durchschnittliche Kernlänge 21,56 $\mu$, Max. 28,00 $\mu$, Min. $16,00 \mu$.

\section{Celloidin-Quer- und -Längsschnitte, Färbung nach Calleja.}

Das Callejabild entspricht dem unter 1 beschriebenen. Eine Fibrillenfärbung tritt nur an manchen dickeren Stellen der Septa hervor.

\section{Celloidin-Quer- und -Längsschnitte, Färbung mit Orcein.}

Nur hin und wieder an den dickeren Stellen der Septa einige feine elastische Fasern. Der Muskel ist also sehr arm an elastischen Fasern.

\section{Celloidin-Qner- nnd -Längsschnitte, Färbung mit Karbol-Toluidinblan.}

Hin und wieder vereinzelte Mastzellen, die der Dünne der Septa entsprechend mehr oder weniger lang gestreckt erscheinen.

\section{Pectoralis pars epicoracoidea (400 Fasern, 1081 Kerne). 1. Celloidin-Querschnitte, Färbung mit Hämatoxylin (Ehrlich).}

Auf dem Querschnitte des Muskels erscheinen die Muskelfasern teilweise im Querschnitte, teilweise im Schrägschnitte, mitunter sogar im Längsschnitte. 
Bündelanordnung undeutlich; so weit die: Septa sichtbar sind, enthalten - sie ziemlich viele Kerne. Zwischen den Muskelfaserquerschnitten, die dicht aneinander liegen, nur hin und wieder ein Bindegewebskern. Die Muskelfaserquerschnitte sind polygonal mit hald mehr scharfen, bald mehr abgerundeten Ecken; im allgemeinen sind die Ecken schärfer als bei den meisten anderen Froschmuskeln. Kleine Faserquerschnitte, die unvermittelt zwischen den grossen liegen, treten hier nur selten hervor; dagegen findet man hin und wieder mehrere kleine Querschnitte von ähnlicher Grösse eng zusammen liegend, die einen ganz anderen Eindruck machen, wie die sonst bei den anderen Muskeln beschriebenen. Die Oberfläche der Faserquerschnitte erscheint fein punktiert, hin und wieder sieht man ziemlich deutlich abgegrenzte Fibrillenbündel. Die fast sämtlich binnen. ständigen Kerne sind meist kurz oval bis unregeJmässig polygonal. Durch schnittliche Grösse des Faserquerschnittes $2942 q \mu$, Max. $8290 q \mu$, Min. $425 q \mu$ Durchschnittliche Kernzahl 2,70, Max. 6, Min. 1. Durchschnittliche Kerngrösse 9,61 $q \mu$, Max. 17,50 $q_{\mu}$, Nin. 2,00 qu.

\section{Celloidin-Längsschnitte, Färbung mit Hämatoxylin (E h r li ch).}

Fasern schön gestreckt, Querstreifung deutlich, Ruhezustand, Längsstreifung ebenfalls deutlich, Kerne lang oval bis stäbchenförmig, mässig stark gefärbt. Kernkörperchen mitunter deutlich, meist 1-2, mitunter fehlend. Durchschnittliche Kernlänge $21,60 \mu$, Max. $28,00 \mu$, Min. 14,00 $\mu$.

\section{Celloidin-Quer- und -Längsschnitte, Färbung nach Calleja.}

Das Bild entspricht dem unter 1 beschriebenen.

\section{Celloidin-Quer- und -Längsschnitte, Färbung mit Orcein.}

Elastische Fasern nur in den Hauptsepten, zum Teil der Länge, zum Teil der Quere nach verlaufend, und sich von hier aus in die abtretenden Septa als Querfasern fortsetzend. Im ganzen sebr wenig elastisches Gewebe.

\section{Celloidin-Quer- und -Längsschnitte, Färbung mit Karbol-Tolnidinblau.}

Nastzellen hin und wieder, im ganzen selten.

\section{E. Anconaeus caput scapulare (400 Fasern, 1273 Kerne).}

\section{Celloidin-Qnerschnitte, Färbung mit Hämatoxylin (E h rlich).}

Die Zerteilung in Bündel ist sehr undeutlich, da die Septa nur hin und wieder sichtbar sind. Die Muskelfaserquerschnitte liegen dicht aneinander, hin und wieder ein Bindegewebskern zwischen ihnen. Sie sind polygonal, die Kanten mehr oder weniger abgerundet, aber im Vergleiche zu den meisten anderen Froschmuskeln doch verhältnismässig scharf. Die Oberfläche der Faserquerschnitte erscheint sehr fein punktiert. Hin und wieder sieht man zwischen den grossen Querschnitten unvermittelt kleine liegen, mit scharfen Ecken, doch sind sie im ganzen auf diesen Schnitten selten. Die Kerne liegen fast sämtlich binnenständig, sind mässig stark gefärbt, kreisförmig bis kurz oval. Durchschnittliche Grösse des Faserquerschnittes $2910 q \mu$, Max. $8005 q \mu$, Min. $615 q \mu$. Durchscbnittliche Kernzabl 3,18, Max. 7, Min. 1. Durchschnittliche Kerngrösse 6,37 qu, Max. 12,50 q $\mu$, Min. 2,00 qu. 


\section{Celloidin-Längsschnitte, Färbung mit Hämatoxylin (Eh rlich).}

Die Fasern liegen lang gestreckt, dicht aneinander und erscheinen kernreich. Querstreifung sehr deutlich, fast überall Ruhezustand. Längsstreifung nur angedeutet. Kerne stäbchenförmig oder lang oval, mässig stark gefärbt, meist mit 1-2 Kernkörperchen versehen. Die Konturen der Kerne sind meist glatt, hin und wieder leicht geschlängelt. Kernreihen nicht sichtbar. Wo die Kerne geschlängelt verlaufen, verlaufen auch die Fibrillen etwas geschlängelt. Die Schlängelung der Kerne ist also wohl auf eine Durchbiegung im Verlaufe der Faser zurückzuführen. Durchschnittliche Kernlänge 22,44 $\mu$, Max. 30,00 $\mu$, Min. $16,00 \mu$.

\section{Celloidin-Qner- und -Längsschnitte, Färbung nach Calleja.}

Das Callejabild bestätigt durchaus die unter 1 gegebene Beschreibung; trotz der Färbung treten die Septa nur hin und wieder hervor.

\section{Celloidin-Quer- und -Längsschnitte, Färbung mit Orcein.}

Die elastischen Fasern treten nicht deutlich genug durch die Färbung hervor, um eine Beschreibung geben zu können.

5. Die Färbnng mit Karbol-Toluidinblau ist bei diesem Muskel ausgefallen.

$$
\text { F. Tensor fasciae latae (400 Fasern, } 1299 \text { Kerne). }
$$

\section{Celloidin-Querschnitte, Färbung mit Hämatoxylin (Ehrlich.)}

Eine Zerteilung in Bündel ist auch bei diesem Muskel nur unvollkommen sichtbar, eben nur an den Stellen, wo die Hauptsepta etwas dicker werden. Hier sind in dem Bindegewebe ziemlich zahlreiche Kerne vorhanden, sonst grenzen die einzelnen Muskelfaserquerschnitte dicht aneinander, nur hin und wieder sind zwischen ihnen Kerne sichtbar. Die Faserquerschnitte sind polygonal, die Ecken bald mehr stumpf, bald mẹ̣r scharf. Sie enthalten ziemlich viele Kerne, die fast alle binnenständig liegen, nur selten randständig. Eine besondere Anordnung in bezug auf die Lage ist nicht $\mathrm{zu}$ bemerken. Die Kernquerschnitte sind meist kreisförmig bis kurz oval, mässig dunkel gefärbt. Durchschnittliche Grösse des Faserquerschnittes $3546 q \mu$, Max. $9985 q u$, Min $710 q \mu$. Durchschnittliche Kernzahl 3,25, Max. 6. Durchschnittliche Kerngrösse 5,75 qu, Max. $15,50 q \mu$, Min. 2,50 q $\mu$.

\section{Celloidin-Längsschnitte. Färbung mit Hämatoxylin (Ehrlich).}

Fasern lang gestreckt, Querstreifung mässig deutlich, ebenso Längsstreifung, meist Ruhezustand. Kerne lang gestreckt, schwach gefärbt. Kernkörperchen mehr oder weniger deutlich hervortretend, durchschnittlich $1-3$. Kernreihen nicht sichtbar. Durchschnittliche Kernlänge 23,12 $\mu$, Max. 28,00 $\mu$, Min: 16,00 $\mu$.

\section{Celloidin-Quer- und Längsschnitte. Färbung nach Calleja.}

Das Calleja bild entspricht dem unter 1 beschriebenen, nur an den seltenen dicken Stellen der Septa sieht man gefärbtes Bindegewebe.

\section{Celloidin-Quer- und Längsschnitte. Färbung mit Orcein.}

Nur an den dickeren Stellen der Septen finden sich mehr oder weniger viele elastische Fasern. Der Muskel ist also wieder sehr arm an elastischen Fasern. 


\section{Celloidin-Quer- und Längsschnitte. Färbung mit Karbol-Toluidinblau:}

Hin una wiedèr einżelne Mastzellen, die der Dünne der Septa entsprechend vielfach stark in die Länge gezogen sind.

$$
\text { G.: Gastrocnemius. (400 Fasern, } 2233 \text { Kerne.) }
$$

\section{Celloidin-Quersehnitte. Färbung mit Hämatoxylin (Ehrlich).}

Die Eintëilung in Muskelbündel ist sehr undeutlich, die Muskelfasern zeigen schöne Querschnitte, nur hin und wieder auch Schrägschnitte, die Querschnitte sind polygonal mit stark abgerundeten Ecken; nur die kleinen .Muskelfaserquerschnitte, die in mässiger. Menge unvermittelt zwischen den grossen liegen, zeigen schärfere Ecken. Die Oberfläche der Faserquerschnitte lässt polygonale Felder mehr oder weniger deutlich erkennen und in diesen feine Pünktchen: Fibrillenbündel und Fibrillensäulchen. Die ziemlich "stark gefärbten Kernquerschnitte liegen fast alle binnenständig und erscheinen kreisförmig oder kurz oval. Durchschnittliche Grösse des Faserquerschnittes 4481 qu, Max. 9210 q $\mu$, Min. 1010 q . Durchschnittliche Kernzahl 5,58. Durchschnittliche Kerngrösse 4,43

\section{Celloidin-Längsschnitte. Färbning mit Hämatoxylin (Ehrli ch).}

Die Fasern verlaufen schön gestreckt, Querstreifung nur schwach sichtbar, Längsstreifung deutlicher. Wo die Querstreifung deutlich hervortritt, ist Ruhezustand vorhanden, hin und wieder auch Kontraktion. Die mässig stark gefärbten Kerne sind meist lang stäbchenförmig und lassen meist 1-2 Kernkörperchen deutlich erkennen. Kernreihen nicht sichtbar. Durchschnittliche Kernlänge 2:3,44 $\mu$, Max. $32,00 \mu$, Min. $18,00 \mu$.

\section{Celloidin-Quer- und Längsschnitte. Färbung nach Calleja.}

Zerteilung in Bündel nur undeutlich sichtbar, da die Septa nur hin and wieder deutlich hervortreten. Die Muskelfaserquerschnitte liegen dicht aneinander, von Fibrillen ist zwischen ihnen nichts zu erkennen.

\section{Celloidin-Quer- und längsschnitte. Färbung mit Orcein.}

Das elastische Gewebe ist in ausserordentlich geringer Menge vorhanden. Nur an den Stellen, wo die Anschwellungen der dickeren Septa vorhanden sind, sieht man eine grössere Anzahl von feinen elastischen Fasern, die teils der Quere, teils der Länge nach verlaufen, und von denen dann auch quer verlaufende Fasern in die nächst abtretenden Septa übergehen.

\section{Celloidin-Quier- und Längsschnitte. Färbung mit Karbol-Toluidinblau.}

Seltene Mastzellen sind hin und wieder sichtbar.

\section{H. Coraco-Radialis. (400 Fasern, 1572 Kerne.)}

\section{Celloidin-Querschnitte. Färbung mit Hämatoxylin (Ehrlich).}

Die Bündel sind nur unvollkommen voneinander abgetrennt, da die Septa sehr schmal sind und teilweise so schmal werden, dass sie nicht weiter verfolgt werden können, sie enthalten mässig viele Kerne. Die Muskelfaserquerschnitte 
sind polygonal mit abgerundeten Ecken, mitunter fast kreisförmig; sie liegen im allgemeinen dicht aneinander und zeigen eine sehr feine Punktierung. Zwischen ihnen liegen mitunter Bindegewebskerne. Die mässig stark gefärbten Muskelkerne sind kreisförmig bis kurz oval und liegen fast sämtlich binnenständig. Hin und wieder sielt man zwischen den grossen Faserquerschnitten unvermittelt kleine liegen, die vielfach schärfere Kanten zeigen als die grossen, und mitunter auch in kleinen Gruppen zusammen liegen. Auch in ihnen liegen die Kerne binnenständig. Durchschnittliche Grösse des Faserquerschnittes $5505 q \mu$, Max. $11650 q \mu$, Min. $1380 q \mu$. Durchschnittliche Kernzahl 3,98, Max. 6. Durchschnittliche

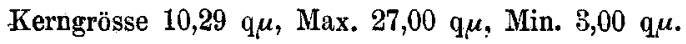

\section{Celloidin-Längsschnitte. Färbung mit Hämatoxylin (Ehrlich).}

Die Fasern liegen lang gestreckt, dicht nebeneinander. Die Querstreifung tritt ziemlich deutlich hervor, meist Ruhezustand, Lüngsstreifung undeutlich. Die Kerne sind lang gestreckt, stäbchenförmig, mässig stark gefärbt. Sie zeigen deutliche Kernkörperchen, gewöhnlich 1-2. Kernreihen nicht vorhanden. Durchschnittliche Kernlänge 24,28 $\mu$, Max. 32,00 $\mu$, Min. 20,00 $\mu$.

\section{Celloidin-Quer- und Längsschnitte. Färbung nach Calleja.}

Das Call ej a bild bestätigt im allgemeinen die unter 1 gegebene Beschreibung doch treten hier infolge der Färbung die Septa deutlicher hervor, und infolgedessen erscheinen einzelne Bündel ziemlich gut abgegrenzt.

\section{Celloidin-Quer- und Längsschnitte. Färbung mit Orcein.}

Die elastischen Fasern sind nicht hinreichend gut gefärbt, um eine $\mathrm{Be}$ schreibung za erlauben.

5. Die Färbung mit Karbol-Toluidinblau ist bei diesem Muskel ausgefallen.

\section{J. Flexor carpi radialis. (400 Fasern, 1501 Kerne.)}

\section{Celloidin-Qnerschnitte. Färbung mit Hämatoxylin (Eh r li ch.)}

Die Zerteilung in Bündel ist sehr unvollkommen, da die Septa nur stellenweise hervortreten, oft aber so dünn werden, dass sie nicht zu verfolgen sind. Soweit sie sichtbar sind, enthalten sie ziemlich viel Kerne. Die Muskelfaserquerschnitte sind polygonal mit ziemlich scharfen Ecken und liegen sehr dicht aneinander. Kleine Muskelfaserquerschnitte, die unvermittelt zwischen den grossen liegen, kommen nur hin und wieder vor. Die mässig stark gefürbten Muskelkerne liegen binnenständig. Sie erscheinen kreisförmig bis kurz oval und sind verhältnismässig gross. Sehr häufig sieht man in ihnen ein Kernkörperchen liegen. Die Muskelfaserquerschnitte sind fein punktiert, hin und wieder sieht man zwischen ihnen einen Bindegewebskern liegen. Durchschnittliche Grösse des Faserquerschnittes $3066 q \mu$, Max. $81^{\prime} 5^{\prime} q \mu$, Min. $610 q \mu$. Durchschnittliche Kernzahl

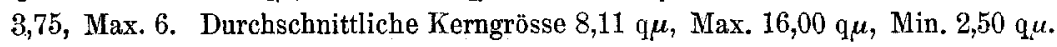

\section{Celloidin-Längsschnitte. Färbung mit Hämatoxylin (Ehrlich).}

Die Muskelfasern liegen gerade, lang gestreckt, dicht nebeneinander. Querstreifung blass, aber deutlich, Ruhezustand. Längsstreifung sehr schwach sichtbar. 
Die schönen, langen, stäbchenförmigen Kerne sind schwach gefärbt und lassen häufig ein Kernkörperchen erkennen, mitunter auch 2. Kernreihen nicht vorhanden. Durchschnittliche Kernlänge 25,44 $\mu$, Max. 38,00 $\mu$, Min. 18,00 $\mu$.

\section{Celloidin-Quer- und Längsschnitte. Färbung nach Calleja.}

Die-Zerteilung in Bündel tritt hier deutlicher hervor als bei der Hämatoxylinfärbung. Die Septa werden häufig sehr schmal, sind aber infolge der Färbung zu verfolgen. Die Form der Bündel ist sehr unregelmässig und sonderbar, doch lässt sie sich infolge der undeutlichen Septa nicht genügend feststellen.

\section{Celloidin-Quer- und Längsschnitte. Färbung mit Orcein.}

Das Verhalten der elastischen Fasern lässt sich an den Präparaten nur unvollkommen feststellen, jedenfalls sind aber nicht viele vorhanden.

5. Celloidin-Quer- und Längsschnitte. Färbung mit Karbol-Toluidinblau. Seltene Mastzellen, die zerstreut liegen, im ganzen sehr wenige.

K. Anconaens caput mediale (400 Fasern, 1131 Kerne).

\section{Celloidin-Querschnitte, Färbung mit Hämatoxylin (Ehrlich).}

Die Zerteilung der Bündel tritt nur wenig hervor, da die Septa sehr schmal sind. Die Muskelfaserquerschnitte sind polygonal mit abgerundeten, mitunter auch mit scharfen Ecken. Die Oberfläche der Querschnitte erscheint fein punktiert, Abgrenzung von Fibrillenbündeln im allgemeinen nicht sichtbar. Die Muskelkerne sind mässig stark gefärbt, fast sämtlich binnenständig, kreisförmig bis kurz oval. Die Faserquerschnitte liegen dicht aneinander, hin und wieder sieht man zwischen ihnen einen Bindegewebskern. Die breiteren Septa sind ziemlich kernreich. Durchschnittliche Grösse des Faserquerschnittes $3569 q \mu$, Max. $8040 q \mu$, Min. $610 q \mu$. Durchschnittliche Kernzahl 2,83, Max. 5. Durch-

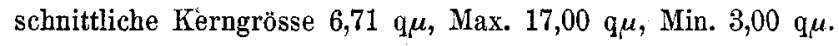

\section{Celloidin-Längsschnitte, Färbung mit Hämatoxylin (Ehrlich).}

Fasern schön gestreckt, Querstreifung deutlich, Ruhezustand. Längsstreifung mehr oder weniger deutlich. Die mässig stark gefärbten Kerne sind lang stäbchenförmig. Kernkörperchen treten nur hin und wieder hervor, dann in verschiedener Anzahl. Kernreihen nicht sichtbar. Durchschnittliche Kernlänge 25,60 $\mu$, Max. 32,00 $\mu$, Min. 18,00 $\mu$.

\section{Celloidin-Quer= und -Längsschnitte, Färbung nach Calleja.}

Die Septa treten hier trotz ihrer Dünne infolge der Färbung deutlich hervor. Sie lassen sich ziemlich gut verfolgen und umgrenzen langgestreckte, im ganzen ziemlich kleine Bündel.

\section{Celloidin-Quer- und -Längsschnitte, Fürbung mit Orcein.}

Die elastischen Fasern scheinen wieder in sehr geringer Menge vorhanden zu sein, sie treten aber auf dem Schnitte nicht deutlich hervor.

\section{Celloidin-Quer- und Längsschnitte, Färbung mit Karbol-Toluidinblau.}

Hin und wieder seltene Mastzellen. 
L. Pectoralis pars sternalis (400 Fasern, 1616 Kerne).

\section{Celloidin-Querschnitte, Färbung mit Hämatoxylin (Ehrlich).}

Die Zerteilung in Bündel erscheint unvollkommen, da die Septa in ihrem Verlaufe mitunter sehr dünn werden. Die Muskelfaserquerschnitte sind polygonal mit abgerundeten Ecken, sie liegen dicht aneinander, zwischen ihnen hin und wieder ein Bindegewebskern. Zwischen den grossen Faserquerschnitten liegen häufig ganz unvermittelt sehr kleine, welche dann häufig-dreieckig sind mit ziemlich scharfen Ecken; doch sind anch diese kleinen Querschnitte mitunter polygonal mit abgerundeten Fcken. Die Faserquerschnitte zeigen eine Zusammensetzung aus Fibrillen nur undeutlich." Die stark gefärbten Kerne liegen fast sämtlich binnenständig und sind kreisförmig bis oval. Durchschnittliche Grösse des Faserquerschnittes $4587 q \mu$, Max. 8540 q $\mu$, Min. 1005 q $\mu$. Durchschnittliche Kernzahl 4,04, Max. 7. Durchschnittliche Kerngrösse 7,29 qu, Max. 20,50 q $\mu$, Min. 1,50 q $\mu$.

\section{Celloidin-Längsschnitte, Färbung mit Hämatoxylin (Ehrlich).}

Die Fasern verlaufen lang gestreckt, Querstreifung sehr schwach sichtbar, Ruhęustand. Längsstreifung meist deutlich. Dịe mässig stark gefärbten Kerne sind meist lang-stäbchenförmig. Kernkörperchen nur hin und wieder sichtbar. Kernreihen fehlen. Durchschnittliche Kernlänge 26,00 $\mu$, Max. 36,00 $\mu$, Min. $20,00 \mu$.

\section{Celloidin-Quer- und -Längsschnitte, Färbung nach Calleja.}

Die Septa zwischen den Bündeln, welche hier deutlicher hervortreten als bei der Hämatoxylinfärbung, werden mitunter so dünn, dass sie sich nicht mehr verfolgen lassen. Auch sieht man hier, dass ihr Bindegewebe nur wenige Kerne enthält.

\section{Celloidin-Quer- und -Längsschnitte, Färbung mit Orcein.}

Dì elastischen Fasern treten nur wenig hervor, so dass man etwas Sicheres nicht aussagen kann. Es scheint indessen; dass sie selten sind.

5. Celloidin-Quer- und Längsschnitte, Färbung mit Karbol-Tolnidinblau. Mastzellen nicht sichtbar.

\section{Delt oides (400 Fasern, 1172 Kerne).}

\section{Celloidin-Querschnitte, Färbung mit Hämatoxylin (Eh rlich).}

Einteilung in Bündel kaum erkennbar, da von den Septen nur kurze Stücke sichtbar sind. Die Muskelfaserquerschnitte liegen dicht aneinander, sind polygonal mit mehr oder weniger abgerundeten Ecken und lassen einen Aufbau aus Muskelsäulchen nicht erkennen. Kleine Muskelfaserquerschnitte, die zwischen den grossen liegen, fehlen hier. Die Kerne, die stark gefärbt sind, liegen sämtlich binnenständig, und sind kreisförmig bis oval. Durchschnittliche Grösse des Faserquerschnittes $3420 q \mu$, Max. $7650 q \mu$, Min. $860 q \mu$. Durchschnittliche

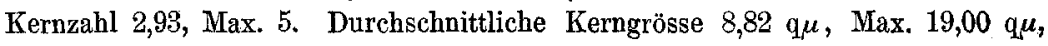
Min. 3,50 qu. 


\section{Celloidin-Längsschnitte, Färbung mit Hämatoxylin (E h r lich.)}

Die Fasern verlaufen langgestreckt. Querstreifung deutlich, Ruhezustand. Längsstreifung mehr oder weniger deutlich. Die mässig stark gefärbten Kerne sind lang-stäbchenförmig. Kernkörperchen meist nicht erkennbar; mitunter aber auch sehr deutlich sichtbar und dann zu mehreren. Kernreihen fehlen. Durchschnittliche Kernlänge 26,12 $\mu$, Max. 38,00 $\mu$, Min. 20,00 $\mu$.

\section{Celloidin-Quer- und Längsschnitte, Färbung nach Calleja.}

Die Septa treten hier entschieden deutlicher hervor als bei den Hämatoxylinpräparaten, sind aber sehr schmal. Eine deutliche Abteilung in Bündel tritt trotzdem nicht hervor, da die Septa in unregelmässiger Weise eine ganze Anzahl. von Ästen abtreten lassen, die bei der oft eintretenden Verfeinerung der Hauptsepta häufig ebenso dick wie diese erscheinen, so dass der Muskel in eine grössere Anzahl von kleinen Feldern zerlegt wird. Dadurch wird das mikroskopische Bild ein durchaus ungewöhnliches. Im ganzen würde man aber daraus schliessen können, dass der Muskel etwas mehr Bindegewebe enthält als die übrigen Froschmuskeln, die ja sehr arm an solchem waren.

\section{Celloidin-Quer- und -Längsschnitte, Färbung mit Fuchsin-Resorcin.}

In den Septen sind hin und wieder einige elastische Fasern sichtbar, im ganzen aber scheint die Menge des elastischen Gewebes sehr gering zu sein.

\section{Celloidin-Qner- nnd -Längsschnitte, Färbung mit Karbol-Toluidinblau.}

Mastzellen nicht sichtbar.

$$
\text { N. Cruralis (400 Fasern, } 1932 \text { Kerne). }
$$

\section{Celloidin-Querschnitte, Färbung mit Hämatoxylin (Ehrlich).}

Die Finteilung in Bündel ist verhältnismässig deutlich, auch Unterabteilungen können mehr oder weniger deutlich erkannt werden. Trotzdem sind die Septa im allgemeinen recht schmal. Die Muskelfaserquerschnitte erscheinen polygonal mit im allgemeinen gut abgerundeten Ecken, nur die ziemlich zahlreichen kleinen Muskelfaserquerschnitte, die zwischen den grossen eingeklemmt liegen, zeigen schärfere Ecken. Die stark gefärbten Muskelkerne liegen fast alle binnenständig und erscheinen auf dem Querschnitte kreisförmig bis kurz oder länger oval bis unregelmässig polygonal. Die Oberfläche der Muskelfaserquerschnitte ist fein punktiert; häufig sieht man zwischen diesen dunklen Pünktchen auch zahllreiche sehr feine, helle Pünktchen. Durchschnittliche Grösse des Faserquerschnittes $2969 q_{\mu} \mu$, Max. $6640 q_{i} \mu$, Min. $230 q \mu$. Durchschnittliche Kernzahl 4,83. Durchschnittliche Kerngrösse 7,82 qu.

\section{Celloidin-Längsschnitte, Färbung mit Hämatoxylin (Ehrlich).}

Die schön gestreckten Muskelfasern zeigen eine sehr deutliche Querstreifung, Ruhezustand. Die Längsstreifung tritt mehr oder weniger deutlich hervor. Die schön ausgebildeten, mässig stark gefärbten Kerne erscheinen ganz lang oval bis lang stäbchenförmig und zeigen vielfach kein Kernkörperchen, vielfach aber auch ein bis zwei deutlich hervortretende. Durchschnittliche Kernlänge 26,32 $\mu$, Max. 36,00 $\mu$, Min. 18,00 $\mu$. 


\section{Celloỉdin-Qner- und -Längsschnitte, Färbung nach Calleja.}

Die Schnitte entsprechen durchaus den unter 1 und 2 beschriebenen.

\section{Celloidin-Quer- und -Längsschnitte, Färbung mit Orcein.}

In den grösseren Septen ziemlich zahlreiche elastische Fasern, die der Länge nach verlaufen, und von denen Äste auch in die dünneren Septa übertreten, die dann wieder der Quere nach verlaufen. Hin und wieder auch quer verlaufende elastische Fasern. Fasern, welche die Muskelfasern quer umspinnen, fehlen ganz. Als Froschmuskel hat dieser Muskel also schon verhältnismässig viele elastische Fasern, im Vergleiche zu andern Muskeln aber doch nur sehr wenige.

\section{Celloidin-Quer- und Längsschnitte. Färbung mit Karbol-Toluidinblau.}

Hin und wieder seltene Mastzellen.

\section{O. Pectineus. (400 Fasern, 1202 Kerne.)}

\section{Celloidin-Querschnitte. Färbung mit Hämatoxylin (Ehrlich).}

Einteilung in Bündel nur unvollkommen sichtbar, da die Septa sehr dünn sind und nur hin und wieder deutlich hervortreten. So weit man es erkennen kann, scheinen die Querschnitte der Bündel hier sehrsch mal und lang gestreckt zu sein. Die Muskelfaserquerschnitte liegen dicht aneinander, mit mehr oder weniger abgerundeten Ecken. Die mässig zahlreichen kleinen Faserquerschnitte, welche unvermittelt zwischen den grossen liegen, zeigen im ganzen schärfere Ecken. Die Oberfläche der Muskelfaserquerschnitte erscheint fein punktiert: Fibrillenquerschnitte, nur hin und wieder auch Andeutungen von Fibrillenbündeln. Die Kernquerschnitte sind mässig stark gefärbt, liegen fast sämtlich binnenständig und sind kreisförmig bis kurz oval. Zwischen den Muskelfaserquerschnitten hin und wieder ein Bindegewebskern. So weit die Septa sichtbar sind, sind sie mässig kernreich. Durchschnittliche Grösse des Faserquerschnittes 3884 q $\mu$, Max. $9920 q \mu$, Min. $320 q \mu$. Durchschnittliche Kernzahl 3,00, Max. 7. Durch-

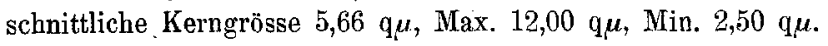

\section{Celloidin-Längsschnitte. Färbnng 'mit Hämatoxylin (E h rlich).}

Die Fasern verlaufen schön gestreckt. Die Querstreifung tritt nur schwach hervor, im allgemeinen Ruhezustand. Die Längsstreifung noch schwächer sichtbar. Die mässig stark gefärbten Kerne sind lang stäbchenförmig und lassen teilweise eins bis mehrere Kernkörperchen erkennen. Kernreihen nicht sichtbar. Durchschnittliche Kernlänge 26,52 $\mu$, Max. 36,00, Min. 18,00 $\mu$.

\section{Celloidin-Quer- und Längsschnitte. Färbung nach Call eja.}

Das Bild entspricht durchaus dem unter 1 beschriebenen.

\section{Celloidin-Quer- und Längsschnitte. Färbung mit Orcein.}

In den breiteren Septen finden sich zahlreiche, sebr feine elastische Fasern, welche im wesentlichen der Länge nach verlaufen, aber in die von diesen Septen abgehenden schmaleren Septen übergehend hier im wesentlichen der Quere nach 
verlaufend, sodass also die Muskelbündel im wesentiichen von querverlaufenden elastischen Fasern umgeben sein würden, nur an den dickstẹ Stellen würden die Längsfasern überwiegen.

\section{Celloidin-Quer- und Längsschnitte. Färbung nit Karbol-Toluidinblau.}

Hin und wieder seltene Mastzellen.

\section{P. Gracilis. (400 Fasern, 1703 Kerne.)}

\section{Celloidin-Querschnitte. Färbung mit Hämatoxylin (Ehrlich).}

Die Einteilung in grössere Bündel nur schwach sichtbar; da die Septa sehr schmal sind. Die gut getroffenen Muskelfaserquerschnitte erscheinen polygonal mit bald mehr scharfen, bald mehr abgerundeten Ecken. Zwischen den grossen Querschnitten sind oft auch kleine unregelmässig eingelagert. Die Kerne liegen alle binnenständig, nur hin und wieder liegt ein Kern dicht am Rande. Die stark gefärbten Kernquerschnitte sind balı melır kreisförmig, bald mehr kurz oval. Durchschnittliche Grösse des Faserquerschnittes 4053 q $\mu$, Max. $9975 q \mu$, Min. $625 q \mu$. Durchschnittliche Kernzahl 4,26, Max. 7. Durchschnittliche Kerngrösse 4,77 q $\mu$, Max. 15,00 q $\mu$, Min. 2,50 q $\mu$.

\section{Celloidin-Längsschnitte, Färbung mit Hämatoxylin (Ehrlich).}

Die Fasern verlaufen ganz glatt, langgestreckt, und liegen dicht nebeneinander. Querstreifung deutlich, im allgemeinen Ruhezustand. Längsstreifung hin und wieder deutlich. Die Kerne sind lang, stäbchenförmig, im ganzen schwach gefärbt. Kernkörperchen sind hin und wieder sichtbar, eins bis mehrere. Kernreihen nicht sichtbar. Durchschnittliche Kernlänge 28,68 $\mu$, Max. $38,00 \mu$, Min. 20,00 $\mu$.

\section{Celloidin-Quer- und -Längsschnitte, Färbung nach Calleja.}

Auch auf dem Calleja präparate treten die Septa zwischen den Bündẹln wegen ihrer grossen Dünne so wenig herror, lass man sie nur hin und wieder dort, wo sie etwas dicker sind, als gefärbte Streifen bervortreten sieht; an den meisten Stellen kann man daher eine Zerlegung in Bündel überhaupt nicht wahrnehmen. Zwischen den Muskelfaserquerschnitten ist natürlich gar nichts von gefärbtem Bindegewebe zu erkennen.

\section{Celloidin-Qner̀- and -Längsschnitte, Färbung mit Orcein.}

In den etwas breiteren Stellen in den Septen finden sich einige sehr feine elastische Fasern; sonst ist von elastj:chem Gewebe nichts zu sehen.

\section{Celloidin-Quer- und =Längsschnitte, Färbnng mit Karbol-Toluidinblau.}

Hin und wieder, unregelmässig ther den Scbnitt verstreut, finden sich Mastzellen, die entsprechend der Dünne d'l Septa vielfach langgestreckt erscheinen.

\section{Q. Tibialis anterior lon $\mathrm{n}$ us (400 Fasern, 1392 Kerne).}

\section{Celloidin "Querschnitte, Farbung mit Hämatoxylin (E hrlich).}

Die Einteilung in Bündel ist seh undeutlich, da die Septa nur wenig hervortreten; wo sie sichtbar sind, whalten sie ziemlich viele Kerne. Die auf 
dem schönen Querschnitte gut hervortretenden Muskelfaserquerschnitte sinu polygonal mit gut abgerundeten Ecken; nur die in mässiger Anzahl vorhandenen, unvermittelt zwischen die grossen eingestreuten kleinen Querschnitte zeigen schärfere Ecken. Die Muskelfaserquerschnitte liegen dicht aneinander, hin und wieder zwischen ihnen ein Kern. Ihre Oberfläche erscheint fein punktiert: Fibrillenquerschnitte, nur hin and wieder sieht man noch Andeutungen einer Einteilung in Fibrillenbündel. Die ziemlich stark gefärbten Kernquerschnitte liegen fast alle binnenständig. Sie sind' meist kreisförmig bis kurz oval. Durchschnittliche Grösse des Faserquerschnittes 4707 q $\mu$, Max. 8870 q $\mu$, Min. 1610 q $\mu$. Durchschnittliche Kernzahl 3,48, Max. 6. Durchschnittliche Kerngrösse 7,68 qu, Max. 18,00 q $\mu$, Min. 2,50 q $\mu$.

\section{Celloidin-Längsschnitte, Färbung mit Hämatoxylin (Ehrlich).}

Die Fasern verlaufen schön gestreckt. Querstreifung meist deutlich, meist Ruhezustand. Längsstreifung ebenfalls deutlich. Die im ganzen schwach gefärbten Kerne sind lang stäbchenförmig. Kernkörperchen sind nur hin und wieder sichtbar. Kernreihen fehlen. Durchschnittliche Kernlänge 30,48 $\mu$, Max. $46,00 \mu$, Min. 20,00 $\mu$.

\section{s. Celloidin-Quer- und -Längsschnitte, Färbung nach Calleja.}

Eine Zerteilung in Bündel ist kaum sichtbar, da die Septa sehr wenig entwickelt sind.

\section{Celloidin-Quer- und -Längsschnitte, Färbnng mit Orcein.}

Das elastische Gewebè ist in ausserordentlich geringer. Menge vorhanden. Nur an den wenigen Stellen, wo die Septa etwas dicker sind, sieht man feine elastische Fasern, die zum Teil der Länge nach, zum Teil auch der Quere nach verlaufen und dann als quer verlaufende Fasern in die abtretenden Septa übergehen.

5. Celloidin-Quer- und Längsschnitte, Färbung mit Karbol-Toluidinblau.

Hin und wieder seltene Mastzellen.

Nach dieser Beschreibung des mikroskopiscben Bildes will ich kurz die Ergebnisse derselben zusammenstellen und besprechen:

1. Was zunächst auffällt, ist die grosse Ähnlichkeit des mikroskopischen Bildes bei sämtlichen Muskeln. Man findet überall gut ausgebildete polygonale Muskelfaserquerschnitte, bei denen die Ecken im allgemeinen abgerundet sind, nur hin und wieder treten sie etwas schärfer hervor. Zwischen den gewöhnlichen grossen Faserquerschnitten liegen in den meisten Muskeln ganz unvermittelt weit kleinere Querschnitte, die dann gewöhnlich weit schärfere Ecken zeigen als die grossen. Hin und wieder fehlen diese kleinen Querschnitte auch, so beim Deltoides, im allgemeinen kommen sie aber so häufig vor, dass sie eigentlich mit zu dem charakteristischen Bilde der Froschmuskeln, bei diesem Tiere wenigstens, zu gehören 
scheinen. Knoll bildet in seiner grossen Muskelarbeit ${ }^{1}$ ) (Taf. VII, Fig. 20 und 21 und S. 684 ff.) ebenfalls solch kleine Fasern mit schärferen Kanten, die zwischen den grossen unvermittelt liegen, $a b$, und verweist dabei auf die Befunde von Grützner. (Ich verweise hier wegen der älteren Literatur auf die Arbeit von Knoll.) Diese kleinen Fasern sind nach jhm dunkler und enthalten eine Menge von Körnchen. Ich bin in meinen Muskelarbeiten auf den Unterschied zwischen den hellen und dunklen Fasern überhaupt nicht eingegangen und will das auch hier nicht tun, da ich die Muskeln nach einer ganz neuen Richtung untersuche und meine hierfür verwendeten Präparate für die Darstellung der hellen und dunklen Fasern unbranchbar sind. Das Vorkommen von hellen und dunklen Fasern in den Muskeln ist ja, um nur einige der hauptsächlichsten Autoren anzuführen, von Grützner, Knoll und später von Schaffer so eingehend untersucht worden, dass neue Untersuchungen kaum nötig waren. Schaffer ${ }^{2}$ ) (S. 77 ff. und Taf. I Fig. 5 und 6) bestätigt im allgemeinen die Angaben von $\mathrm{Knoll}$; ich verweise wegen des näheren auf seine Arbeit. Über die Bedeutung dieser Fasern ist schwer etwas zu sagen. Ich habe früher bei den Muskeln des Menschen solche eingestreute kleine Faserquerschnitte mit mehr scharfen Ecken eigentlich nur dann gefunden, wenn der Muskel mehr oder weniger atrophisch war. Ob man hier beim Frosche zu dieser Jahreszeit eine solche Atrophie annehmen kann, weiss ich nicht. Die schärferen Ecken der kleinen Fasern sprechen ja allerdings dafür, dass die "Protoplasmaspannung" in ihnen nicht so gross ist wie in den sonstigen, grossen Fasern; denn trotzdem dass diese dicht aneinanderlagen, sich also wohl abplatten lionnten, zeigten sie doch in bei weitem den meisten Fällen abgerundete Ecken. Diese kleinen Faserquerschnitte sind bei den Ausmessungen natürlich mit berücksichtigt worden, da sie ja zu dem gesamten Quersehnittsbilde gehören. Ähnliche kleine Fasern; die unvermittelt zwischen den grossen liegen, habe ich früber bei einem Muskel der Karausche gefunden, dem

1) Ph. Knoll, Über protoplasmaarme und protoplasmareiche Muskulatur. Tenkschr. d. k. Akad. d. Wissensch. zu Wien, math.-naturw. Klasse Bd. 58 S. 698-700, mit 9 Tafeln. 1891.

2) J. S ch a f fer, Beiträge zur Histologie und Histogenese der quergestreiften Muskelfasern des Menschen und einiger Wirbeltiere. Sitzungsber. d. k. Akad. d. Wissensch. zu Wien, math.-naturwissensch. Klasse Bd. 102 Abt. 3. S. 7-148 mit 6 Tafeln. 1893 . 
roten Längsmuskel der Mittellinie, doch waren die Konturen dieser Fasern rundlich ${ }^{1}$ ) (S. 163). Ich will auf diese kleinen Fasern hier nicht weiter eingehen.

2. Die Muskelkerne lagen bei sämtlichen Muskeln binneuständig, nur hin und wieder fanden sich randständige Kerne in ganz geringer Anzahl. Die Binnenständigkeit der Kerne ist also jedenfalls für den Froschmuskel charakteristisch und unterscheidet ihn wesentlich von den Muskeln derjenigen Tiere, die ich bis jetzt untersucht habe. Selbst bei der Karausche waren die Kerne bei den weissen Muskeln sowohl wie bei den roten im ganzen randständig, doch fanden sich bei beiden auch Binnenkerne. Diese waren daun bei den weissen Muskeln erheblich seltener als bei den roten. Auch bei den roten Kaninchenmuskeln waren die meisten Kerne randständig. Bei dem Flussneunauge habe ich, wie ich hier einer späteren Arbeit vorgreifend bemerken will, in den zentralen Rumpfmuskeln ebenfalls im wesentlichen binnenständige Kerne gefunden, während in den parietalen Rumpfmuskeln die meisten Kerne randständig waren, aber auch überall binnenständige vorkanen.

3. Sehr auffallend ist bei diesen Froschmuskeln die ausserordentlich geringe Menge des Bindegewebes, die ganz übereinstimmend bei allen hervortritt. Die grösseren Septa sind so dünn, dass eine Einteilung in Bündel auf dem Querschnitte des Muskels 'nur sehr unvollkommen sichtbar ist, nur in den dickeren Teilen dieser Septa tritt bei der Callejafärbung deutlich gefärbtes fibrilläres Bindegewebe, "fulkrales Bindegewebe", wie ich es in meiner dritten Muskelarbeit genannt habe, hervor, und die Muskelfaserquerschnitte liegen übereinstimmend bei allen Muskeln dicht aneinauder, nur durch ganz schmale Züge von „nutritivem Bindegewebe" voneinander getrennt; hin und wieder ist ein Bindegewebskern zwischen ihnen sichtbar. Aus dieser Übereinstimmung bei dieser Beschreibung der hier untersuchten Muskeln -- es sind bei einigen ja ganz leichte Schwankungen vorhanden - ging auch ohne weitere Messung hervor, dass die Menge des Bindegewebes im Verhältnisse zu der des Muskelgewebes bei den Froschmuskeln oder, genauer ausgedrüclit, bei den Muskeln des hier untersuchten Frosches eine

1) P. Schiefferdecker, Muskeln und Muskelkerne. 317 Seiten mit 20 Abbildungen im Text. Joh. Ambros. Barth, Leipzig 1909. 
ganz ausserordentlich geringe ist, weit geringer als bei den Muskeln, die ich bisher untersucht habe. Ich habe es daher auch gar nicht versucht, von den Froschmuskeln Übersichtsbilder über die Bindegewebsverbreitung zu geben, wie ich das in meiner zweiten Muskelarbeit getan habe. Es wäre doch vergeblich gewesen und auch kaum nötig, da eben alle hier untersuchten Muskelu in dieser Hinsicht einen fast übereinstimmenden Bau aufwiesen. Bei der Karausche, auch bei den weissen Muskeln derselben, welche weniger Bindegewebe enthielten als die roten, war doch immerhiu mebr Bindegewebe vorhanden als hier; auch fanden sich grössere Unterschiede zwischen den einzelnen Muskeln. Im allgemeinen haben nach meinen bisherigen Erfahrungen die weissen Muskeln weniger Bindegewebe als die roten, doch darf man hieraus natürlich einen Schluss auf die Froschmuskeln nicht machen. Auffallend ist es mir daher, dass Mayeda ${ }^{1}$ ) (S. 149) in seiner Arbeit bemerkt, dass in den Muskeln des Frosches das Bindegewebe eine ungleich grössere Rolle spielt als in den Muskeln der Maus. Er findet eine Übereinstimmung hiermit bei Rollett und verweist auf dessen Abbildung von einem Gastrocnemius des Frosches und von einer entsprechenden eines weissen Kaninchenmuskels. Ich führe diesen Widerspruch mit meiner Beobachtung an, ohne in dieser Arbeit weiter darauf eingehen zu können. Mayeda hebt dann weiter hervor, dass die Quersehnitte der Muskeln mit spärlichem Bindegewebe (bei Rollett) polygonale, dicht aneinaudergedrückte Muskelfaserquerschnitte erkennen lassen, während die Muskelfasern in dem Querschnitte des Froschmuskels rundliche Felder zeigen, und betont, dass dies mit seinen Beobachtungen vollkommen übereinstimme. Hierzu möchte ich nur bemerken, dass ich schon in meiner ersten Muskelarbeit hervorgeboben habe, dass die Form der Muskelfaserquerschnitte ziemlich unabhängig zu sein scheine von der Menge des zwischen ihnen liegenden Bindegewebes, und bin damals gerade deshalb zu dem Schlusse gekommen, dass die Ursache für das mehr rundliche oder mehr eckige Aussehen der Muskelfaserquerschnitte in der Beschaffenheit der Muskelfasern selbst liege» müsse, und habe deshalb damals angenommen, dass die „Protoplasmaspannung" dieser in den verschiedenen Fällen versehieden gross sein müsse. Die Bilder, welche ich hier beim Frosche erhalten

1) R. Mayeda, Über die Kaliberverhältnisse der quergestreiften Maskelfaser. Zeitschr. f. Biol. Bd. 27, N. F. 1890 ; Bd. 9 S. 119-152, mit 2 Tafeln. 
habe, scheinen mir wiederum durchaus für diese Anschauung zu sprechen.

4. Ganz übereinstimmend ferner bei allen Muskeln ist die geringe Menge des elastischen Gewebes. Auch bei den Karauschenmuskeln war dieses in ganz geringer Menge vorhanden, und bei dem Flussneunauge fehlte es, wie ich hier vorgreifend bemerken will, ganz. Sowohl beim Frosche wie bei der Karausche liegen die elastischen Fasern, soweit sie überhaupt vorhanden sind, in den dickeren Septen, in dem fulkralen Binde. gewebe. Auch bei den Kaninchenmuskeln war das elastische Gewebe verhältnismässig nur in geringer Menge vorhanden, wenn auch immer noch weit stärker entwickelt als bei Karausche und Frosch, und hier waren es wieder die weissen Muskeln, die weniger elastische Fasern enthielten als die roten. Hier lagen die elastischen Fasern aber schon nicht nur in dem fulkralen Bindegewebe der breiteren Septen, sondern auch in dem nutritiven Bindegewebe zwischen den Muskelfaserquerschnitten. Bei der Karausche konnte man einen solchen Unterschied zwischen weissen und roten Muskeln nicht feststellen, wohl weil, wie ich damals schon hervorhob, die Menge des elastischen Gewebes sowohl bei den weissen wie bei den roten Muskeln eine so sehr geringe war. Ich muss es bis auf weitere Untersuchungen dahingestellt sein lassen, ob es yielleicht eine allgemeine Eigenschaft der Muskeln von niederen Wirheltieren ist, wenig elastisches Gewebe zu enthalten. Bei dem Flussneunauge, über das ich in einer weiteren Arbeit Näheres berichten werde, fand ich, wenigstens in den von mir untersuchten Teilen des Rumpfes, überhaupt keine elastischen Fasern. Jedenfalls ist das elastische Gewebe in den Froschmuskeln in so geringer Menge vorhanden, dass es auf die Funktion des Muskels einen Einfluss kaum ausüben kann.

In denjenigen von mir bisher untersuchten Muskeln, welche wenig elastisches Gewebe enthielten, trat es deutlich hervor, dass elastische Fasern hauptsächlich an solchen Stellen vorhanden waren, an denen eine grössere Menge von Bindegewebe sich vorfand. Wo dickere Septa zwischen den Muskelbündeln vorhanden waren oder wo dünne Septa sich verbreiterten, fand sich vielfach auch sofort elastisches Gewebe. An den Stellen, an denen Blutgefässe in den Septen liegen, pflegt die Dicke dieser zuzunehmen, und es tritt dann an diesen Stellen auch gewöhnlich deutlich fibrilläres Bindegewebe, 
fulkrales Bindegewebe, und elastisches Gewebe auf. Andererseits ergab sich aber aus den Muskeluntersuchungen auch mit Sicherheit, dass das elastische Gewebe in seinem Vorkommen im Muskel nicht abhängig ist von dem Vorhandensein des fulkralen Bindegewebes, sondern dass es gerade oft in grösserer Menge in dem "nutritiven Bindegewebe" vorkommt, wie das die mensehlichen und auch die Kaninchenmuskeln beweisen. In beiden Fällen würde es sich ja um Bindegewebe handeln, in dessen Grundsubstanz Fibrillen differenziert sind. Bis zu einem gewissen Grade scheint also die Menge des elastischen Gewebes abzuhängen von der Menge des so differenzierten Bindegewebes. Den grössten Einfluss auf die Ausbildung des elastischen Gewebes hat aber nach meinen Untersuchungen an den Muskeln zweifellos die "Spezifität des Gewebes". Die Menge des vorhandenen elastischen Gewebes richtet, sich eben ganz nach der spezifischen Beschaffenheit des Muskels, und spezifisch verschiedene Muskeln müssen natürlich auch spezifisch verschiedenes Bindegewebe enthalten. Ich habe in meinen früheren Muskelarbeiten zeigen können, so namentlich in der zweiten, dass das elastische Gewebe bei manchen Muskeln eine sehr bedeutsame Rolle spielen muss, und dies waren gerade Muskeln vom Menschen, bei denen man also gerade eine sehr hochgradige Differenzierung annehmen konnte.

5. Wenn bei 16 Muskeln desselben Tieres, die aus den verschiedensten Gegenden des Körpers entnommen sind, eine solche Übereinstimmung des mikroskopischen Aufbaues besteht wie hier bei den Froschmuskeln, so spricht das zunächst dafür, dass eine irgendwie weitergehende spezifische Differenzierung der einzelnen Muskeln nicht vorhanden ist. Dies würde dann für eine tiefe Stufe der Entwicklung bei den Froschmuskeln sprechen. Wie weit dieser Schluss berechtigt ist, wird indessen erst hervorgehen aus den Tabellen, welche die Messungsergebnisse für die einzelnen Muskeln enthalten. Ich will jetzt zu der. Besprechung dieser Tabellen übergehen, vorher aber erst noch eine übersichtliche Zusammenstellung der hier bearbeiteten Muskeln geben.

Wie man aus nachstehender Tabelle ersieht, war die Anzahl der Kerne bei diesen Muskeln so gross, dass es für die Berechnung genügte, wenn von jedem Muskel 400 Fasern ausgemessen wurden. Das Material von 6400 Fasern und 22650 Kernen ist immerhin schon 
so gross, dass die Schlüsse, die man aus den Tabellen ziehen kann, als ziemlich sicher gelten können.

\begin{tabular}{|c|c|c|}
\hline Name des Muskels & $\begin{array}{c}\text { Zahl } \\
\text { der Fasern }\end{array}$ & $\begin{array}{c}\text { Zahl } \\
\text { der Kerne }\end{array}$ \\
\hline 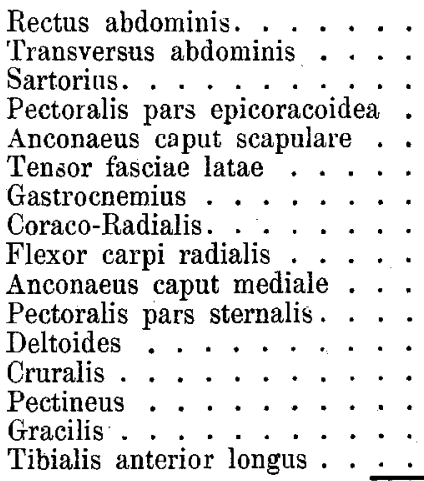 & $\begin{array}{l}400 \\
400 \\
400 \\
400 \\
400 \\
400 \\
400 \\
400 \\
400 \\
400 \\
400 \\
400 \\
400 \\
400 \\
400 \\
400\end{array}$ & $\begin{array}{l}1184 \\
1091 \\
1238 \\
1081 \\
1273 \\
1299 \\
2233 \\
1572 \\
1501 \\
1131 \\
1616 \\
1172 \\
1932 \\
1202 \\
1703 \\
1392 \\
\end{array}$ \\
\hline & 6400 & 22650 \\
\hline
\end{tabular}

In Tabelle I und II (S. 385) sind die Zahlen für den „durchschnittlichen Flächeninhalt eines Faserquerschnittes" zusammengestellt sowie für das jedesmalige Maximum und Minimum. In Tabelle I sind die Muskeln dabei wieder in der bisher angenommenen Reihenfolge, nach der Grösse der Kernlänge, geordnet, in $\mathbf{T}$ abelle II dagegen sind sie angeordnet nach der Grösse ihres Faserquerschnittes. Diese letztere Tabelle ergibt also ein übersichtliches und klares Bild über die Grössenverhältnisse der Fasern bei den einzelnen Muskeln. Aus den beiden Tabellen geht zunächst. schon hervor, dass die Fasergrösse für jeden Muskel spezifisch ist, und dann, dass zwischen ihr und der Kernlänge eine Beziehung nicht vorhanden ist. Der Unterschied zwischen der kleinsten Zahl für die Fasergrösse und der grössten ist verhältnismässig nicht besonders gross. Die Zahlen betragen 2559 q $\mu$ (Transversus abdominis) und 5505 q $\mu$ (CoracoRadialis), verhalten sich also etwa wie $1: 2$. Bei den sieben verschiedenen von mir in meiner zweiten Muskelarbeit untersuchten Muskeln des Kaninchens (soweit das eine Formoltier in Betracht kommt) lagen die Zahlen' zwischen 367 und 1481 q $\mu^{1}$ ) (S. 133,

1) P. Schiefferdecker, Muskeln und Muskelkerne. 317 Seiten mit 20 Abbildungen im. Text. Joh. A mbros. Barth, Leipzig 1909. 
Tabelle I.

Rana esculenta. Flächenimhalt eines Faserquerschnittes im Durchschnitt, Maximum, Minimum in Quadratmikra.

\begin{tabular}{|c|c|c|c|}
\hline \multirow{2}{*}{ Name des Muskels } & \multicolumn{3}{|c|}{ Grösse des Faserquerschnittes } \\
\hline & Durchschnitt & Maximum & Minimum \\
\hline 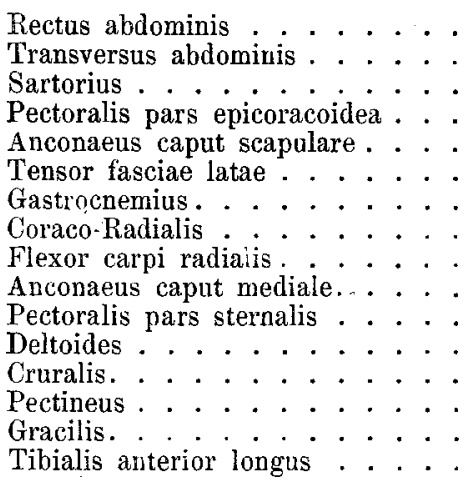 & $\begin{array}{l}3790,68 \\
2558,61 \\
4368,23 \\
2941,80 \\
2910,35 \\
3545,95 \\
5505,33 \\
4481,21 \\
3066,35 \\
3568,65 \\
4587,20 \\
3419,83 \\
2968,86 \\
3884,31 \\
4053,09 \\
4707,28\end{array}$ & $\begin{array}{r}7050 \\
5750 \\
10480 \\
8290 \\
8005 \\
9985 \\
11650 \\
9210 \\
8155 \\
8040 \\
8540 \\
7650 \\
6640 \\
9920 \\
9975 \\
8870\end{array}$ & $\begin{array}{r}680 \\
680 \\
1005 \\
425 \\
615 \\
710 \\
1380 \\
1010 \\
610 \\
610 \\
1005 \\
860 \\
230 \\
320 \\
625 \\
1610\end{array}$ \\
\hline
\end{tabular}

Tabelle II.

Rana esculenta. Reihenfolge der Muskeln nach der Grösse des durchschnittlichen Faserquerschnittes.

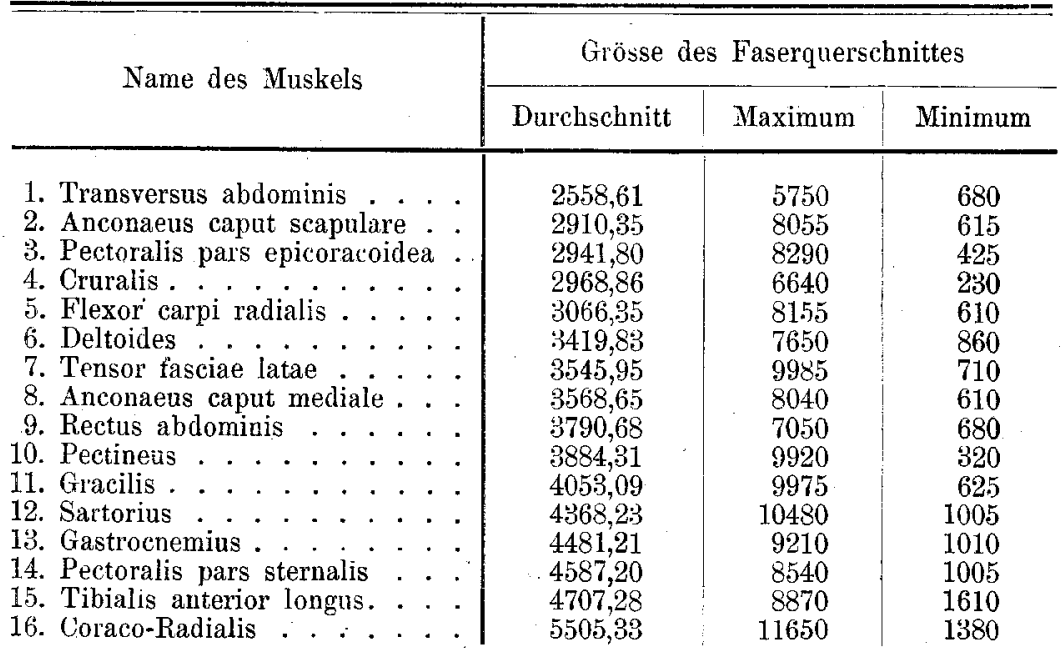

Tisb. XX); der Unterschied war also weit grösser, etwa wie $1: 4$. Bei den Muskeln der Karausche ${ }^{1}$ ) (S. 168, Tab. XXXI) lagen die

1) P. Schiefferdecker, Muskeln und Muskelkerne. 317 Seiten mit 20 Abbildungen im Text. Joh. Ambros. Barth, Leipzig 1909. 
Zahlen für die sechs Muskeln zwischen 261 und 627, Verhältnis etwa wie $1: 2,4$. Auch hier war der Unterschied noch etwas grösser, wenn auch bei weitem nicht so gross wie bei den Kaninchenmuskeln. Auch dieser verhältnismässig geringe Unterschied in der durchschnittlichen Grösse der Muskelfasern zwischen den einzelnen Froschmuskeln spricht also zunächst für eine verhältnismässig geringe Differenzierung. In ähnlicher Weise wie die Durchschnittszahlen verhielten sich bei den beiden oben angefübrten Muskeln die Maximalzahlen: 5750 q $\mu$ bei dem Transversus abdominis und 11650 q $\mu$ bei dem Coraco-Radialis. Auch hier ist das Verhältnis etwa wie 1:2. Es sind übrigens dieselben Muskeln wie bei den Durchschnittszahlen, die hier für das grösste Maximum in Betracht kommen. Es dürfte dies indessen mehr auf Zufall beruhen, denn wenn man bei den übrigen Muskeln die Maxima mit den Durchschnittszahlen vergleicht, findet man kein konstantes Verhältnis. Sehr a uffallend ist die gewaltige Grösse der Faserquerschnitte des Frosches im Verhältnisse $z u$ den anderen bisher untersuchten Muskeln. Die grösste Zahl für die bisher untersuchten menschlichen Skelettmuskeln fand. sich bei dem Del toides des Mannes von 19 Jahren: Durchschnittszahl $1421 q \mu$. Maximum $2625 q \mu^{1}$ ) (S. 71 Tab. XI), beim Zwerchfelle betrug die grösste Zahl bei dem Manne von 29 Jahren (Kroate) 1808 q $\mu$, Maximum $3215 q \mu^{2}$ ) (S. 373, Tab. I). Für die Kaninchenmuskeln betrug die grösste Zahl bei dem Semitendinosus des Formoltieres $1481 q \mu$, Maximum $3410 q \mu^{\mathbf{1}}$ ) (S. 168, Tab. XXXI). Das Alkoholkaninchen wies allerdings grössere Zahlen als das Formolkaninchen auf, doch habe ich damals schon hervorgehoben, dass die Muskeln dieses Tieres sich überhaupt abweichend verhielten. Das Flussneunauge hat, wie icb hier einer später erscheinenden Arbeit vorgreifend erwähnen will, in den parietalen Fasern seiner Rumpfmuskulatur ebenfalls sehr grosse Fasern: Durchschnitt $1977 q \mu$, Maximum $3460 q \mu$, und noch weit grössere in seinen zentralen Muskeln, welch letztere sich aber überhaupt so abweichend verhalten, dass sie nur schwer mit den

1) P. Schiefferdecker, Muskeln und Muskelkerne. 317 Seiten mit 20 Abbildungen im Text. Joh. A mbros. Barth, Leipzig 1909.

2) P. Schiefferdecker, Untersuchung des Zwerchfelles auf seinen Bau und seine Kernverhältnisse. Pflüger's Arch. Bd. 139 S. 337. 
Fasern der höheren Tiere verglichen werden können. Alle anderen bisher untersuchten Muskeln zeigten weit geringere Werte, so namentlich auch die der Karausche, bei welcher die dicksten Fasern nur die Zahlen 627 im Durchschnitte und 1390 q $\mu$ im Maximum erreichten $^{1}$ ) (S. 168, Tab. XXXI). Der Froseh hat also verhältnismässig sehr grosse Fasern.

Recht interessant ist es, dass, wie man aus Tabelle II(S. 385) leicht ersehen kann, die verschiedenen Abteilungen mancher Muskeln sich in bezug auf dieFasergrösse sehr wesentlich unterscheiden. So haben die Fasern des Anconaeus caput scapulare eine durchschnittliche Grösse von 2910 qu, die des Anconaeus caput mediale eine solche von 3569 q $\mu$. Die Maxima stimmen allerdings bei beiden Muskeln fast genau überein (8055 q $\mu: 8040 q \mu$ ); diese Maxima hängen aber, wie ich das schon mehrfach in meinen Arbeiten hervorgehoben habe, immer mehr oder weniger vom Zufalle ab. Ähnliches findet sich bei dem Pectoralis: hier hat die Pars epicoracoidea Fasern von einer durchschnittlichen Grösse von $2942 q \mu$, die Pars sternalis solche von $4587 q u$, der Unterschied ist also ein sehr bedeutender. Dagegen nähern sich die Maxima einander wieder sehr (8290 q $\mu$ und $8540 q \mu$ ). Auch die beiden Bauchmuskeln sind sehr wesentlich voneinander verschieden: Transversus 2559 q $\mu$ und Kectus $3791 q \mu$; hier weichen auch die Maxima erheblich voneinander $a b: 5750 q \mu: 7050 q \mu$. Die Bedeutung dieser Unterschiede zwischen den einzelnen Muskeln ist ja vorläufig noch unbekannt und müsste erst durch eingehendere physiologische Untersuchungen festgestellt werden.

Jedenfalls geht aus diesen Unterschieden $z$ wischen den einzelnen Abteilungender obengenannten Muskeln aber hervor, dass dieselben als Muskeln von ganz verschiedener Bedeutung anzusehen sind, was, wie wir sehen werden, durch die weiteren Tabellen durchaus bestätigt wird.

In Tabelle III a u. b (S. 388-391) sind die Muskeln in Fasergruppen zerlegt, die ihrer Querschnittsgrösse nach, nach einer geometrischen Reihe mit dem Quotienten 1,5, in Gruppen angeordnet sind; für jede Gruppe ist dann die „Faseranzahl" und "Faserwertigkeit"

1) P. Schiefferdecker, Muskeln und Muskelkerne. 317 Seiten mit 20 Abbildungen im Text. Joh. Ambros. Barth, Leipzig 1909. 
P. Schiefferdecker:

\begin{tabular}{|c|c|c|c|c|c|c|c|c|c|}
\hline \multirow{3}{*}{ 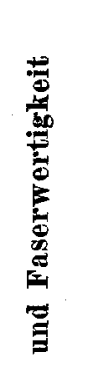 } & \multirow{3}{*}{ 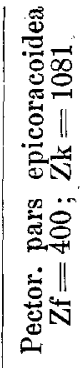 } & $\begin{array}{l}\stackrel{0}{\circ} \\
3\end{array}$ & 1 | & $\frac{13}{\infty}$ & कi & $\stackrel{8}{8}$ & 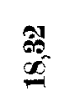 & $\underset{-1}{*}$ & 1 \\
\hline & & $\begin{array}{l}0 \\
\frac{0}{5}\end{array}$ & 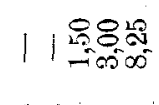 & $\begin{array}{l}0 \\
10 \\
10 \\
-2\end{array}$ & $\sum_{0}^{8}$ & $\frac{28}{8}$ & 管 & $\stackrel{\text { s. }}{=} 1$ & 1 \\
\hline & & $\sum_{\mathbf{Z}} \mid \mathbf{N}$ & | 1808 & $=8$ & 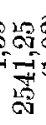 & 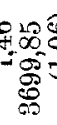 & 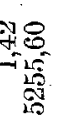 & 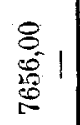 & - \\
\hline בี & \begin{tabular}{l}
$\infty$ \\
\multirow{H}{*}{}
\end{tabular} & $\begin{array}{l}\stackrel{0}{\circ} \\
3\end{array}$ & $1111 \stackrel{20}{6}$ & $\underset{f}{f}$ & 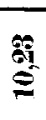 & 害 & $\begin{array}{l}\text { g: } \\
\text { oi } \\
\text { q }\end{array}$ & 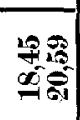 & 1 \\
\hline है & 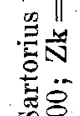 & $\begin{array}{l}9 \\
\stackrel{9}{0}\end{array}$ & 11 & $\stackrel{8}{\Rightarrow}$ & $\stackrel{20}{5}$ & $\begin{array}{l}10 \\
5 \\
\frac{15}{90}\end{array}$ & की & $\begin{array}{l}200 \\
0 \\
0 \\
0\end{array}$ & 1 \\
\hline 交 & 茳 & 要过 & $1111 \stackrel{5}{\mathrm{~s}}$ & $\begin{array}{l}8 \\
8 \\
25 \\
5\end{array}$ & की & $\begin{array}{l}28 \\
85 \\
-15 \\
8\end{array}$ & 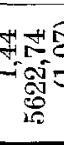 & 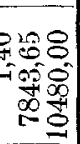 & is \\
\hline$\underbrace{e}_{E}$ & 窇官 & $\begin{array}{l}\circ \\
\div\end{array}$ & $111 \frac{198}{9}$ & $\stackrel{0}{=}$ & $\frac{3}{\infty}$ & $\underset{\infty}{\infty}$ & $\underset{F}{F}$ & 11 & 1 \\
\hline 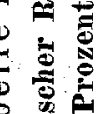 & 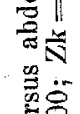 & 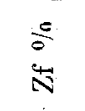 & $1|1| \begin{array}{c}0.9 \\
000\end{array}$ & $\frac{20}{50}$ & $\begin{array}{l}80 \\
00 \\
80\end{array}$ & $\frac{10}{50}$ & 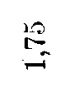 & 11 & 1 \\
\hline 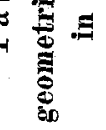 & 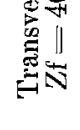 & $\sum \mid H$ & 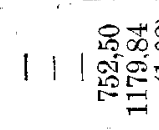 & $=$ & Fi: & 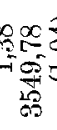 & $\underset{20}{*}$ & 11 & - \\
\hline$\Xi$ & $\stackrel{\infty}{\stackrel{\infty}{\Xi}}$ & $\begin{array}{l}\stackrel{\circ}{\circ} \\
=\end{array}$ & | | | | & 6 & $\frac{g}{g}$ & $\stackrel{0}{=}$ & $\underset{\tilde{q}}{\tilde{q}}$ & $\stackrel{E}{E} 1$ & 1 \\
\hline : & 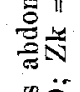 & $\begin{array}{l}\stackrel{0}{0} \\
\dot{N}\end{array}$ & 1 1 | & $\underset{5}{8}$ & $\begin{array}{l}20 \\
\infty \\
\pi\end{array}$ & 每 & $\underset{8}{8}$ & की & 1 \\
\hline 苞 & 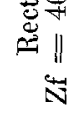 & 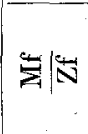 & 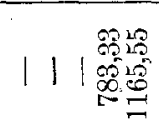 & $\sum_{\substack{\infty \\
0}}^{2}$ & 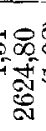 & 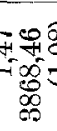 & 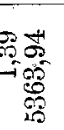 & $\begin{array}{l}8 \\
8 \\
81 \\
8\end{array}$ & $\stackrel{8}{-10}$ \\
\hline 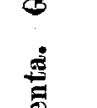 & 焉 & 萬 & 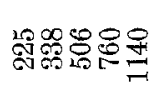 & $\underset{\Xi}{E}$ & $\begin{array}{l}28 \\
200 \\
20\end{array}$ & $\stackrel{5}{\infty}$ & $\sum_{i=0}^{F}$ & 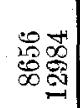 & \\
\hline 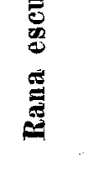 & & 䓂 & 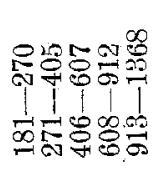 & 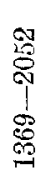 & 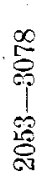 & 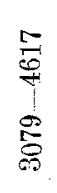 & 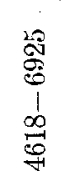 & 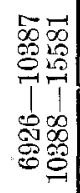 & \\
\hline
\end{tabular}


Untersuchung einer Anzahl von Muskeln von Rana esculenta etc. $\quad 389$

\begin{tabular}{|c|c|c|c|c|c|c|c|c|}
\hline \multirow{3}{*}{ 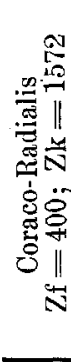 } & $\begin{array}{l}\stackrel{\circ}{\circ} \\
3\end{array}$ & 11111 & 5! & $\mathscr{\not}$ & 5 & $\vec{g}$ & 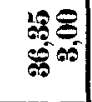 & | \\
\hline & $\begin{array}{l}\circ \\
\stackrel{0}{N}\end{array}$ & 11111 & $\underset{f}{8}$ & $\stackrel{20}{\stackrel{2}{\varrho}}$ & $\begin{array}{l}8 \\
\text { 今ิ }\end{array}$ & $\overbrace{0}^{20}$ & $\begin{array}{l}80 \\
80 \\
25 \\
0\end{array}$ & 1 \\
\hline & 嶳芯 & 11111 & \multicolumn{5}{|c|}{ 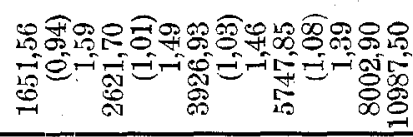 } & 禺 \\
\hline \multirow{3}{*}{ 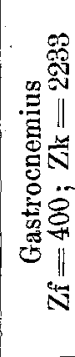 } & $\because$ & $1111 \Xi$ & $\underline{z}$ & 8 & $\stackrel{6}{9}$ & 象 & $\stackrel{0}{ \pm}$ & 1 \\
\hline & $\begin{array}{l}\circ \\
\dot{0}\end{array}$ & 11118 & $\stackrel{8}{+}$ & $\begin{array}{l}20 \\
5 \\
15 \\
-1\end{array}$ & $\stackrel{20}{+\infty}$ & $\begin{array}{l}29 \\
0 \\
6 \\
6 \\
6\end{array}$ & $\frac{12}{\infty} \mid$ & 1 \\
\hline & 突岕 & $1|1| \stackrel{8}{8}$ & \multicolumn{5}{|c|}{ 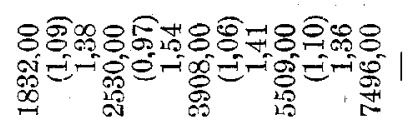 } & 8 \\
\hline \multirow{3}{*}{ 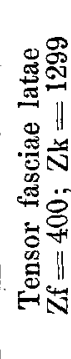 } & $\begin{array}{l}\frac{0}{0} \\
3\end{array}$ & $1 \mid 1=$ & 25 & $\stackrel{9}{ \pm}$ & 薄 & 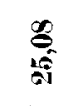 & $\begin{array}{l}\infty \\
\infty \\
\infty\end{array}$ & 1 \\
\hline & $\frac{\circ}{0}$ & 111501000 & $\begin{array}{l}0 \\
0 \\
0 \\
9\end{array}$ & $\frac{8}{8}$ & $\frac{8}{8}$ & $\begin{array}{l}10 \\
0 \\
0\end{array}$ & $\frac{2}{2}$ & 1 \\
\hline & 岁岕 & 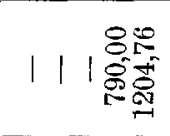 & \multicolumn{5}{|c|}{ 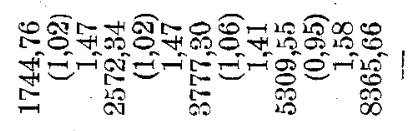 } & i⿱ \\
\hline \multirow{3}{*}{ 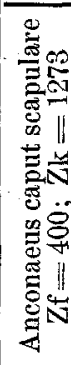 } & $\begin{array}{l}\frac{0}{0} \\
3\end{array}$ & $11 \mid \begin{array}{c}0 \times 0 \\
0\end{array}$ & $\frac{9}{2}$ & 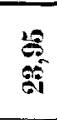 & $\underset{\mathscr{\theta}}{\mathscr{\theta}}$ & \begin{tabular}{l}
$\infty$ \\
â \\
\multirow{2}{*}{}
\end{tabular} & $\stackrel{\infty}{\infty} 1$ & 1 \\
\hline & $\frac{0}{8}$ & $1118 \%$ & $\stackrel{50}{50}$ & $\begin{array}{l}0 \\
0 \\
0 \\
0\end{array}$ & $\frac{8}{5}$ & $g_{1}$ & 袋। & 1 \\
\hline & 标 & \multicolumn{5}{|c|}{ I I | } & $\begin{array}{l}8 \\
8 \\
\infty \\
\infty\end{array}$ & in \\
\hline & 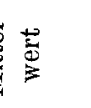 & 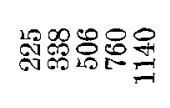 & $\underset{⿱}{\stackrel{9}{\Xi}}$ & $\begin{array}{l}20 \\
\stackrel{2}{3}\end{array}$ & 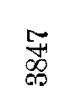 & $\underset{⿱ 乛}{5}$ & $\begin{array}{l}50 \\
\infty \\
\infty \\
\infty\end{array}$ & \\
\hline & 莒 & 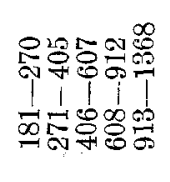 & 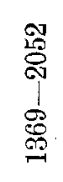 & 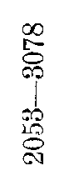 & & 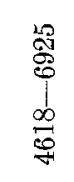 & 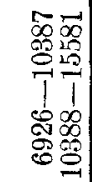 & \\
\hline
\end{tabular}


P. Schiefferdecker:

\begin{tabular}{|c|c|c|c|c|c|c|c|c|c|}
\hline $\overrightarrow{3}$ & $\stackrel{N}{N}$ & $\begin{array}{l}\frac{9}{8} \\
3\end{array}$ & $111=08$ & $\begin{array}{l}\text { S1 } \\
\text { si }\end{array}$ & 触 & 空 & 国 & $\stackrel{8}{=1}$ & \\
\hline$\frac{5}{5}$ & 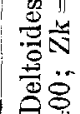 & $\begin{array}{l}0 \\
0 \\
+1\end{array}$ & 1110 & $\begin{array}{l}08 \\
20 \\
00\end{array}$ & 용 & $\underset{8}{8}$ & $\underset{\infty}{8}$ & $\frac{10}{2}$ & 1 \\
\hline 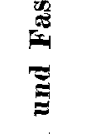 & ॥ี & $\mathbf{z} \mid \mathbf{N}$ & 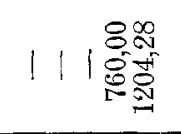 & 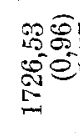 & $\sum_{0}^{2}=$ & 象 & 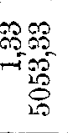 & $\begin{array}{l}\infty \\
8 \\
8 \\
8 \\
0\end{array}$ & in \\
\hline 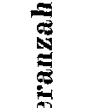 & 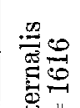 & $\frac{0}{\circ}$ & 11110 & 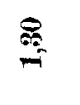 & $\stackrel{9}{\infty}$ & $\begin{array}{l}\text { E: } \\
\text { â }\end{array}$ & $\vec{\infty}$ & $\stackrel{5}{ \pm}$ & I \\
\hline$\dot{1}$ & 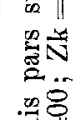 & $\begin{array}{l}\stackrel{0}{\circ} \\
4 \\
4\end{array}$ & $1111 \stackrel{8}{\rightarrow}$ & os & $\underset{8}{8}$ & 㤐 & $\frac{10}{5}$ & 81 & 1 \\
\hline$\stackrel{5}{=}$ & 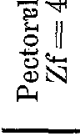 & 索过 & 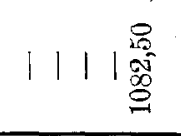 & 焉 & 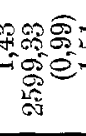 & 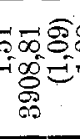 & 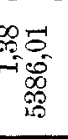 & 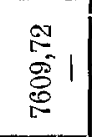 & 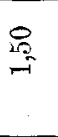 \\
\hline $\begin{array}{l}\mathscr{Q} \\
\stackrel{\Xi}{\Xi}\end{array}$ & 㺼 & $\stackrel{\circ}{i}$ & 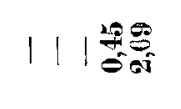 & $\ddot{\theta}$ & $\underset{10}{21}$ & $\frac{\mathbb{a}}{01}$ & 悉 & $\stackrel{\mathscr{N}}{\approx} 1$ & 1 \\
\hline 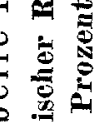 & 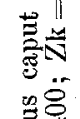 & $\begin{array}{l}\frac{0}{2} \\
\stackrel{4}{N}\end{array}$ & $1 \mid 18.80$ & $\S_{\delta}$ & बू & $\underset{8}{8}$ & $\begin{array}{l}8 \\
\text { ถิ }\end{array}$ & 紫 1 & 1 \\
\hline 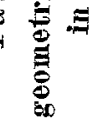 & 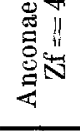 & 莫芯 & $111 \underset{8}{0}$ & 急 & 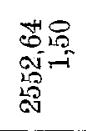 & $\begin{array}{l}+6 \\
0 \\
0 \\
0 \\
0 \\
0\end{array}$ & 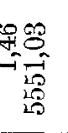 & $\begin{array}{l}5 \\
\frac{5}{5} \\
\frac{5}{5} \\
\frac{5}{5}\end{array}$ & 昰 \\
\hline 咅 & 蛋宫 & $\frac{0}{8}$ & $11.1 \stackrel{0000}{0}$ & $\stackrel{\text { จิ }}{8}$ & $\frac{9}{8}$ & $\stackrel{\ominus}{\stackrel{9}{8}}$ & है & $\stackrel{\infty}{-} 1$ & 1 \\
\hline 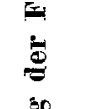 & 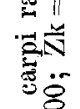 & $\begin{array}{l}8 \\
\dot{N}\end{array}$ & $111 \%$ & 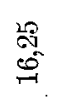 & 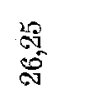 & $\frac{8}{8}$ & 然 & $\frac{12}{61}$ & 1 \\
\hline 总 & 总 & 㞫|ה & 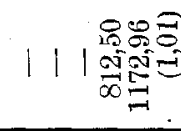 & 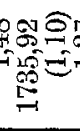 & 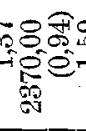 & 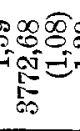 & 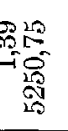 & $\begin{array}{l}\infty \\
0 \\
0 \\
0 \\
0 \\
0\end{array}$ & 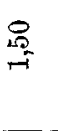 \\
\hline$\stackrel{5}{5}$ & & 莺 & 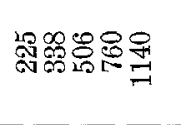 & 옽 & $\begin{array}{l}29 \\
20 \\
201\end{array}$ & 点 & E & 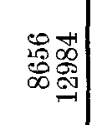 & \\
\hline 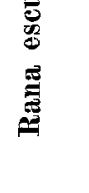 & & 吾 & 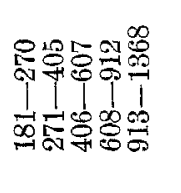 & 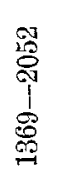 & $\begin{array}{l}\infty \\
5 \\
0 \\
0 \\
0 \\
0 \\
0 \\
8\end{array}$ & 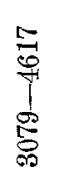 & 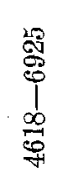 & 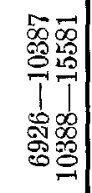 & \\
\hline
\end{tabular}


Untersuchung einer Anzahl von Muskeln von Rana esculenta etc. 391

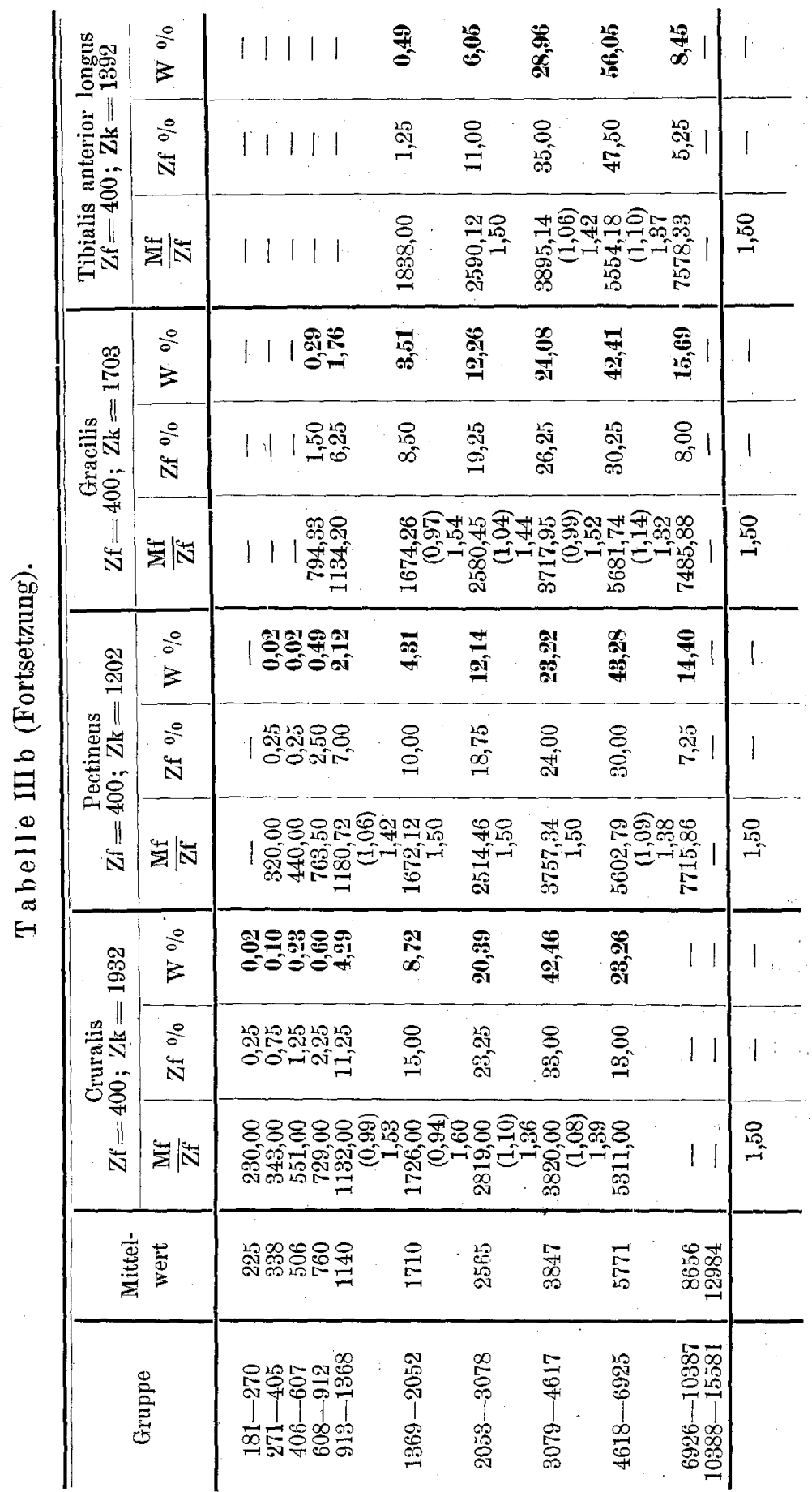


festgestellt worden. Die Faseranzahl ist ausgedrückt in Prozenten der Gesamtfaserzahl (Zf \%). Die Höhe dieser Prozentzahl gibt an, wieviel Fasern durch sie vertreten werden, und daraus kann ich dann ersehen, wie weit die betreffenden Zahlen Zutraven verdienen, und ob man sie infolgedessen zu der Berechnung benutzen kann. Gewöhnlich habe ich als untere Grenze für die Benutzbarkeit $4 \%$ angenommen. Die erste Kolumne mit der Überschrift „Gruppe“ gibt mir die einzelnen Gruppen an, in welche die Muskelfasern je nach ihrem Flächeninhalte eingeteilt worden sind. Der Quotient der geometrischen Reihe beträgt 1,5. Die zweite Kolumne mit der Überschrift „Mittelwert" gibt die aus diesen Gruppenzahlen berechneten Mittelzahlen an. Dann folgen die Fächer für die einzelnen Muskeln, wobei jedes Fach in drei Kolumnen zerfällt. Die erste Kolumne enthält die Zahlen für die wirklich gefundenen Mittelwerte, die zweite für die Prozentzahlen der Fasern; diese beiden Kolumnen wiederholen sich bei den sämtlichen jetzt folgenden Gruppentabellen. Die dritte Kolumne ist bei jeder Tabelle anders und enthält die Zahlen, die für die betreffenden Tabellen von Wichtigkeit sind. Für die Tabelle II also die Zahlen für die "Faserwertigkeit". Da die gefundenen Mittelwerte nicht immer genau mit den berechneten übereinstimmen, aber doch maassgebend sind für die in der dritten Kolumne befindlichen Zahlen, und da diese Abweichungen natürlich bei jedem Muskel wieder andere sind, so habe ich, um die Schlusszahlen vergleichen zu können, "Korrekturzahlen" angebracht. Man sieht, dass zwischen je zwei Zahlen der ersten Kolumne jedes Muskelfaches in der Mitte eine Zahl steht, die das Verhältnis der aufeinanderfolgenden gefundenen Mittelwerte angibt. Diese Zabl soll 1,50 betragen, weicht sie hiervon ab, so stelle ich das Verhältnis zwischen beiden Zahlen fest, das in Klammer über die Verhältniszahl herübergeschrieben wird. Nach diesen so gefundenen "Korrekturzahlen" werden die in der dritten Kolumne stehenden "Verhältniszahlen" korrigiert, und dann wird aus diesen die "Schlussverhältniszabl" gefunden, die unter dem Schlussstriche der Kolumne angegeben ist. Bei meiner ersten Muskelarbeit ${ }^{1}$ )

1) P. Schiefferdecker, Beiträge zur Kenntnis der Myotonia congenita, der Tetanie mit myotonischen Symptomen, der Paralysis agitans und einiger anderer Muskelkrankbeiten, zur Kenntnis der Aktivitätshypertrophie und des normalen Muskelbaues. Mit klinischen Beiträgen von Prof. Fr. Schultze, Deutsche Zeitschr. f. Nervenheilk. Bd. 25 H. 1-4 S. 1-345 mit 15 Tafeln. 1908. 
habe ich diese Verhältniszahlen überhaupt nicht benutzt; bei meiner zweiten Muskelarbeit ${ }^{1}$ ) habe ich sie benutzt, die Korrektur aber an der Schlussvérhältniszahl ausgeführt. Ich halte es aber für noch genauer und besser, jede einzelne Verhältniszahl so zu korrigieren und habe es auch in meiner dritten Muskelarbeit ${ }^{2}$ ) so ausgeführt. Diese so korrigierten "Schlussverhältniszahlen" sind sehr wichtig und geben mir Auskunft über den feineren Aufbau des Muskels nach der Richtung hin, in welcher Weise sich die Kerne verhalten bei zunehmender Dicke der Muskelfasern. Da nun aber jeder Muskel sich in ganz konstanter Weise aus verschiedenen dicken Fasern zusammensetzt, und da das Kernverbältnis für jede Faser ein spezifisches ist, so erlauben mir die Sehlussverhältnis̀zahlen in der Tat einen Einblick in einen wichtigen Teil des feineren Aufbaues der Muskeln. In Tabelle III sind nur die Mittelwerte selbst korrigiert worden, für die Zahlen für die Faserwertigkeit war eine' solche Korrektur nicht nötig, da bei ihnen die Verhältniszahlen keine Rolle spielen. Die Zahlen für die Faserwertigkeit geben mir an, welchen Wert die morphologischen Prozentzahlen der zweiten Kolumne für die Funktion des Muskels haben; sie sind also die "physiologischen" Zahlen, während die der zweiten Kolumne die "morphologischen" Zahlen sind. Aus den Zahlen der dritten Kolumne kanu also jeder Physiologe

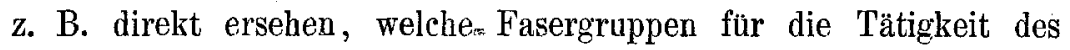
Muskels hauptsächlich wichtig sind und welche Kernverhältnisse daher für den Muskel hauptsächlich von Bedeutung sind. Man braucht dazu nur diese Tabelle III mit den folgenden Gruppentabellen zu vergleichen.

In den Tabellen IV a und b (S. 394-397) sind die „Abs oluten Kernzahlen“ für jede Gruppe in jedem Muskel mitgeteilt und ausserdem die Schlussverhältniszahlen, unter dem Schlussstriche der jedesmaligen dritten Kolumne, d. h. jene Zahlen, welche mir angeben, in welchem Grade die Zahl der Muskelkerne mit dem zunehmenden Flächeninhalte der Faserquerschnitte, also mit der Dicke der Fasern, zunimmt. Da der Flächeninhalt der Fasern in jeder Gruppe um 1,50

1) P. Schiefferdecker, Muskeln und Muskelkerne. 317 Seiten mit 20 Abbildungen im Text. Joh. Ambros. Barth, Leipzig 1909.

2) P. Schiefferdecker, Untersuchung des Zwerchfelles auf seinen Bau and seine Kernverhältnisse. Pflüger's Arch. Bd. 139 S. 337. 
P. Schiefferdecker:

\begin{tabular}{|c|c|c|c|c|c|c|c|c|c|}
\hline & 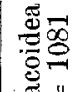 & 곤 & 111 & $\mathbb{H} 8$ & $\approx a$ & 9 & & $E_{\infty}$ & $\overrightarrow{\mathrm{a}}$ \\
\hline & 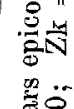 & $\begin{array}{l}\circ \\
\text { s }\end{array}$ & 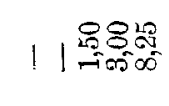 & 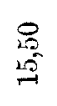 & $\stackrel{8}{8}$ & की & $\stackrel{201}{9}$ & 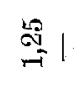 & 1 \\
\hline مْ & 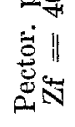 & $\exists \mid \mathbb{N}$ & $110 \begin{array}{c}85 \\
808 \\
802\end{array}$ & & & & 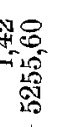 & $\begin{array}{l}8 \\
8 \\
0 \\
0 \\
0 \\
0\end{array}$ & 承 \\
\hline 咅 & 亦 & 光隌 & $1111=$ & & & & $+1=\hat{x}$ & 88 & - \\
\hline$\stackrel{8}{\circ}$ & 驾管 & $\begin{array}{l}\circ \\
\vdots \\
\frac{1}{N}\end{array}$ & $\left.111\right|^{20}$ & $\stackrel{8}{=}$ & $\stackrel{20}{\stackrel{2}{5}=-1}$ & 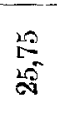 & 旅 & $\begin{array}{l}2920 \\
010 \\
00 \\
-10\end{array}$ & I \\
\hline 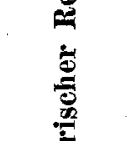 & ti & $\mathbf{z}$ & 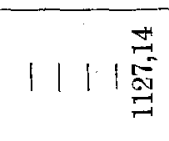 & & - & & 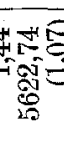 & 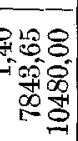 & 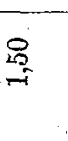 \\
\hline 递总 & . & $\stackrel{M}{\mathbb{N} \mid \vec{N}}$ & 1118 & & & & & 11 & 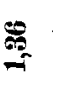 \\
\hline 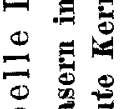 & 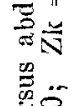 & $\begin{array}{l}\therefore \\
\text { i }\end{array}$ & 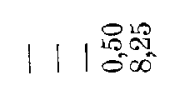 & $\stackrel{100}{50}$ & 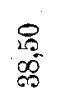 & 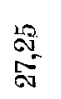 & $\stackrel{10}{=}$ & 11 & 1 \\
\hline 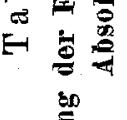 & 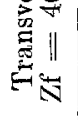 & $\vec{z} \mid \vec{N}$ & $111 \begin{array}{r}105 \\
100 \\
05 \\
50\end{array}$ & & 5 & & 焉 & 11 & 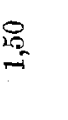 \\
\hline 离 & $\stackrel{\not 1}{=}$ & $\stackrel{\sim}{*} \mid \tilde{N}$ & $11 \mid \stackrel{0}{=}$ & & $\ldots$ & os & & $\varepsilon_{\infty} 1$ & $\stackrel{\infty}{=}$ \\
\hline 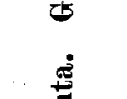 & 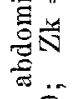 & $\begin{array}{l}\stackrel{8}{0} \\
\ddot{N}\end{array}$ & $1|1|$ & $\underset{\sim}{8}$ & $\begin{array}{l}29 \\
\substack{20 \\
0} \\
9\end{array}$ & 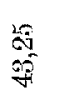 & 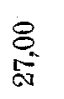 & $\begin{array}{ll}29 \\
\text { 到1 } \\
0\end{array}$ & 1 \\
\hline 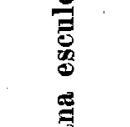 & $\begin{aligned} & \\
& \text { S }\end{aligned}$ & $\bar{\Sigma} \mid \vec{N}$ & 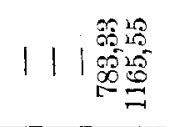 & & & $\begin{array}{ccc}\infty \\
\infty \\
\infty \\
\infty \\
\infty\end{array}$ & 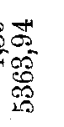 & $\begin{array}{l}8 \\
8 \\
0 \\
01 \\
0\end{array}$ & 点 \\
\hline & 要 & $\overleftrightarrow{\mathrm{E}}$ & 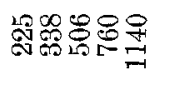 & 总 & 旅 & 武 & 沗 & 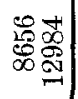 & \\
\hline & & & 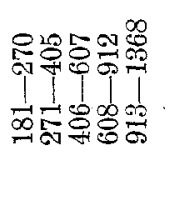 & 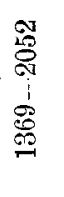 & 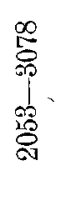 & 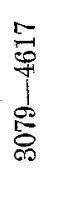 & 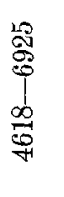 & 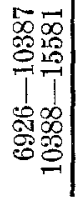 & \\
\hline
\end{tabular}


Untersuchungen einer Anzahl von Muskeln von Rana esculenta etc, 395

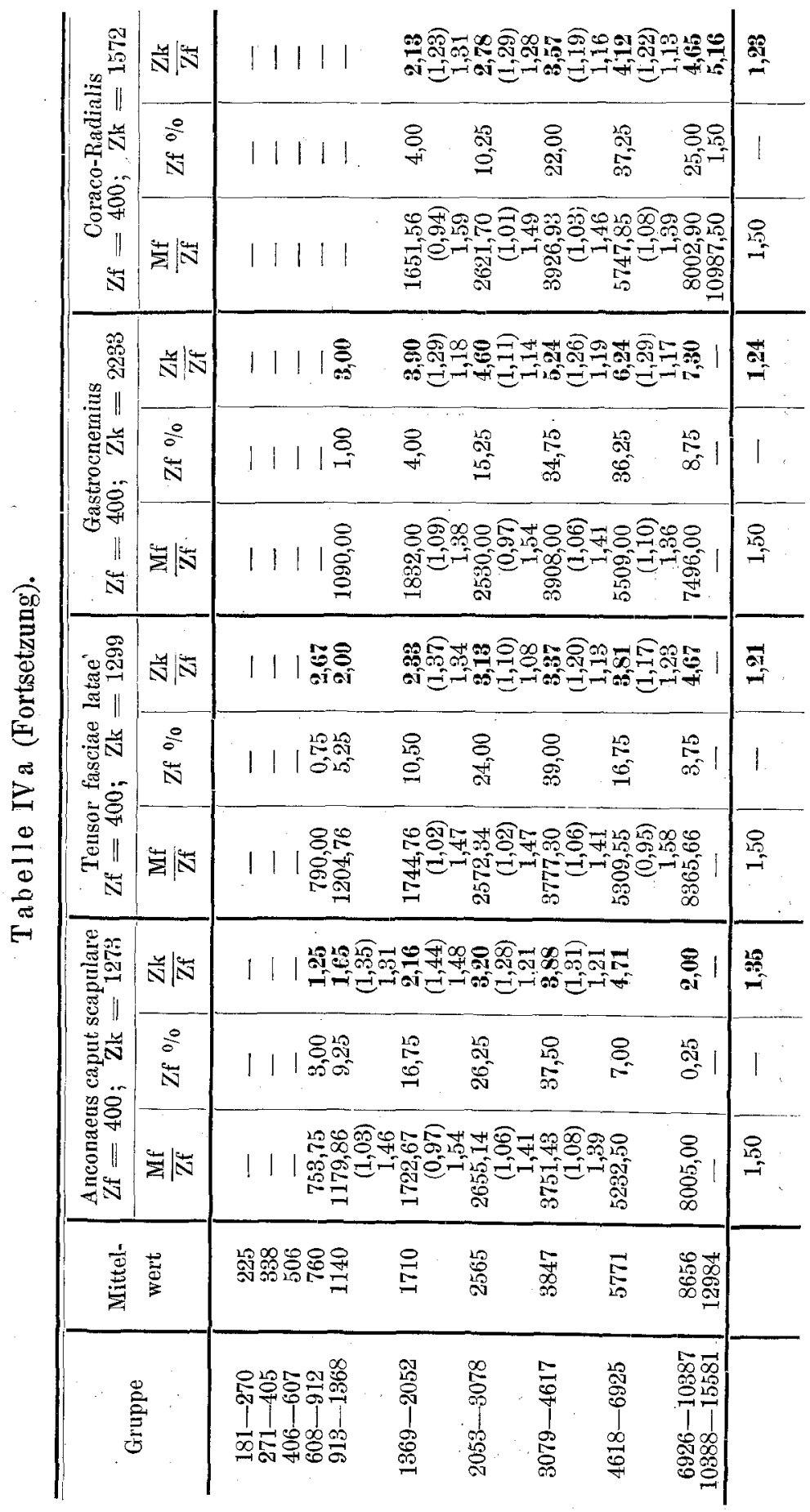


P. Schiefferdecker:

\begin{tabular}{|c|c|c|c|c|c|c|c|c|c|}
\hline & $\stackrel{\Omega}{\Xi}$ & $\stackrel{\Delta N}{N}$ & $11 \mid \underset{\text { 울 }}{\overrightarrow{0}}$ & a & 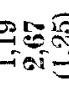 & 2 & & $\sum_{\text {oi }} 1$ & 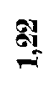 \\
\hline & 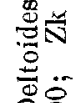 & $\begin{array}{l}\stackrel{8}{8} \\
\dot{N}\end{array}$ & $11 \mid \begin{array}{l}20 \\
0.5\end{array}$ & 足 & कog & $\underset{8}{8}$ & 8 & $\frac{12}{5}$ & 1 \\
\hline 20 & $\begin{array}{l}\| \\
\mathbb{N}\end{array}$ & 言俉 & 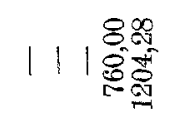 & 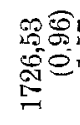 & 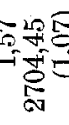 & 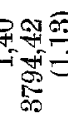 & 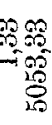 & $\begin{array}{l}\infty \\
\infty \\
0 \\
0 \\
0 \\
0\end{array}$ & - \\
\hline 萨 & 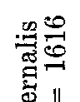 & $\frac{y}{N} \mid *$ & $1111 \stackrel{20}{=}$ & $\underset{\theta=}{\vec{\theta}=}$ & 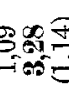 & $\begin{array}{l}\theta \\
-\infty \\
-\infty\end{array}$ & & की & $\stackrel{\infty}{=}$ \\
\hline$\stackrel{8}{9}$ & 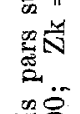 & $\begin{array}{l}\frac{0}{\vdots} \\
\frac{N}{N}\end{array}$ & $\left.1|1|\right|^{80}$ & 盟 & $\underset{80}{80}$ & $\frac{8}{80}$ & 点 & $\begin{array}{l}8 \\
8 \\
0\end{array}$ & $!$ \\
\hline 里 & 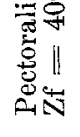 & 㞫| & 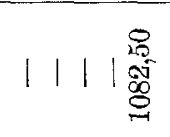 & 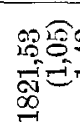 & 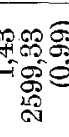 & 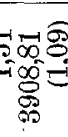 & 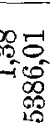 & $\begin{array}{l}0 \\
\frac{5}{2} \\
\frac{8}{2}\end{array}$ & 号 \\
\hline 总 & 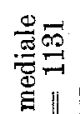 & 忞徒 & 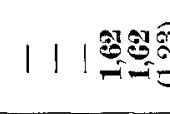 & $\stackrel{808}{9}$ & oin- & 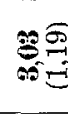 & & ${ }_{\text {की }}$ & क्ष \\
\hline 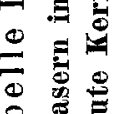 & 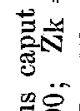 & $\begin{array}{l}9 \\
\vdots\end{array}$ & 111800 & 8 & 茕 & $\begin{array}{l}8 \\
\text { की }\end{array}$ & $\begin{array}{l}8 \\
8 \\
619\end{array}$ & of & I \\
\hline 可 & 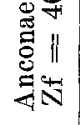 & $\overrightarrow{\mathbb{N}}$ & 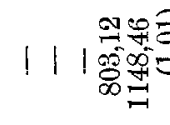 & 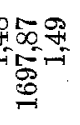 & 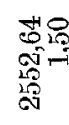 & 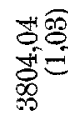 & 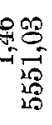 & $\frac{5}{\frac{5}{5}}$ & $\stackrel{8}{8}$ \\
\hline$\stackrel{5}{\tilde{E}}$ & 章 & 신 & 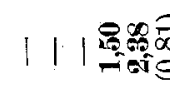 & 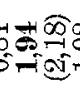 & $\begin{array}{l}0+0 \\
000\end{array}$ & 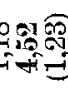 & & $⿹_{\infty}^{\infty}$ & 里 \\
\hline s & 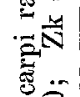 & $\begin{array}{l}\frac{9}{8} \\
+1\end{array}$ & | | 1 180 & $\stackrel{n=0}{\Omega}$ & $\begin{array}{l}10 \\
0.5 \\
60\end{array}$ & 8 & 露 & 量 1 & 1 \\
\hline $\begin{array}{l}\stackrel{0}{3} \\
3 \\
0 \\
0 \\
0\end{array}$ & 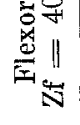 & 新新 & | | | 告空 & 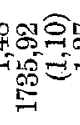 & 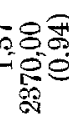 & 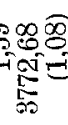 & 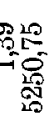 & 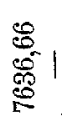 & $\stackrel{8}{10}$ \\
\hline & 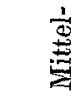 & $\overrightarrow{0}$ & 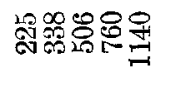 & 옫 & 绝 & 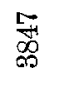 & E & 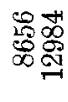 & \\
\hline & & 芯 & 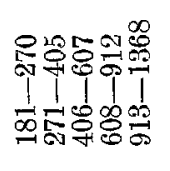 & 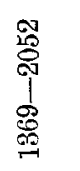 & 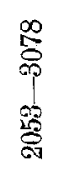 & 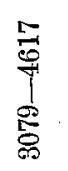 & 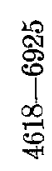 & 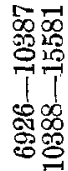 & \\
\hline
\end{tabular}


Untersuchung einer Anzahl von Muskeln von Rana esculenta etc.

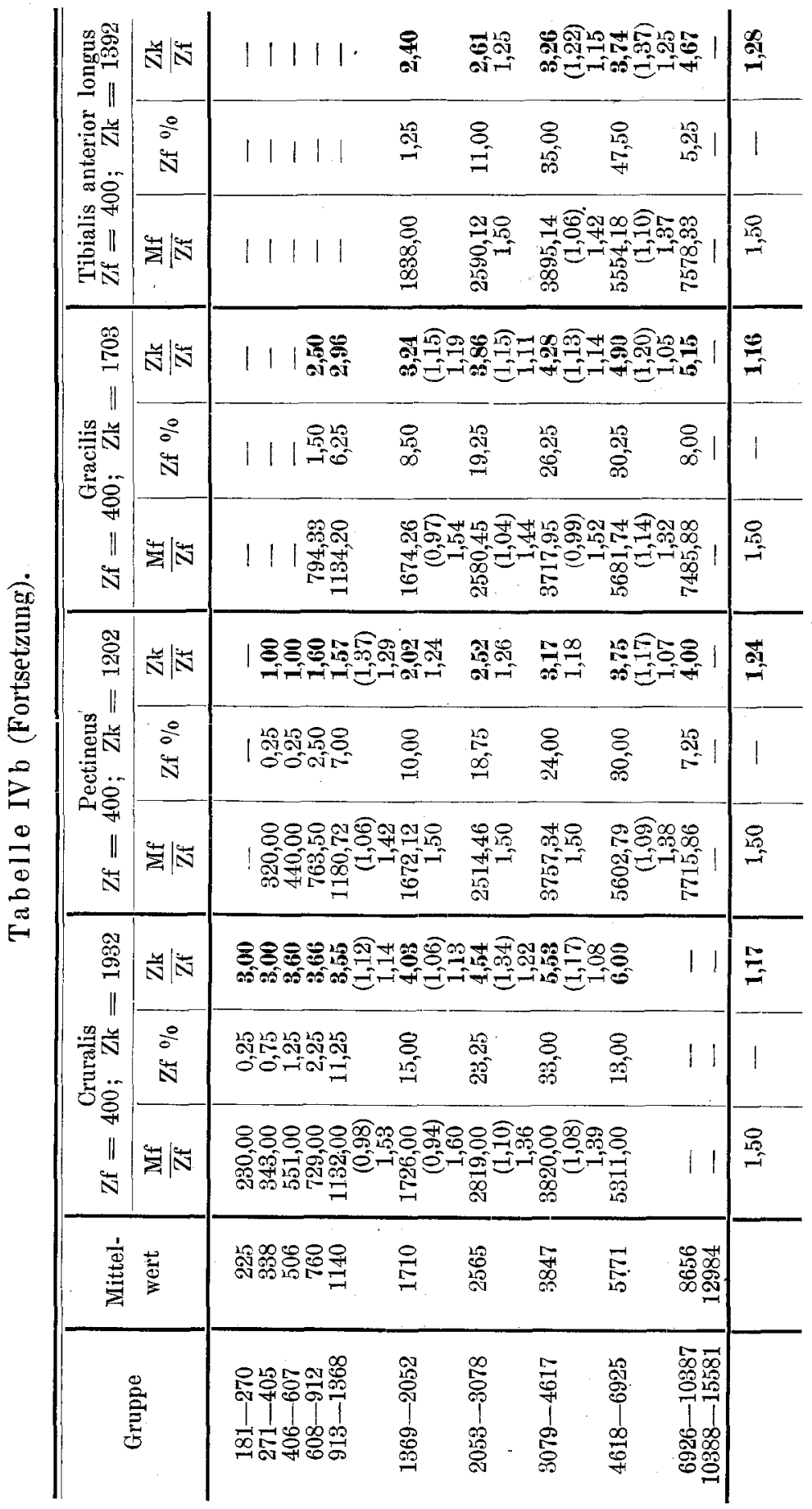


ansteigt, so würde die Mittelzahl für die Kernzunahme ebenfalls 1,50 betragen müssen, $d . h$. wenn die Schlussverhältniszahl 1,50 betrüge, so würden die sämtlichen Fasergruppen mit relativ derselben Kernzahl arbeiten; ist die Schlussverhältniszahl kleiner, so arbeiten die Fasern mit zunebmender Dicke relativ mit immer weniger Kernen; ist sie höher als 1,50, so arbeiten die Fasern mit zunehmender Dicke relativ mit immer mehr Kernen. Auch die absoluten Zahlen für jede Gruppe sind nicht" uninteressant; sie geben mir an, wieviel Kerne im Durchschnitte auf einen Faserquerschnitt der betreffenden Gruppe entfallen. Wichtiger aber sind die Schlussverhältniszahlen. Um eine klare Übersicht zu ermöglichen, habe ich diese in T a belle IVc in der Weise zusammengestellt, dass die untersuchten 16 Muskeln nach der Grösse ihrer Schlussverhältniszablen, mit der niedrigsten beginnend, angeordnet sind. Wie man sieht, liegen die Schlussverhältuiszahlen zwischen 1,16 und 1,36 , man kann sie also leicht in drei Gruppen zerlegen: Von 1,16-1,22, von 1,23-1,29 und von $1,30-1,36$. Tut man das, so findet sich, dass zu der ersten Gruppe 7 Muskeln gehören, zu der letzten 3, und dass auf die mittlere Gruppe. 6 entfallen. Die Zablen dieser letzteren 6 Muskeln liegen verhältnismässig nahe aneinander: zwischen 1,23 und 1,28: Mehrere Muskeln haben dieselben Zahlen. Die beiden Abteilungen des Pectoralis zeigen stark verschiedene Zahlen (1,18 und 1,24), die beiden Abteilungen des Anconaeus nit 1,22 und 1,35 weichen

Tabelle IV c.

Absolute Kernzahl.

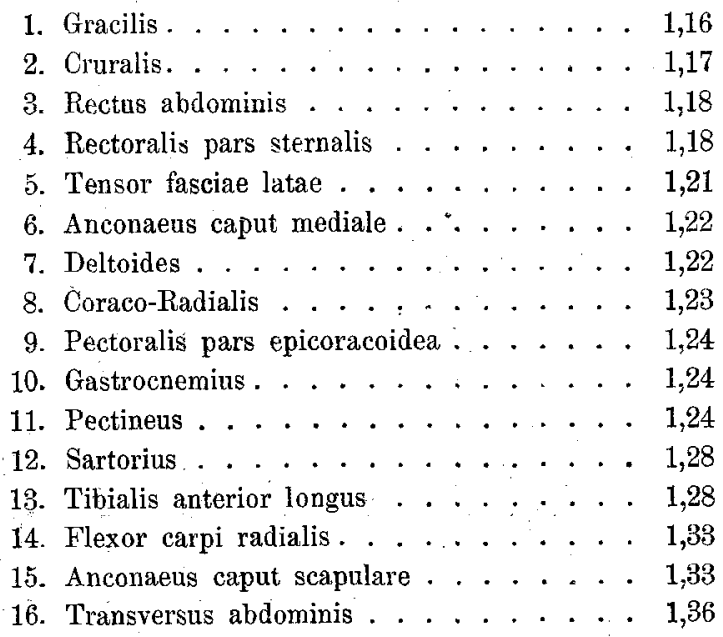


ebenfalls sehr stark voneinander ab. Sehr niedrige Zahlen haben Gracilis, Cruralis und Rectus abdominis, sehr hohe Flexor carpi radialis, Anconaeus caput scapulare und Transversus abrominis. Die beiden Bauchmuskeln sind also mit 1,18 und 1,36 wieder sehr wesentlich voneinander verschieden. $\mathrm{Da}$ ich in dieser Arbeit nur die Muskeln eines einzigen Tieres untersucht babe, so konnte ich natürlich nicht feststellen, wie weit die hier gerade für die einzelnen Muskeln gefundenen Zahlen nur für dieses Tier charakteristische individnelle Abweichungen von einer Mittelzahl darstellen, welche für den Frosch an sich charakteristisch gewesen wäre. Ich kann hier nur die für die einzelnen Muskeln gefundenen Zahlen direkt miteinander vergleichen, und das genügt ja schliesslich auch, wenigstens bis zu einem gewissen Grade, um die Verschiedenheiten der einzelnen Muskeln festzustellen.

Wie man leicht sieht, liegen sämtliche Schlussverhältniszahlen mehr oder weniger weit unter der Mittelzahl $(1,50), d . h$. also: Bei allen Muskeln nimmt die Kernzahl bei steigender Fasergrösse verhältnismässig ab, in mehr oder weniger hohem Grade. Es stimmt dieser Befund durchaus überein mit dem, den ich bei der Mehrzahl der bisher untersuchten Muskeln gemacht habe. Beim Kaninchen war es nur ein Muskel, der rote Masseter, bei dem die absolute Kernzahl stärker zunahm als das Mittel. Auch bei diesem Tiere waren die Unterschiede zwischen den einzelnen Muskeln recht bedeutend. Jeder Muskel ist eben spezifisch gebaut. Auch bei der Karausche überschritt nur ein Muskel, der rote Muskel der Brustflosse, die Mittelzahl um ein weniges, und auch hier waren wieder stärkere Untersehiede zwischen den einzelnen Muskeln vorhanden. In beiden Fällen besassen übrigens die hohen Zahlen solche Muskeln, die mehr oder weniger andauernd tätig sind.

Man wird bei Betrachtung der Tabellen IVa and $b$ mehrfach feststellen können, dass die für die einzelnen Gruppen angegebenen Zahlen für die absolute Kernzahl mehr oder weniger unregelmässig sind, insofern, als höhere und niedere Zahlen bei den aufeinander folgenden Gruppen eventuell durcheinander vorkommen. Dieselben Unregelmässigkeiten werden auch die folgenden Tabell en $\mathrm{V}$ und VI (S. 400-403 und 406-409) aufweisen. Der Grund für diese Unregelmässigkeiten ist natürlich der, dass die Menge der aus gemessenen Fasern immer noch bei weitem zu klein 


\begin{tabular}{|c|c|c|c|c|c|c|c|c|c|}
\hline & 焉 & 产| & $11 \frac{90}{\infty}=7$ & & 8 & & & $\frac{80}{\infty}$ & 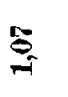 \\
\hline & 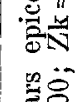 & $\frac{0}{5}$ & $11 \stackrel{8095}{2000}$ & 里 & $\begin{array}{l}8 \\
\mathscr{8}\end{array}$ & $\frac{20}{\infty}$ & $\begin{array}{l}29 \\
\text { : } \\
\text { : }\end{array}$ & $\stackrel{29}{\mathrm{G}}=1$ & 1 \\
\hline$\dot{10}$ & 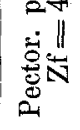 & 湈| & 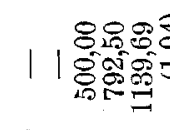 & 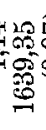 & 为 & 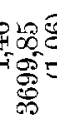 & 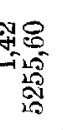 & $\begin{array}{l}8 \\
001 \\
0.01 \\
0\end{array}$ & $\underset{0}{\infty}$ \\
\hline 芦 & 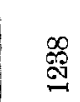 & 受|商 & $11 i 1 \stackrel{0}{\mathrm{~N}}$ & & -10 & & 596 & $\begin{array}{l}8 \\
89 \\
-50 \\
-10\end{array}$ & $\stackrel{5}{=}$ \\
\hline$\underbrace{E}_{\infty}$ & 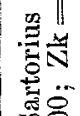 & $\begin{array}{l}\stackrel{8}{8} \\
\text { is }\end{array}$ & $11 \mid 1 \stackrel{20}{\stackrel{20}{-}}$ & $\stackrel{8}{=}$ & 点 & 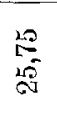 & $\frac{20}{65}$ & $\begin{array}{l}2900 \\
60 \\
0\end{array}$ & 1 \\
\hline 它 & 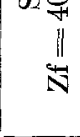 & 索| & 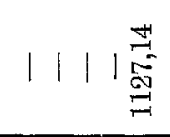 & $\begin{array}{l}87 \\
15 \\
15 \\
-1\end{array}$ & 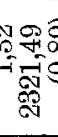 & $\frac{9}{8}$ & 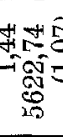 & 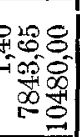 & ณึ \\
\hline 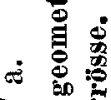 & . & 芝| & 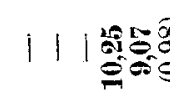 & & & & & 11 & 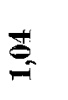 \\
\hline $\begin{array}{ll}0 & \equiv \\
0 & 0\end{array}$ & 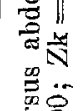 & $\begin{array}{l}\frac{0}{0} \\
+\end{array}$ & 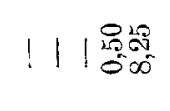 & $\frac{20}{25}$ & $\begin{array}{l}0 \\
20 \\
\infty \\
\infty\end{array}$ & $\frac{20}{\sigma N}$ & $\stackrel{20}{20}$ & 11 & 1 \\
\hline 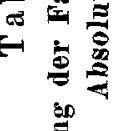 & 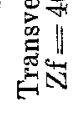 & 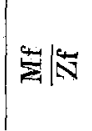 & 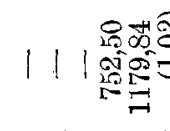 & 5 & 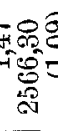 & की & $\frac{10}{10}$ & 11 & 足 \\
\hline 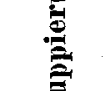 & 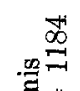 & 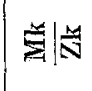 & || $\mid \begin{array}{l}\mid \infty ⿻ \infty \\
+20\end{array}$ & & $\begin{array}{c}-10 \\
-1 \times 20\end{array}$ & & (4) & 21 & g) \\
\hline E & 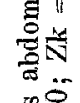 & $\begin{array}{l}\frac{0}{8} \\
\text { i }\end{array}$ & 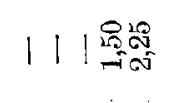 & $\underset{8}{8}$ & $\stackrel{20}{\infty}$ & $\begin{array}{l}20 \\
\text { की } \\
\text { की }\end{array}$ & $\stackrel{8}{5}_{5}$ & $\frac{1}{g}=1$ & 1 \\
\hline 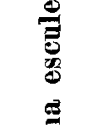 & 焉 & $\underset{N}{ }$ & 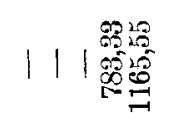 & $\begin{array}{l}20 \\
20 \\
0 \\
0\end{array}$ & 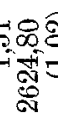 & 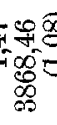 & 要 & 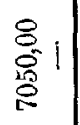 & 星 \\
\hline-7 & $\begin{array}{l}\text { 焉 } \\
\text { 壱 }\end{array}$ & $\stackrel{3}{*}$ & 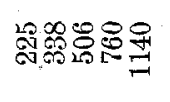 & 옴 & $\begin{array}{l}20 \\
\frac{20}{20} \\
\text { anj }\end{array}$ & $\underset{\substack{5 \\
0}}{\tilde{c}}$ & $\underset{5}{E}$ & 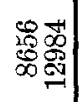 & \\
\hline & & 竧 & 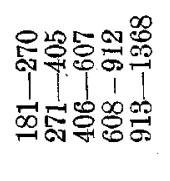 & 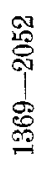 & 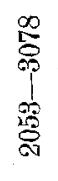 & $\sum_{\substack{0 \\
0}}^{\substack{0 \\
0}}$ & 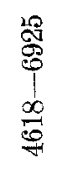 & $\begin{array}{ll}5 & -1 \\
0 & 0 \\
0 & 0 \\
0 & 0 \\
1 & 1 \\
0 & 1 \\
0 & 0 \\
8 & 0 \\
8 & 0\end{array}$ & \\
\hline
\end{tabular}


Untersuchung einer Anzahl von Muskeln von Rana esculenta etc.

\begin{tabular}{|c|c|c|c|c|c|c|c|c|}
\hline \multirow{3}{*}{ 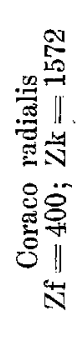 } & 突| & 11111 & \multicolumn{5}{|c|}{ 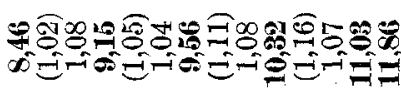 } & \multirow{2}{*}{ 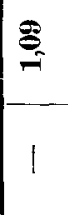 } \\
\hline & 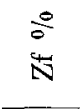 & 1111 & 8 & $\stackrel{2 g}{\stackrel{2}{O}}$ & $\underset{\mathfrak{N}}{\stackrel{8}{\mathcal{N}}}$ & 管 & 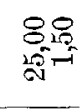 & \\
\hline & 索迹 & 111 & \multicolumn{5}{|c|}{ 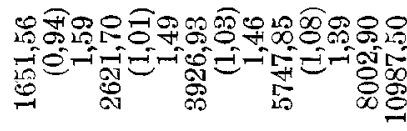 } & $\stackrel{8}{-\infty}$ \\
\hline \multirow{3}{*}{ 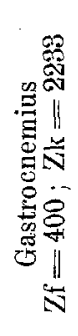 } & 娄| & $1|1| \frac{12}{4}$ & \multicolumn{5}{|c|}{ 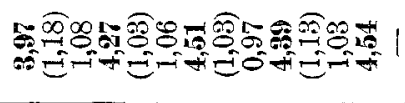 } & 8 \\
\hline & $\begin{array}{l}\stackrel{0}{0} \\
\text { 蒲 }\end{array}$ & 11118 & 8 & $\begin{array}{l}20 \\
25 \\
20\end{array}$ & $\frac{12}{i^{5}}$ & $\stackrel{20}{8}$ & $\stackrel{20}{\infty}$ & 1 \\
\hline & 索出 & $1|1| \stackrel{8}{8}$ & \multicolumn{5}{|c|}{ 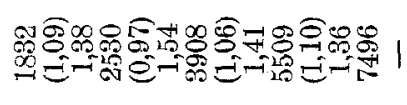 } & $\stackrel{8}{-10}$ \\
\hline \multirow{3}{*}{ 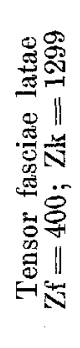 } & ي & 1||$\underset{\pi}{\infty}=$ & \multicolumn{5}{|c|}{ 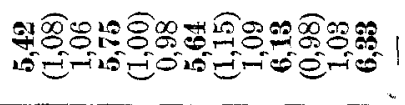 } & $\stackrel{19}{9}$ \\
\hline & $\begin{array}{l}\stackrel{0}{\circ} \\
+1\end{array}$ & 111007 & 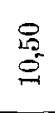 & $\frac{8}{8}$ & $\frac{8}{8}$ & $\stackrel{20}{0}$ & $\stackrel{10}{20}$ & 1 \\
\hline & 窝|N & $|1| \mathscr{S}_{5}^{8} \mathbb{8}$ & \multicolumn{5}{|c|}{ 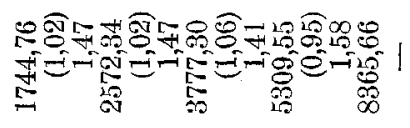 } & 욛 \\
\hline \multirow{3}{*}{ 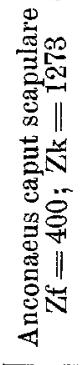 } & 言| $\mid \vec{N}$ & \multicolumn{6}{|c|}{ 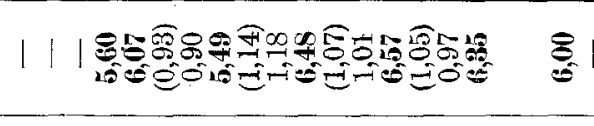 } & $\stackrel{2 g}{=}$ \\
\hline & $\frac{0}{0}$ & 1|| $\begin{array}{c}8 \% \\
805\end{array}$ & $\stackrel{12}{0}$ & 色 & $\underbrace{\infty}_{60}$ & 8 & 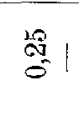 & \\
\hline & 参 $\mid \mathbf{N}$ & \multicolumn{6}{|c|}{ 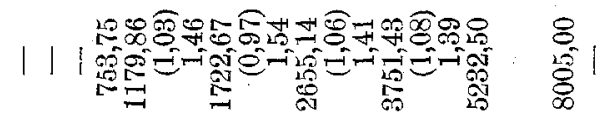 } & $\stackrel{0}{10}$ \\
\hline 竞 & $\stackrel{\vec{d}}{\geqslant}$ & 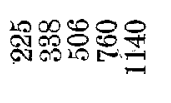 & $\stackrel{ }{ }$ & 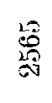 & 点 & E & 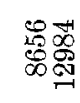 & \\
\hline & $\frac{8}{b}$ & 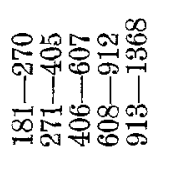 & 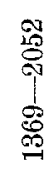 & 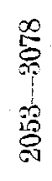 & $\begin{array}{l}\frac{5}{\mathscr{c}} \\
\frac{6}{5} \\
\stackrel{6}{0}\end{array}$ & 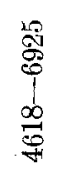 & 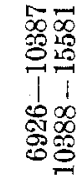 & \\
\hline
\end{tabular}




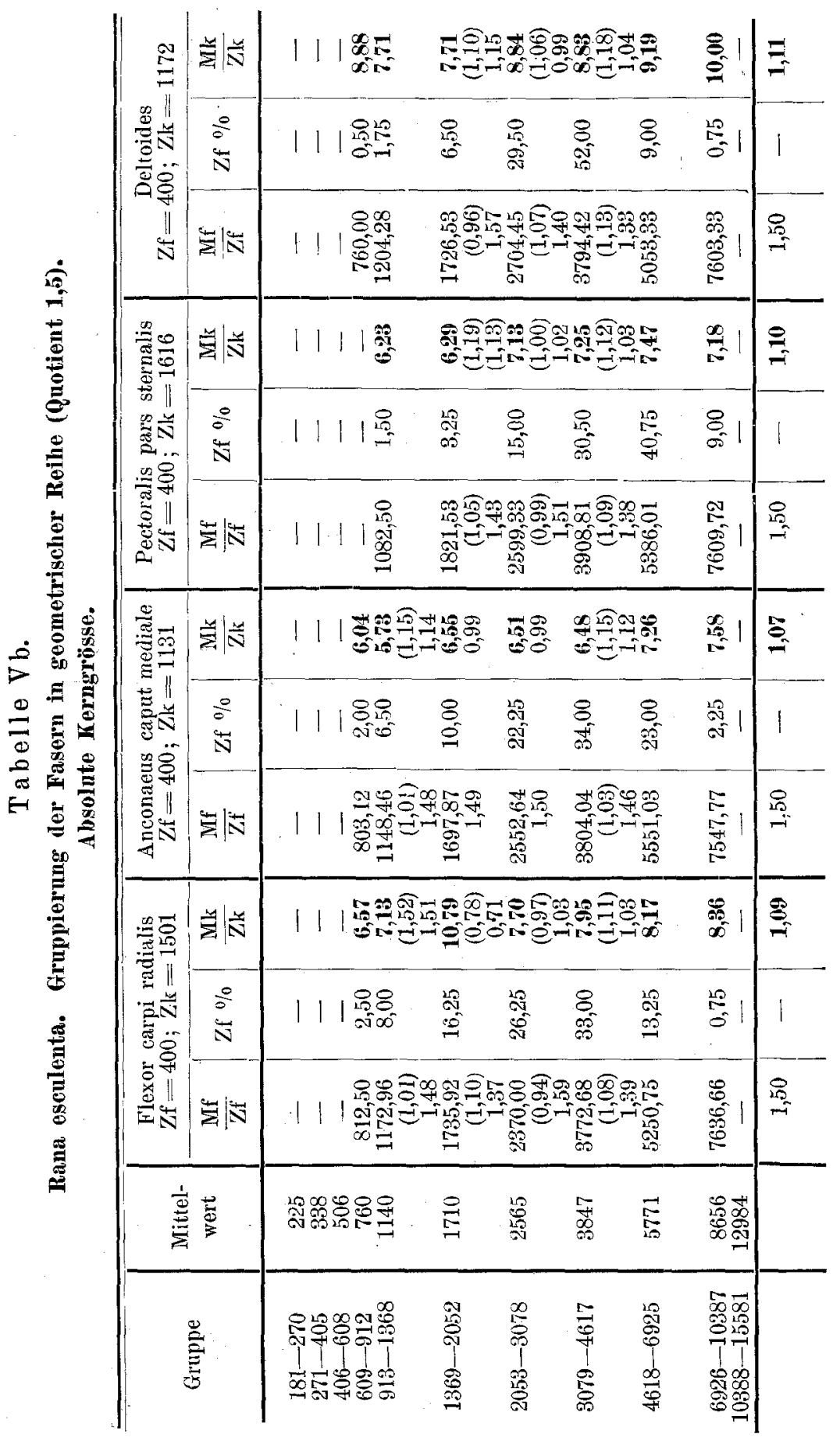


Untersuchung einel Anzall von Muskeln von Rana esculenta etc.

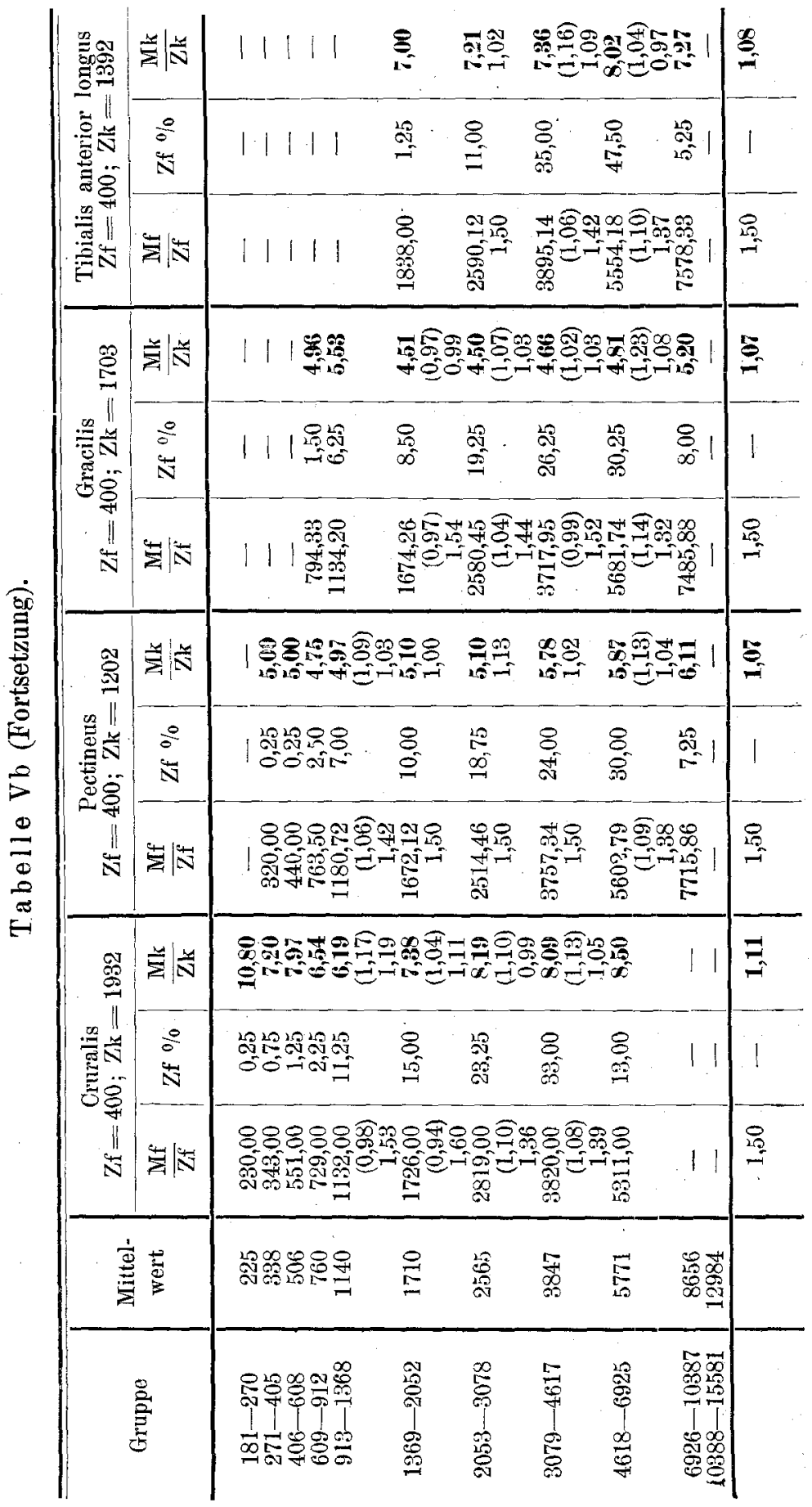


ist, um sicher richtige, regelmässige Zahlen zu ergeben. Die Zahlen würden zweifellos weit regelmässiger geworden sein, wenn bei jedem Muskel die zehnfache Zahl der Fasern ausgemessen worden wäre oder noch mehr, aber solches gebörte zunächst in das Gebiet der frommen Wünsche, und ich hoffe und glaube, dass auch die vorliegenden Ausmessungsresultate schon hinreichen werden, um uns wenigstens einen Einblick in die Verhältnisse dieser Muskeln tun zu lassen. Mir wäre es auch natürlich weit lieber gewesen, wenn eine weit grössere Anzahl von Fasern hätte ausgemessen werden können, aber das war unmöglich.

In den Tabellen Va und b (S. 400-403) sind die Zahlen für die "A bs ol u te Kerngrösse" zusammengestellt, d. h. für die durchschnittliche Querschnittsgrösse der Kerne. Hier liegen die Schlussverhältniszahlen noch tiefer unter dem Mittel als bei der absoluten Kernzahl, d. h. also: Mit zunehmender Fasergrösse werden die Kernquerschnitte im Verhältnisse zu der Grösse des Faserquerschnittes immer kleiner. Ich habe hier wiederum zur leichteren Übersicht in Tabelle Ve (S.405) die Muskeln nach der Grösse ihrer Schlussverhältniszahlen in aufsteigender Reihe geordnet. Man erkennt leicht, dass die Zahlen hier sich nicht so stark unterscheiden wie bei der absoluten Kernzahl, sie steigen von 1,04-1,11. Dementsprechend liegen auch durchschnittlich die Zahlen der verschiedenen Muskeln dicht aneinander oder stimmen miteinander überein. So haben 2 Muskeln die Zahl 1,05, 5 Muskeln die Zahl 1,07, 3 Muskeln die Zahl 1,09. Vergleicht man die Tabelle Ve mit der Tabelle IVc, so erkennt man leicht, dass die Anordnung der Muskeln in den beiden Tabellen eine durchaus verschiedene ist. Die Beobachtung, dass die Kernquerschnitte mit zunehmender Grösse der Faserquerschnitte absolut grösser, relativ aber immer kleiner werden, und die, dass die Unterschiede zwischen den Schlussverbältniszahlen bei der Kerngrösse nicht so bedeutend sind wie bei der Kernzahl, habe ich bei allen bisher untersuchten Muskeln gemacht, es scheint sich hier also um allgemein gültige Gesetze zu handeln. Die Unterschiede zwischen den einzelnen Muskeln waren allerdings bei den Kaninchenmuskeln und den Karauschenmuskeln etwas grösser, als sie es hier sind. 
Tabelle V c.

\section{Absolute Kernmasse.}

1. Transversus abdominis. . . . . . 1,04

2. Anconaeus caput scapulare . . . . . 1,05

3. Tensor fasciae latae . . . . . . . 1,05

4. Rectus abdominis . . . . . . 1,07

5. Sartorius . . . . . . . . . 1,07

6. Pectoralis pars epicoracoidea . . . . . 1,07

7. Anconaeus caput mediale. . . . . . . 1,07

8. Pectineus . . . . . . . . . . 1,07

9. Gracilis. . . . . . . . . . 1, 1,07

10. Tibialis anterior longus. . . . . . . 1,08

11. Coraco-Radialis . . . . . . . . . . 1,09

12. Gastrocnemius . . . . . . . . 1,09

13. Flexor carpi radialis. . . . . . . . 1,09

14. Pectoralis pars sternalis . . . . . . 1,10

15. Deltoides . . . . . . . . . . 1,11

16. Cruralis . . . . . . . . . . 1,11

Ich möchte hjer gleich bemerken, dass die „Grösse des Kernquerschnittes" patürlich noch nicht maassgebend ist für die Grösse des ganzen Kernes, für diese ist eben auch die "Kernlänge" von wesentlicher Bedeutung. Hierüber werden die späteren Tabellen noch Auskunft geben.

Aus dem Vergleiche der Zahlen in den Tabellen IVc (S. 398) und Ve geht weiter hervor, dass die Querschnittsgrösse des Kernes mit der zunehmenden Grösse des Faserquersehnittes relativ weit stärker abnimmtals die Kernzahl. Auch diese Beobachtung stimmt durchaus überein mit den Beobachtungen, die ich bei den bisher untersuchten Muskeln gemacht habe.

Wenn mit zunehmender Fasergrösse sowohl die Kernzahl wie die Kerngrösse verhältnismässig mehr und mehr abnimmt, so folgt daraus, dass diegrösseren Fasern überhaupt verhältnismässig weniger Kernmasse besitzen als die kleineren.

Diese soeben gemachte Feststellung tritt klar hervor in den Tabellen VI a und b (S. 406-409), welche die wichtigen Zahlen für die "Relative Kernmasse" enthalten, d. h. welche mir angeben, wie gross prozentualisch die Kernmasse in den einzelnen Fasergruppen ist, und wie sie sich bei zunehmender Fasergrösse verhält. Schon aus den absoluten Zahlen der einzelnen Gruppen geht klar hervor, dass die relative Kernmasse bei den kleineren Fasern nicht un- 


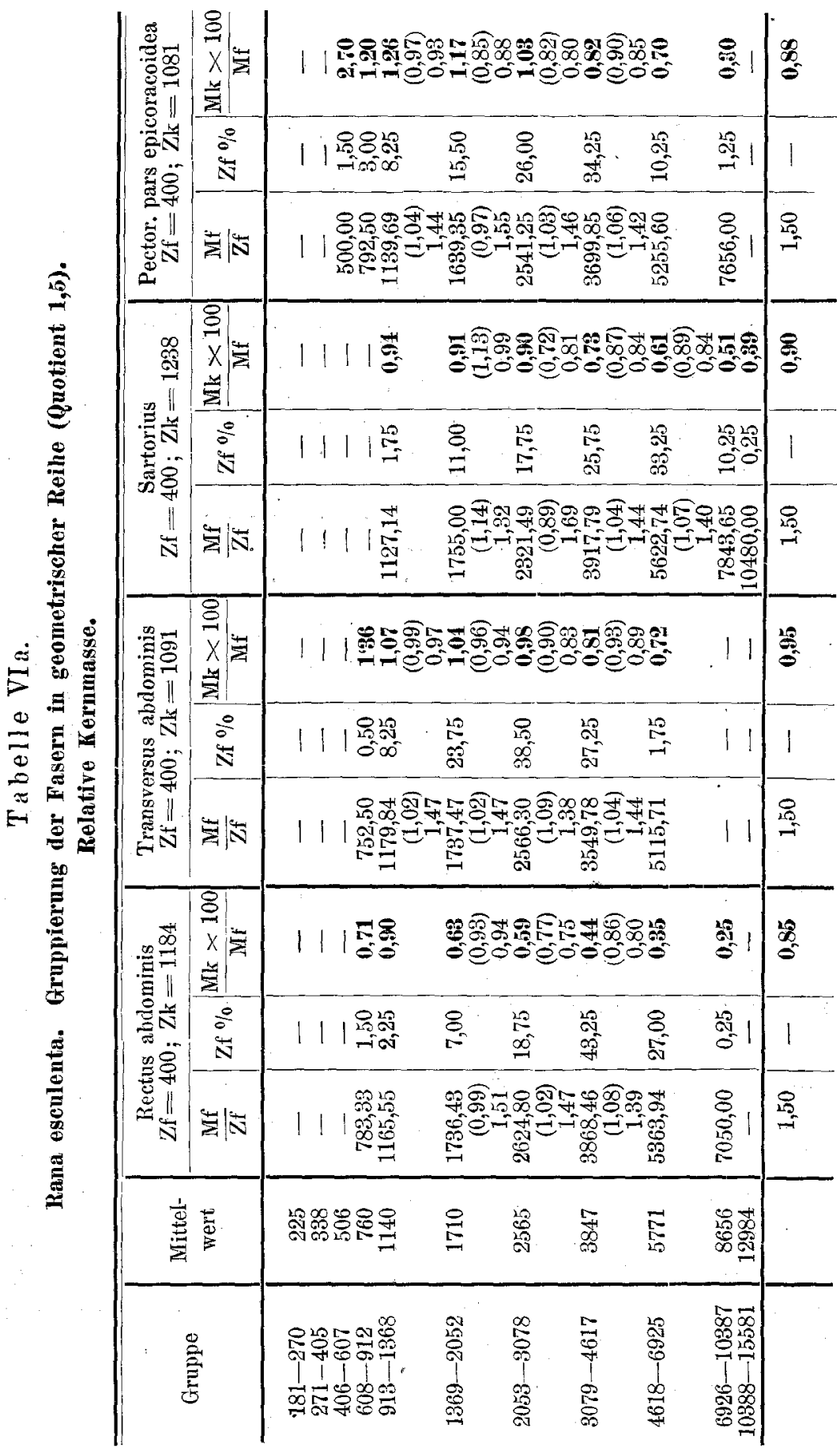


Untersuchung einer Anzahl von Muskeln von Rana esculenta etc.

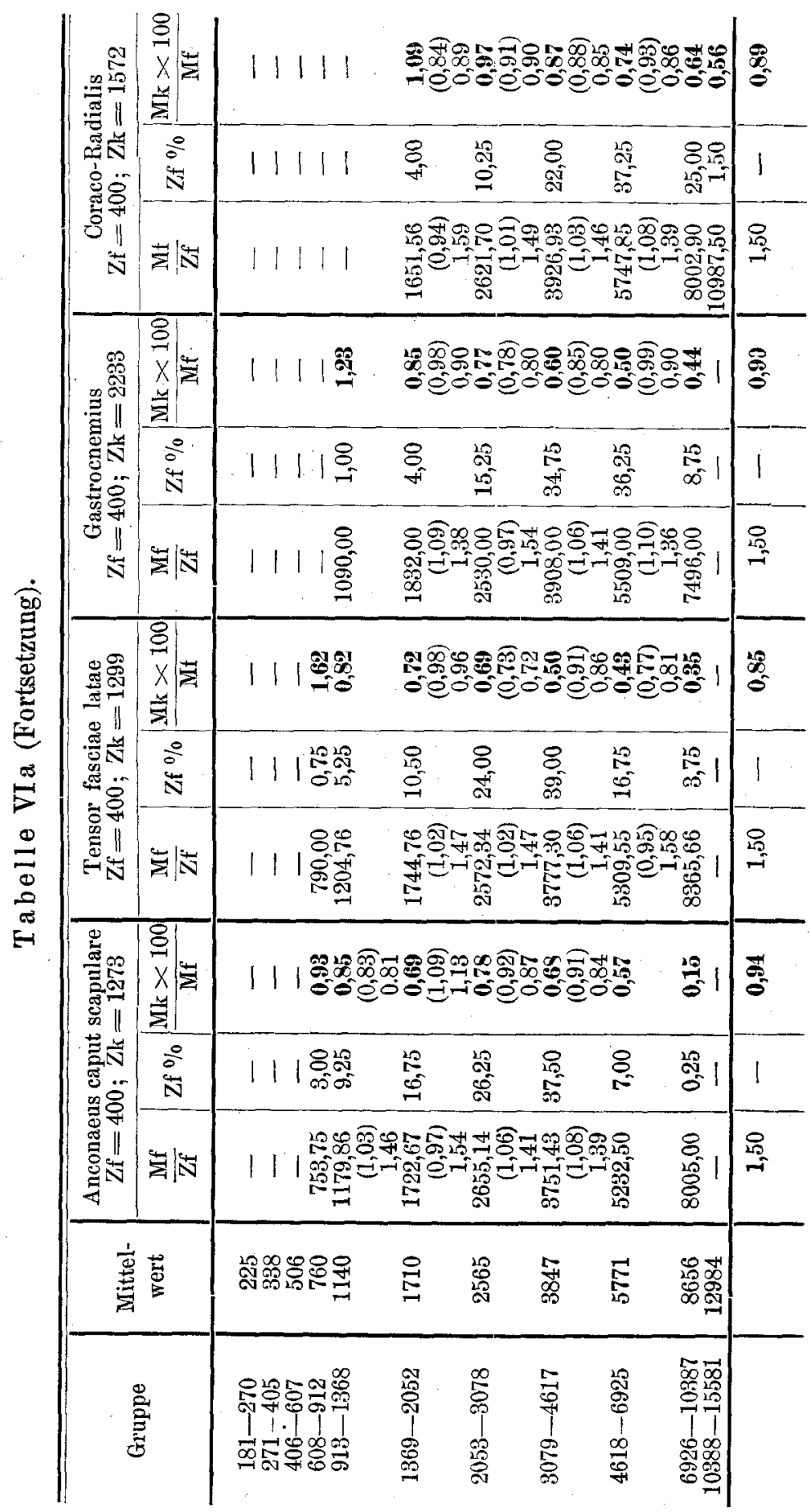




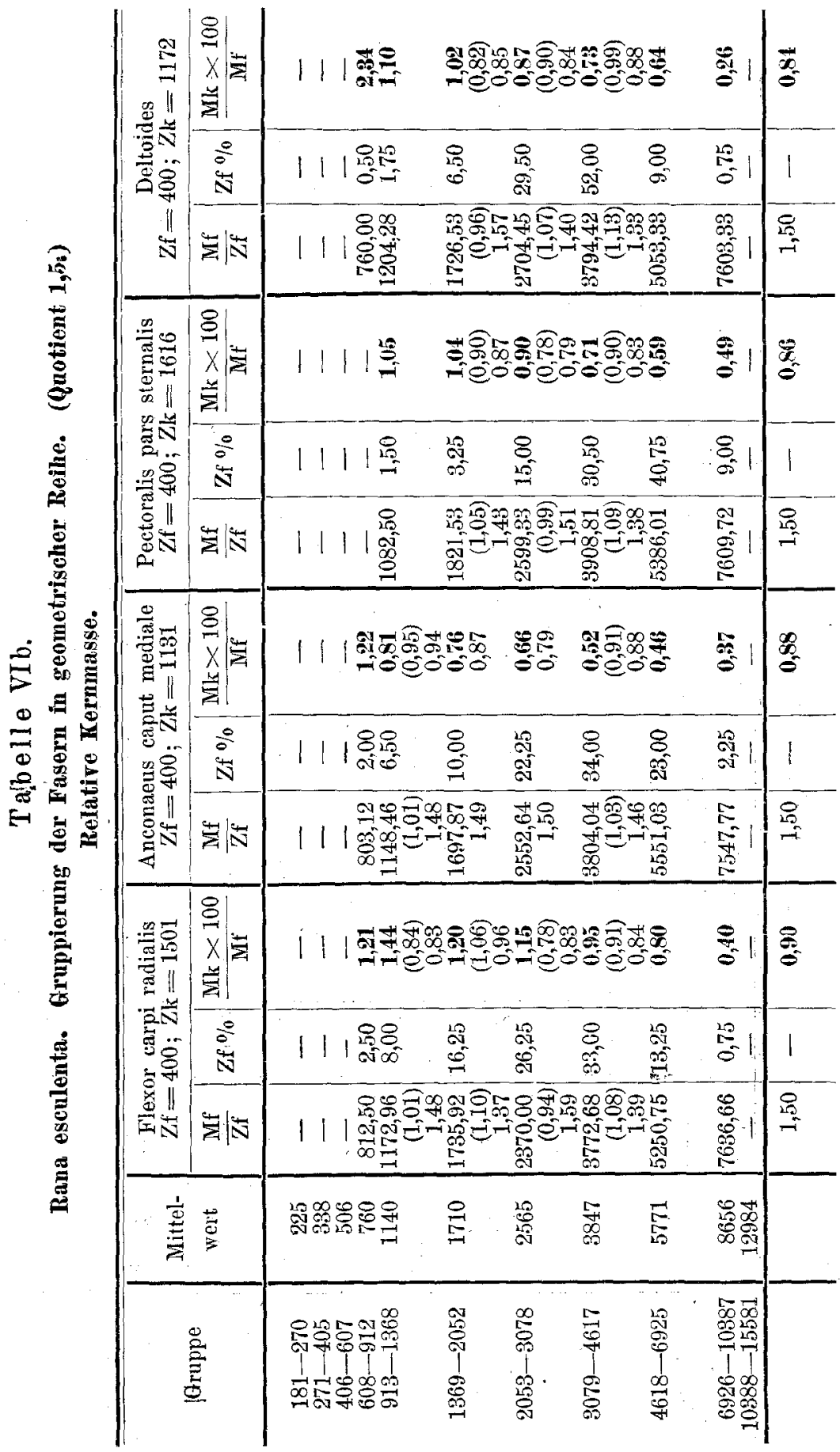


Untersuchung einer Anzahl von Muskeln von Rana esculenta etc.

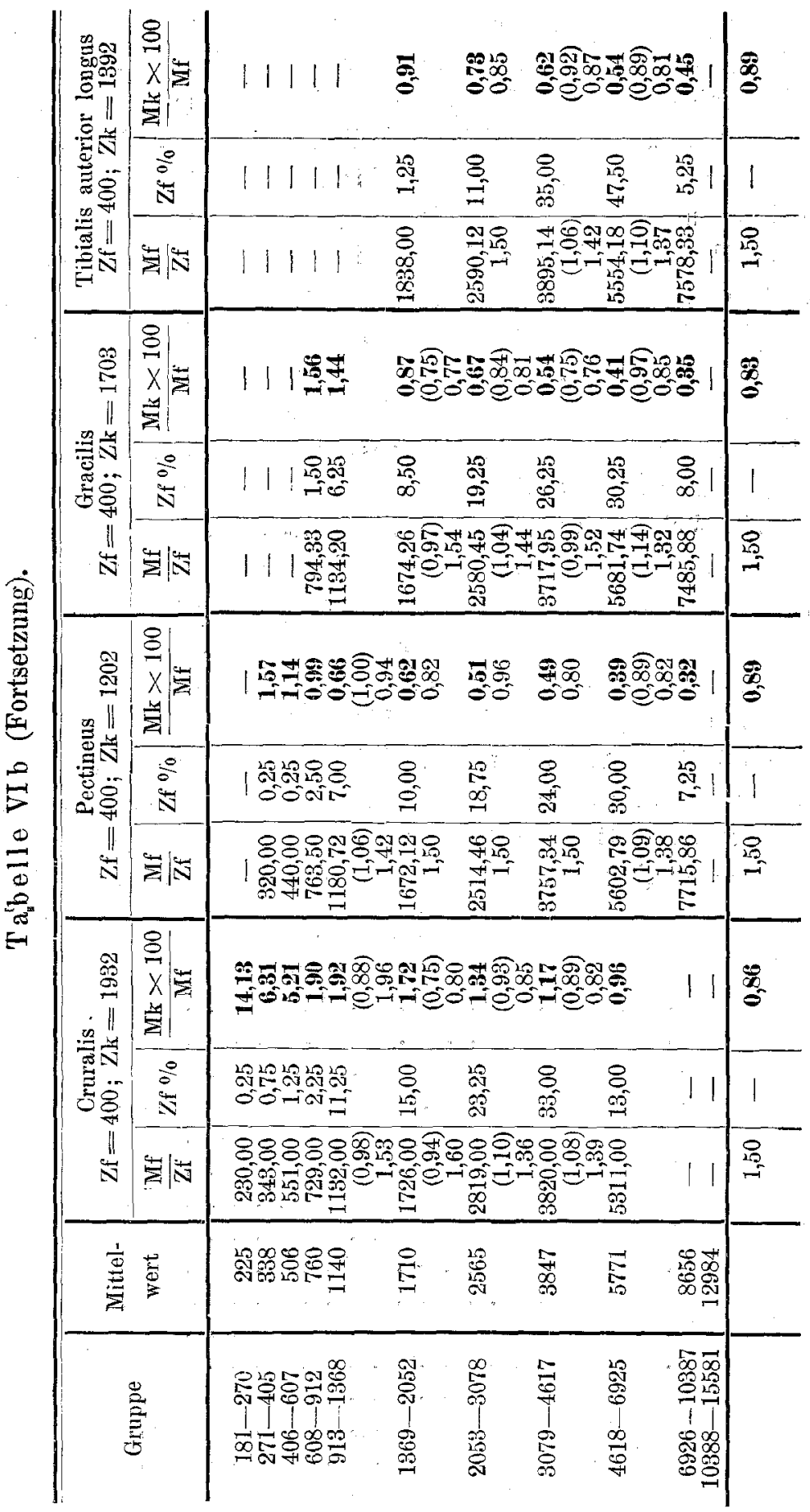


wesentlich böher ist als bei den grösseren. Ziffernmässig dargelegt wird dieses Verhalten durch die Schlussverbältniszahlen. Während in den Tabellen IV und $V$ nur die Zahlen für die Kerne an sich behandelt worden sind, sind hier die Kernzahlen im Verhältnisse zur Faserdicke behandelt, daher die Wichtigkeit dieser Zahlen, die gewissermaassen das Schlussergebnis für die Gruppen darstellen. Zwecks einer klareren Übersicht habe ich hier wieder die T abelle VIc eingeschaltet, in der wiederum die Muskeln nach der Grösse ihrer Schlussverhältniszahlen in aufsteigender Reihe angeordnet worden sind. Es geht aus dieser Tabelle hervor, dass die Unterschiede in bezug auf die relative Kernmasse bei den verschiedenen Muskeln als mässig gross zu bezeichnen sind. Dementsprechend weisen wieder mebrere Muskeln dieselben Zahlen auf, so je 2 Muskeln 0,$85 ; 0,86$ und 0,88, je 3 Muskeln 0,89 und 0,90. Die beiden Teile des Pectoralis stimmen hier fast miteinander überein $(0,86$ und 0,88$)$, die beiden Teile des Anconaeus aber zeigen ziemlich starke Verschiedenheiten $(0,88$ und 0,94$)$ und die beiden Bauchmuskeln sind voneinander fast durch die ganze Breite der Tabelle getrennt $(0,85$ und 0,95$)$. Da die Mittelzahl für die relative Kernmasse 1,00 beträgt, so liegen die Zahlen sämtlicher Muskeln unter ihr, d. h. bei sämtlichen Muskeln nimmt bei zunehmender Fasergrösse die Kernmasse ab im Verhaltnisse zur Grösse der Fasern. Die Bedeutung des Verbaltens der relativen

Tabelle VIe.

Relative Kernmasse.

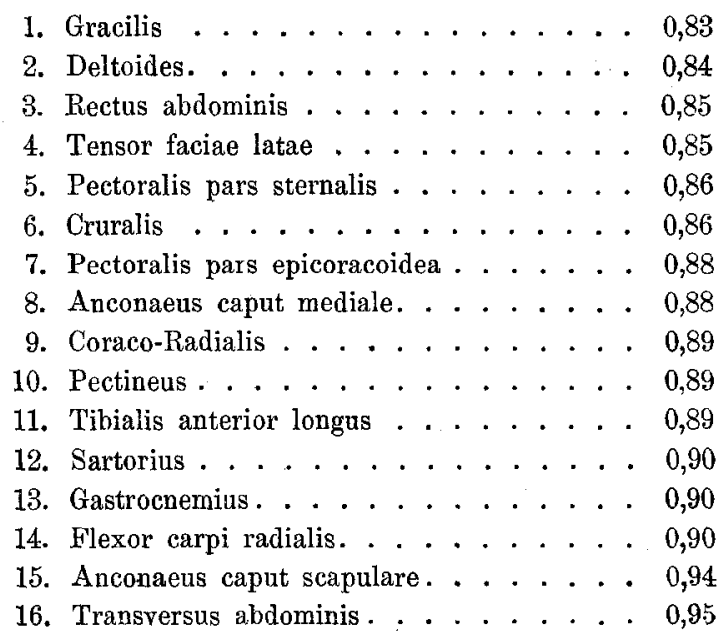


Kernmasse für die Funktion des Muskels ist bis jetzt leider noch ziemlich dunkel. Bei dem Kaninchen liess sich feststellen ${ }^{1}$ ) (S. 147 und 148), dass die roten Muskeln etwas, höhere Schlussverhältniszahlen besassen als die weissen, und dass namentlich wieder der Masseter sich durch eine ganz besonders hohe Schlussverhältniszabl auszeichnete, die mit 1,26 nicht unwesentlich über dem Mittel lag, während die anderen roten Muskeln das Mittel noch nicht ganz erreichten. Diese Beobachtung könnte dafür sprechen, dass Muskeln, welche andauernder tätig zu sein haben, höhere Schlussverhältniszahlen für die relative Kernmasse besitzen als solche, deren Tätigkeit eine mehr plötzliche und kurze ist. Auch bei der Karausche traten wieder zwei rote Muskeln mit besonders hohen Zahlen hervor: der der Bauchflosse mit 1,09 und der der Brustflosse mit 1,13. Auch hier handelte es sich wieder um andauernder tätige Muskeln. Bei dem Zwerchfelle des Menschen waren die Zahlen im allgemeinen nur mässig hoch, $0,75-0,92$, der Hund aber zeigte bei seinem Zwerchfelle 1,09, und für den Hund gerade konnte man eine recht kräftige $Z$ werchfellstätigkeit annehmen. Im ganzen aber scheint gerade nach den Befunden am Zwerchfelle die Stärke der Tätigkeit auf die Schlussverhältniszahl der relativen Kernmasse kaum von Einfluss zu sein, so dass also mehr das Andauern der Tätigkeit, auch wenn die Stärke dabei eine geringe ist, von Bedeutung zu sein scheint. Sicheres lässt sich hierüber aber vorläufig, noch nicht aussagen. Es wird Sache der physiologischen Untersuchung sein, die hier gefundenen anatomischen Tatsachen in bezug auf ihre physiologische Bedeutung zu prüfen.

Ich will hier jetzt versuchen, eine übersichtliche Zusammenstellung der Muskeln $z u$ geben auf Grund der Tabellen IVe, Ve und VIc, und zwar werde ich das in der Weise machen, dass ich die Muskeln in der Grundordnung aufführe und hinter jedem Muskel in drei aufeinanderfolgenden Zahlen den Platz des Muskels in den drei Tabellen angebe:

$\begin{array}{lllrrr}\text { Rectus abdominis . . . . . . . . . . } & 3 & 4 & 3 \\ \text { Transversus abdominis . . . . . . . . . } & 16 & 1 & 16 \\ \text { Sartorius . . . . . . . . . . . . . } & 12 & 5 & 12 \\ \text { Pectoralis pars epicoracoidea. . . . . } & 9 & 6 & 7 \\ \text { Anconaeus caput scapulare . . . . . } & 15 & 2 & 15\end{array}$

1) P. Schiefferdecker, Muskeln und Muskelkerne. 317 Seiten mit 20 Abbildungen im Text. Joh. A mbros. Barth, Leipzig 1909. 


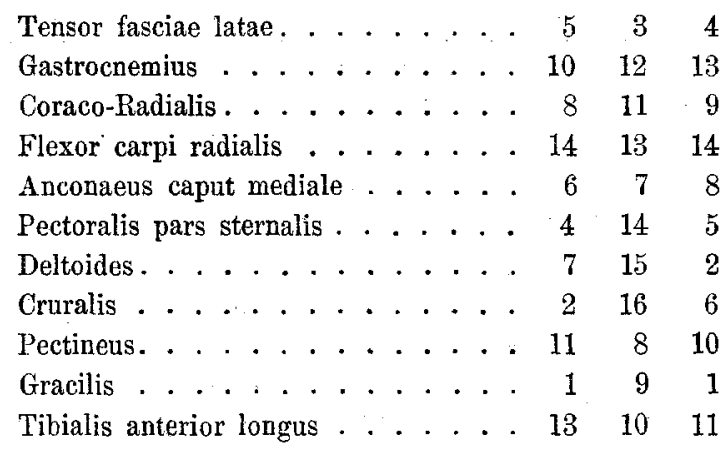

Diese Zusammenstellung ist nicht uninteressant, denn sie lässt deutlich erkennen, dass bei den einzelnen Muskeln bestimmte Beziehungen existieren zwischen der Höhe der Schlussverhältniszahlen bei der „absoluten Kernzahl“, der "absoluten Kerngrösse “ und der „relativen Kernmasse"; jedoch geht ebenfalls deutlich daraus hervor, dass diese Beziehungen bei den einzelnen Muskeln versehieden sind. Manche Muskeln stehen in allen drei Tabellen an niedriger Stelle, andere an hoher oder mittlerer, andere wieder stehen in zwei Tabellen an hoher, in einer an niedriger Stelle oder umgekehrt, und bei einigen Muskeln ist die Stelle in wenigstens zwei Tabellen die gleiche. Die hier gegebene Zahlenzusammenstellung für jeden Muskel ist sicher als eine Formel anzusehen, die den feineren Aufbau des Muskels ziemlich klar erkennen lässt; nur ist vorläufig die physiologische Deutung derZahlen noch nicht zu geben. Hierzu bedarfeseingehender physiologischer Untersuchungen. Ich möchte bier darauf aufmerksam machen, dass aus meiner Zwerchfellarbeit hervorging, dass die Schlussverhältniszahlen gerade für die "Qualität" der Tätigkeit eines Muskels von wesentlicher Bedeutung sind. So würde man aus der hier gegebenen Zahlenzusammenstellung voraussichtlich also auch gerade wieder auf die "Qualität" der Muskeltätigkeit Schlüsse ziehen können. Die beiden $\mathrm{Bauchmuskeln}$ zeigen hier wieder sehr grosse Unterschiede: Réctus abdominis $3,4,3$, Transversus abdominis $16,1,16$; die heiden Teile des Pectoralis sind ebenfalls recht verschieden: Pars epicoracoidea 9, 6, 7, Pars sternalis 4, 14, 5. Die beiden Teile des Ancona eus sind sehr wesentlich verschieden: Caput scapulare 15, 2, 15, Caput mediale $6,7,8$.

Bei der Betrachtung über die Ergebnisse der Beschreibung des 
mikroskopischen Bildes habe ich oben hervorgehoben, dass dieses bei den versehiedenen Muskeln so sehr übereinstimmte, dass man auf eine verhältnismässig sehr geringe Differenzierung dieser verschiedenen Muskeln, in dieser Hinsicht wenigstens, schliessen konnte. Ich betonte damals aber auch schon, dass man erst die Ergebnisse der Ausmessungen abwarten müsse, um über die Differenzierung der Muskeln sicherer urteilen zu können. Aus dem bisher Besprochenen ergibt sich nun schon, dass der feinere Aufbau der Muskeln in bezug auf das Verhältnis der Kernmasse zur Fasermasse eine sehr deutliche Differenzierung erkennen lässt. Die Ausmessungsmethode hat uns hier Unterschiedekennen gelehrt, welche mit den sonstigen histologischen Untersuchungsmethoden unmöglich zu erkennen gewesen wären. Ich habe auf diesen Vorteil der Ausmessungsmethode auch schon in meiner ersten Muskelarbeit aufmerksam gemacht.

Ich will jetzt übergehen zu denjenigen Tabellen, welche mir die absoluten Zahlen für den ganzen Muskel an: geben, die also nicht mehr speziell für den inneren Aufbau wesentlich sind, sondern hauptsächlich für den Vergleich der einzelnen ganzen Muskeln miteinander.

In Tabelle VII (S. 414) sind die Durchschnittszahlen für die gesamten Muskeln zusammengestellt. Die "absolute Kernzahl“" ist verhältnismässig hoch, da es sich um verhältnismässig dicke Fasern handelt, die also auch verbältnismässig viele Kerne enthalten müssen. Da die Grösse der Fasern bei diesen Zahlen nicht berücksichtigt worden ist, so lehren dieselben zunächst nicht viel. Das Verhältnis der Kernzahl zur Fasergrösse tritt am klarsten hervor bei den "Kernfaserzahlen" in Tabelle VIII und IX (S. 415). In der ersteren sind die Muskeln wieder geordnet nach der Länge der Kerne, in der ursprünglichen Grundanordnung: in der zweiten nach der Grösse ihrer Kernfaserzahl. Man sieht leicht, dass ziemlich grosse Unterschiede in bezug auf die Kernmenge vorkommen: Während der Cruralis schon auf 615 q $\mu$ des Faserquerschnittes einen Kern besitzt; kommen bei dem Sartorius und dem Coraco-Radialis $1400 \mathrm{q} \mu$ auf einen Kern. Das Gebiet, das der Kern in den Fasern derverschiedenen Muskeln zubeherrschen hat, ist also recht verschieden gross. Vergleicht man die hier gefundenen Zahlen mit denen der bisher, untersuchten Muskeln, so ergibt sich zunächst im allgemeinen, dass die Froschmuskeln ver- 


\begin{tabular}{|c|c|c|c|}
\hline 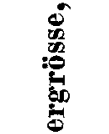 & \multicolumn{2}{|c|}{ 密焉总 } & 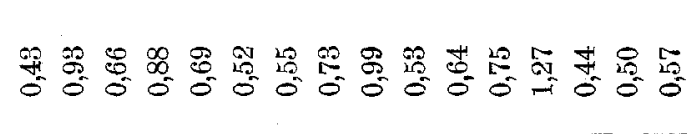 \\
\hline$\stackrel{N}{\Xi}$ & \multicolumn{2}{|c|}{ 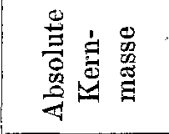 } & 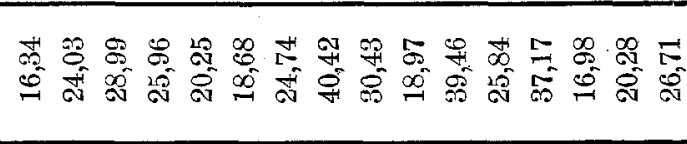 \\
\hline 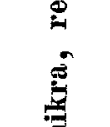 & \multicolumn{2}{|c|}{ 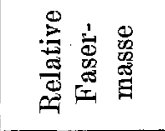 } & 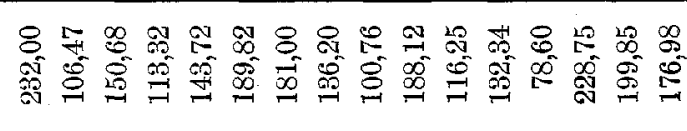 \\
\hline 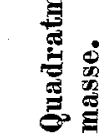 & \multicolumn{2}{|c|}{ 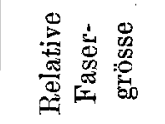 } & 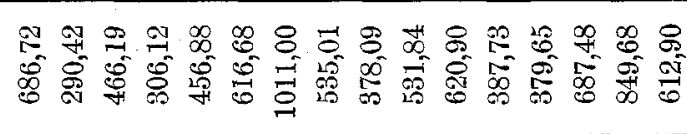 \\
\hline 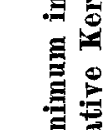 & \multirow{3}{*}{ 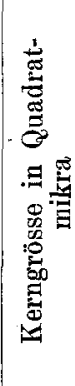 } & 富泀 & 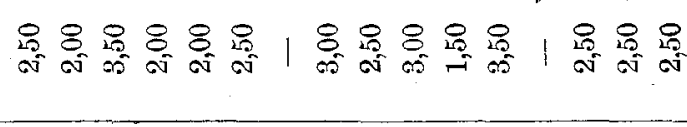 \\
\hline 8 & & 离焉 & 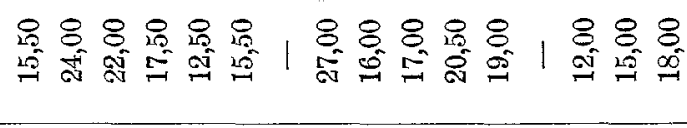 \\
\hline . & & 步:总 & 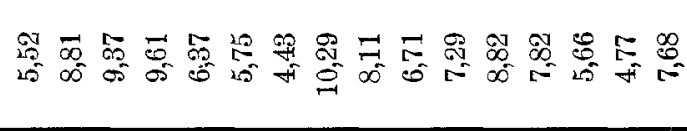 \\
\hline 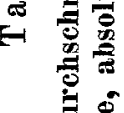 & \multirow{3}{*}{ 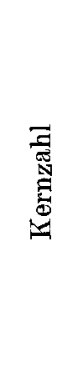 } & 湜要 & -||||$-|-|-1-$ \\
\hline$\stackrel{0}{0}$ & & 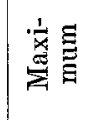 & 010 \\
\hline 焉递 & & 总惫 & 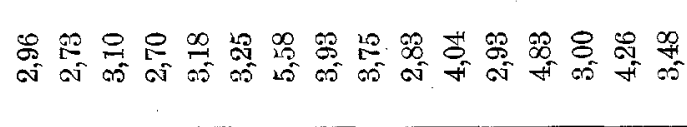 \\
\hline 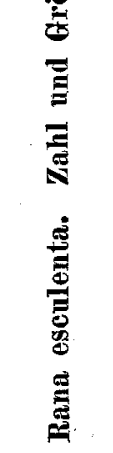 & \multicolumn{2}{|c|}{ 䒘 } & 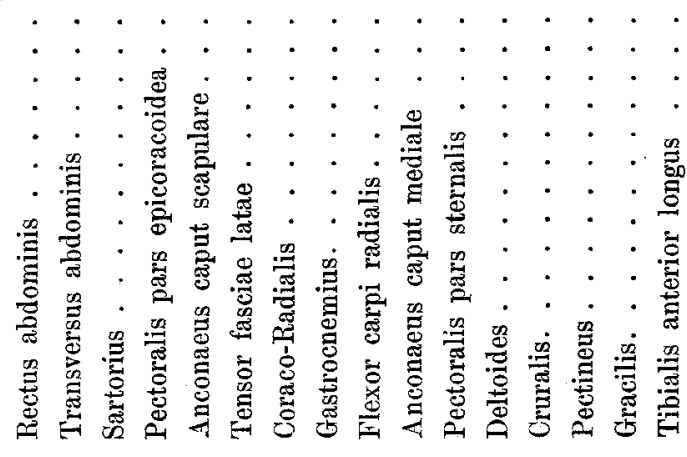 \\
\hline
\end{tabular}


Tabelle VIII.

Rana esculenta. Kernfaserzahlen.

\begin{tabular}{|c|c|}
\hline Name des Muskels & Kernfaserzahlen \\
\hline 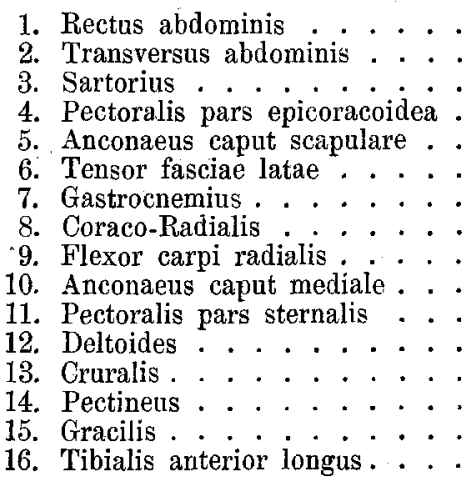 & $\begin{array}{l}1: 1280 \\
1: 937 \\
1: 1400 \\
1: 1090 \\
1: 915 \\
1: 1090 \\
1: 803 \\
1: 1400 \\
1: 818 \\
1: 1261 \\
1: 1130 \\
1: 1170 \\
1: 615 \\
1: 1295 \\
1: 951 \\
1: 1350\end{array}$ \\
\hline
\end{tabular}

Tabelle IX.

Rana esculenta. Die Muskelin geordnet nach der Grösse der KernfaserzahIen.

\begin{tabular}{|c|c|}
\hline Name des Muskels & Kernfaserzahl \\
\hline 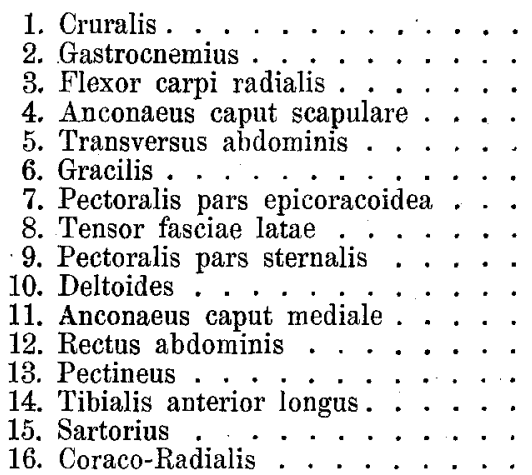 & $\begin{array}{l}1: 615 \\
1: 803 \\
1: 818 \\
1: 915 \\
1: 937 \\
1: 951 \\
1: 1090 \\
1: 1090 \\
1: 1130 \\
1: 1170 \\
1: 1261 \\
1: 1280 \\
1: 1295 \\
1: 1350 \\
1: 1400 \\
1: 1400\end{array}$ \\
\hline
\end{tabular}

hältnismässig arm an Kernen sind. Bei den Kaninchenmuskeln lagen die Zahlen bei den roten Muskeln zwischen 1:317 und 1:379, bei den weissen Muskeln zwischen 1:406 und 1:617 ${ }^{1}$ ) (S. 282 und 283, Tab. LX). Die weissen Muskeln waren also ärmer an Kernen als die roten. Umgekehrt war das Verhältnis bei den Karauschen-

1) P. Schiefferdecker, Muskeln und Muskelkerne. 317 Seiten mit 20 Abbildungen im Text. Joh. A mbros. Barth, Leipzig 1909. 
muskeln: bei den weissen waren die Zahlen hier $1: 284$ und $1: 387$, bei den roten $1: 310,1: 509,1: 570$ und $1: 1060^{1}$ ) (S. 282 und 283 , Tab. LX). Der Deltoides der beiden untersuchten Männer ergab die Zahlen 1:726 und 1:790, und der Rectus oculi superior des Menschen zeigte Zahlen, die zwischen 1:214 und 1:344 lagen. Bei dem $\mathrm{Z}$ werchfelle endlich lagen die Zahlen bei den menschlichen Muskeln zwischen 1:461 und 1:857, wobei die erste Zahl einem weiblichen Muskel angehörte und die letzte einem sehr kräftigen Kroaten ${ }^{2}$ ) (S. 390, Tab. VII); doch ergab sich, dass sonst zwischen den männlichen und weiblichen Zwerchfellmuskeln der Deutschen ein Unterschied in bezug auf die Kernfaserzahl nicht aufzufinden war. Die Kernfaserzahl des Zwerchfelles eines $\mathrm{Hundes}$ stimmte mit den menschlichen gut überein. Aus allen diesen Zahlen gebtjedenfalls hervor, dass die Froschmuskeln verhältnismässig arm an Kernen sind. Die physiologische Bedeutung der Kerufaserzahlen ist ja bis jetzt noch dunkel. Das einzige, was man mit einiger Wahrscheinlichkeit annehmen kann, ist das, dass bei einer grösseren Anzahl von Kernen der Stoffwechsel ein regerer sein wird als bei einer geringeren. Das würde ja nun wohl für den Froschmuskel als solchen schon stimmen können. Die Unterschiede zwischen den einzelnen Muskeln desselben Tieres würden sich dadurch aber doch wohl noch nicht erklären lassen, wenigstens kann ich mir noch nicht recht denken, in weleher Weise die Funktion sich durch eine solche Verschiedenheit ändern würde. Man könnte ja wohl annehmen, dass ein Muskel mit wenig Kernen leichter ermüdet und sich wieder langsamer erholt; aber andererseits habe ich in meiner zweiten Muskelarbeit gerade nachweisen können, dass bei der Aktivitätshypertrophie des Sartorius des Hundes infolge eines auf Ausdauer gerichteten Trainings die Anzahl der Kerne in dem trainierten Muskel ausserordentlich stark abgenommen hatte; sie betrug nur etwa den dritten Teil der normalen Zahl, während dabei die Grösse des gesamten Kernes von $67 \mathrm{k \mu}$ auf $83 \mathrm{k} \mu$ gestiegen war. Der trainierte Muskel besass also grössere, aber weit seltenere Kerne als der nichttrainierte. Ich habe damals auch daraus den Schluss gezogen, dass die Grösse des Stoffwechsels

1) P. Schiefferdecker, Muskeln und Muskelkerne. 317 Seiten mit 20 Abbildungen im Text. Joh. A mbros. Barth, Leipzig 1909.

2) P. Schiefferdecker, Untersuchung des Zwerchfelles auf seinen Bau und seine Kernverhältnisse. Pflüger's Arch. Bd. 139' S. 337. 
bei dem trainierten Muskel verringert worlen war; denn wir wissen ja aus Erfahrung, dass trainierte Muskeln sparsamer arbeiten als nicht trainierte. Wie weit man hieraus aber Schlüsse auf die Tätigkeit der Froschmuskeln zu ziehen berechtigt ist, diese Frage will ich vorläufig offen lassen.

Was die „absolute Kerngrösse" anlangt, d. h. die Querschnittsgrösse des Kernes, so ist diese nach den einzelnen Muskeln ziemlich starken Schwankungen unterworfen (Tabelle VII). Die Zahlen liegen zwischen $4,43 q \mu$ und 10,29 q $\mu$. Die Muskeln haben also sehr verschieden dicke Kerne. Das lässt sich auch bei den mikroskopischen Beobachtungen sofort feststellen, dass wir hier beim Frosche Muskeln haben mit schmalen und langen Kernen und andere mit dicken und kurzen. Die Bilder sind sehr auffallend. In Tabelle $\mathrm{X}$ habe ich die Muskeln geordnet nach der Grösse des Verhältnisses des Durchmessers des Kernes zur Länge des Kernes (DK:LK). Diese Zahlen sind geeignet, das Verhältnis der Dicke zur Länge bei den Kernen der einzelnen Muskeln ziffernmässig auszudrücken. Da die Kerne bei den Froschmuskeln fast alle binnenständig waren und infolgedessen auch fast immer im Querschnitte kreisrund erschienen, so konnte man ohne wesentliche Fehler aus der Querschnittsgrösse des Kernes den Durchmesser desselben berechnen. Wenn man die Zahl für den Durchmesser in die Zahl für die Kernlänge dividierte, so erhielt man die hier angegebenen Zahlenverbältnisse. Die Tabelle beginnt wieder mit den

Tabelle X.

Rana esculenta. Muskeln, geordnet nach dem Verhältnisse von DK : LK.

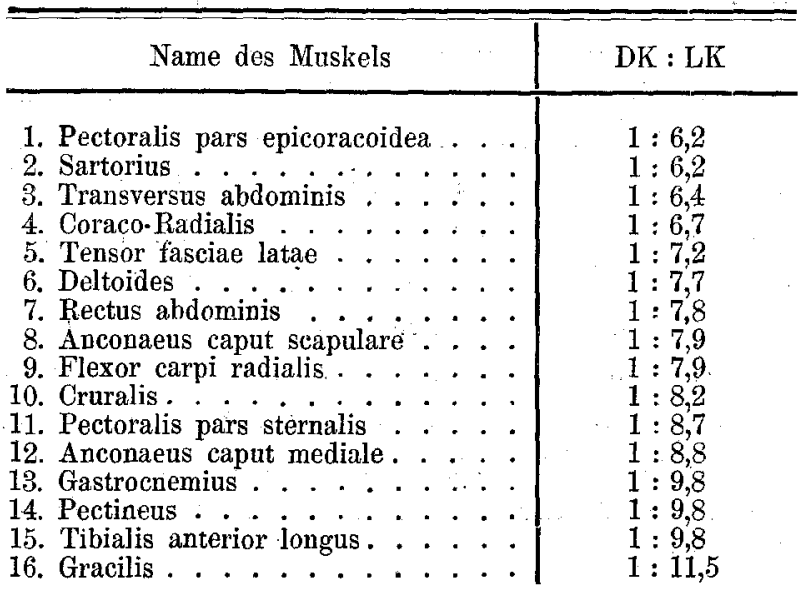


dicksten und kürzesten Kernen und steigt auf zu den dünnsten und längsten. Die kürzesten und dicksten Kerne besitzt der Pectoralis pars epicoracoidea $(1: 6,2)$, die längsten und dünnsten der Gracilis $(1: 11,5)$. Die beiden Portionen des Pectoralis liegen hier wieder ziemlich weit auseinander $(1: 6,2$ und $1: 8,7)$, ebenso die des Anconaeus $(1: 7,9$ und $1: 8,8)$. Auch die beiden Bauchmuskeln sind wieder deutlich verschieden voneinander: Transversus abdominis $1: 6,4$ und Rectus abdominis 1:7,8. Dem Gracilis mit seinen dünnen und schlanken Kernen nahe stehen der Gastrocnemius, der Pectineus, der Tibialis anterior longus; dem Pectoralis pars epicoracoidea mit seinen kurzen und dicken Kernen stehen nahe der Sartorius, der Coraco-Radialis, der Transversus abdominis, die anderen liegen in der Mitte. Dass diese Eigentümlichkeiten der Kernform von Bedeutung sind, ist ja zweifellos, es fragt sich nu r, von welcher. Bei den bisher von mir untersuchten Muskeln sind mir derartige, so bestimmt auftretende, verschiedene Kernformen nur, wie ich vorgreifend bemerken will, bei Petromyzon fluviatilis vorgekommen; hier betrug für die zentralen Muskelfasern das Verhältnis 1:9,37, für die parietalen Muskelfasern 1:2,50. Der Unterschied war also ein sehr grosser. Wie aus diesen Zahlen hervorgeht, waren die kurzen Kerne beim Neunauge noch weit kürzer und dicker als beim Frosche, während die langen etwa den langen Froschmuskelkernen entsprachen. Ich werde in einer späteren Arbeit die Muskulatur des Neunauges eingehend behandeln. Was die Bedeutung der verschiedenen Kernformen anlangt, so ist es zunächst klar, dass je länger ein Kern im Verbältnisse zu seiner Dicke ist, er eine um so grössere Oberfläche im Verhältnisse zu seinem Inhalte besitzt. Die geringste Oberfläche im Verhältnisse zu ihrem Inhalte besitzt bekanntlich die Kugel. Je weiter sich also die Form eines Gegenstandes von der der Kugel entfernt, um so grösser wird die Oberfläche im Verhältnisse zum Inhalte. Je grösser aber die Oberfläche im Verhältnisse zum Inhalte ist, desto leichter wird ein cheimischer Austausch zwischen dem Kerne und der Zelle möglich sein. Wie ich schon in meiner zweiten Muskelarbeit ausgeführt habe, muss man aber doch wohl annehmen, dass die Beziehungen zwischen Kern und Zelle in einem chemischen Austausche besteben. Ich werde auf diese Betrachtungen noch weiter unten zurückzukommen haben, wenn ich das Kernvolumen bespreche. 
Untersuchung einer Anzahl von Muskeln von Rana esculenta etc. 419

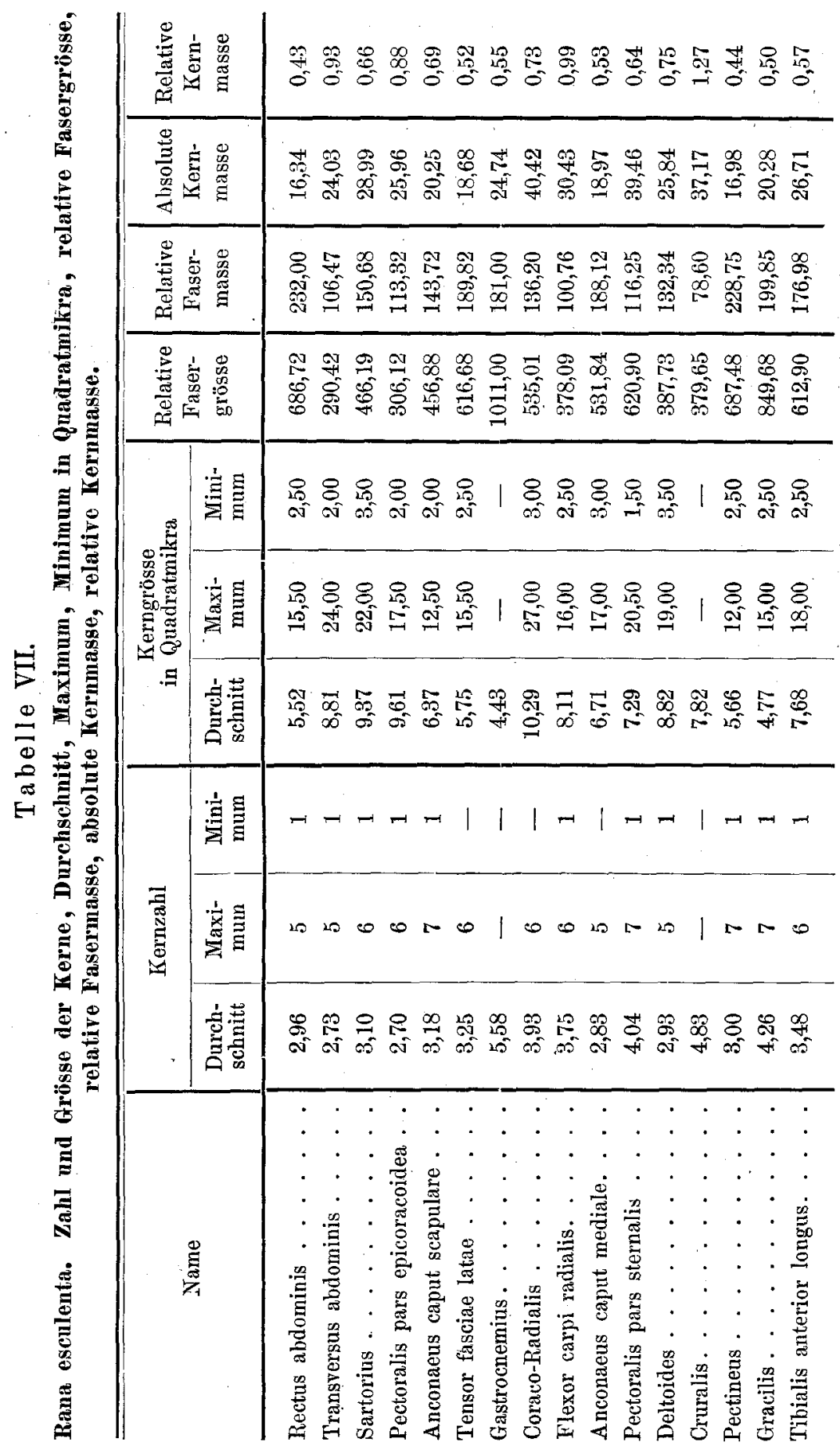


Die nächstfolgenden drei Kolumnen der Tabelle VII: die "relative Fasergrösse", die "relative Fasermasse". die „absolute Kernmasse" will ich überspringen, da sie nicht von grundlegender Bedeutung sind, und will gleich übergehen zu der letzten Kolumne, der für die "relative Kernmasse“, die ja sehr wichtige Zahlen enthält. Man sieht leicht, dass die Zahlen hier sellr wesentliche Verschiedenheiten aufweisen. Um diese klar hervortreten zu lassen, habe ich in Tabelle XI die Muskeln nach der Grösse ihrer "relativen Kernmasse" geordnet. Die Zahlen steigen an von 0,43 bis 1,27 , das ist für die relative Kernmasse ein ganz gewaltiger Unterschied verhalten sich die Zahlen doch ziemlich genau wie 1:3. Der Cruralis würde danach mit der dreifachen Kernmasse arbeiten wie der Rectus abdominis. Die anderen Muskeln liegen dazwisehen. Man erkennt leicht, dass bei einer Anzahl von Muskeln die Zahlen einander sehr ähnlich sind: Bei dem Rectus abdominis und dem Pectineus ist die relative Kernmasse so gut wie gleich. Auch bei der folgenden Gruppe, die aus 5 Muskeln besteht, bleiben die Zahlen für die relative Kernmasse innerhalb der 50 er. Die folgenden drei Muskeln: der Pectoralis pars sternalis, der Sartorius und der Anconaeus caput scapulare haben eng zusammenliegende Zahlen; desgleichen wieder: der Coraco-Radialis und der Deltoides; weiterhin liegen die Zahlen dann mehr vereinzelt. Die beiden Teile des Pectoralis sind wieder

Tabelle XI.

Rana esculenta. Reihenfolge der Muskeln nach der Grösse der relativen Kernmasse.

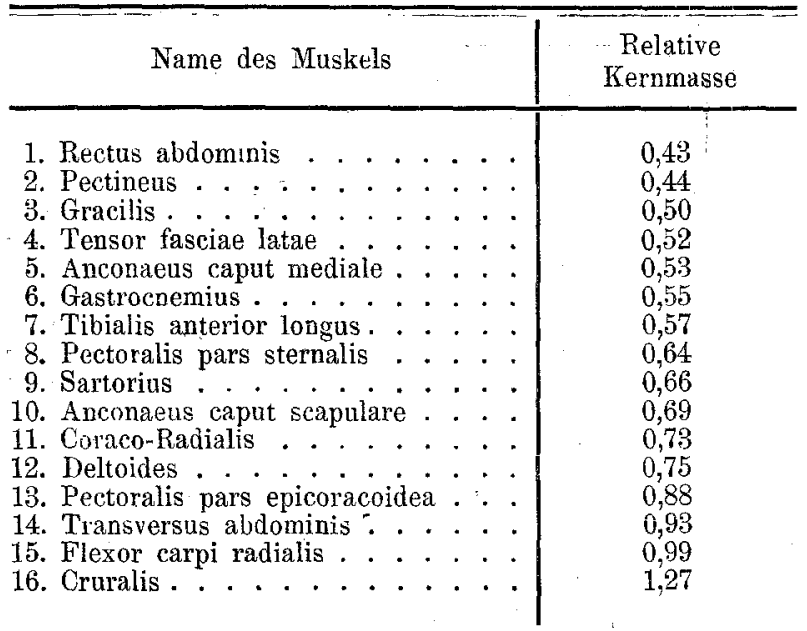


weit voneinander getrennt $(0,64$ und 0,88$)$, ebenso die des Anconaeus $(0,53$ und 0,69$)$. Sehr weit auseinander liegen die beiden Bauchmuskeln: Rectus abdominis 0,43 , Transversus abdominis 0,93 . Von den menschlichen Muskeln, die ich bisher untersucht habe, hatte die höchste relative Kerumasse der Rectus oculisuperior, hier lagen die Zahlen bei den einzelnen Menschen zwischen 2,34 und 4,17 ${ }^{\wedge}$ (S. 50, Tab. VIII). Bei dem Del to ides war die relative Kernmasse bei den beiden untersuchten Männern 0,99 und 1,045 . Bei dem Pectoralis des letzteren Mannes betrug sie 1,02, bei dem Biceps 1,01 , bei dem Serratus anterior 1,39. Die Zahlen für die drei ersten Muskeln stimmten also genau überein, die Zahl des letzteren war höher ${ }^{1}$ )(\$.91, Tab.XVII). Bei dem Levator palpebrae superioris betrugen die Zahlen bei den beiden Erwachsenen 0,70 und $0,78^{1}$ ) (S. 214, Tab. XLIX); die Zahlen für die relative Kernmasse schwankten also bei den menschlichen Muskeln zwischen 0,70 und 4,17, also auch sehr bedeutend. Bei den weissen Kaninchenmuskeln ${ }^{1}$ ) (S. 150; Tab. XXVI) lagen die Zahlen zwischen 0,78 und 0,91 (bei dem Formoltiere), bei den roten Muskeln zwischen 1,94 und 2,83 (bei dem Formoltiere). Die roten Muskeln hatten also bedeutend höhere Zahlen als die weissen, d. h. sie arbeiteten mit mehr Kernmasse. Bei den Karauschenmuskeln waren die Zahlen für die relative Kernmasse bei den weissen Muskeln 0,68 und 0,94, bei den roten Muskeln lagen sie zwischen 0,41 und 1,04. Der bei den Kaninchenmuskeln so stark hervortretende Unterschied in der Höhe der relativen Kernmasse zwischen den weissen und den roten Muskeln war hier also nicht vorbanden; dagegen traten hier grosse Verschiedenheiten zwischien je den einzelnen roten und weissen Muskeln hervor; Unterschiede, die freilich noch nicht zu deuten waren. Bei dem Sartorius des Hundes ${ }^{1}$ ) (S. 236, Tab. LVII) war die relative Kernmasse sehr niedrig: 0,58 für den normalen Muskel und 0,24 für den in Aktivitätshype trophie befindlichen. Ich habe schon oben bei der Besprechung der Kernzahl hervorgehoben, dass bei dem trainierten Sartorius die Anzahl der Kerne sich etwa auf den dritten Teil verringert hatte, während das Kernvolumen im Verhältnisse von 1:1,23 zugenommen batte. Daher dann die niedrige Zahl für die relative Kernmasse,

1) P. Schiefferdecker, Muskeln und Muskelkerne. 317 Seiten mit 20 Abbildungen im Text. Joh. A mbros. Barth, Leipzig 1909. 
bei der noch in Rechnung zu ziehen ist, dass die Muskelfasern hypertrophiert waren. Beim Z werch felle $\mathrm{e}^{1}$ ) (S. 390, Tab. VI) betrug die relative Kernmasse bei den meisten Erwachsenen zwischen 0,97 und 1,05, entsprach also ungefähr der der Skelettmuskeln des Menschen; nur bei den beiden kräftigen Männern stieg sie auf 1,34 und 1,29, und bei dem Hunde betrug sie 1,37. Aus den mitgeteilten Zahlengeht hervor, dass die Zahlen für die relative Kernmasse des Frosches verhältnismässig niedrig sind. Sie erinnern noch am meisten an die der Karausehe. Beim Neunauge fand ich bei den beiden Faserarten der Rumpfmuskulatur, wie ich hier, einer späteren Arbeit vorgreifend, mitteilen will, für die zentralen Muskelfasern die Zahl 1,02 und für die parietalen Muskelfasern die Zahl 1,52. Beide Zahlen erinnerten also durchaus an die der höheren Tiere und des Menschen und waren hoch im Verhältnisse zu den Zahlen des Frosches. Es geht also nicht an, zu sagen, dass niedrige Zahlen für die relative Kernmasse charakteristisch seien für niedriger stehende Tiere, sondern es sind diese Zahlen augenscheinlich ganz verschieden je nach der Art des Muskels. Mit den geringen Zahlen für die relative Kernmasse beim Frosche stimmte es ja einigermaassen überein, dass auch aus den Kernfaserzahlen hervorging, dass bei diesem Tiere die Anzahl der Kerne im Verhältnisse zur Dicke der Fasern eine verhältnismässig geringe war. Doch kommt ja für die relative Kernmasse ausser der Zahl der Kerne auch noch das Volumen derselben wesentlich in Betracht.

In Tabelle XII (S. 423) habe ich die Zahlen für die „Kernlänge" und für das „Kernvolumen“ zusammengestellt, und zwar sind in dieser Tabelle die Muskeln wieder geordnet nach der durehschnittlichen Kernlänge. Ich habe in meinen früheren Arbeiten immer wieder hervorheben können, dass die "Kernlänge" ein sehr wichtiges Maass darstellt, das als ganz spezifisch für die einzelnen Muskeln anzusehen ist, so spezifisch, dass es schon bei den Embryonen des vierten und fünften Monates in der späteren richtigen Grösse hervortritt, und bei den Erwachsenen nur ganz geringe individuelle Unterschiede erkennen lässt. Wie aus Tabelle XII hervorgeht, beträgt die niedrigste Zahl, bej dem Rectus abdominis, $20,64 \mu$, die höchste Zahl, bei dem

1) P. Schiefferdecker, Untersuchung des $Z_{w}$ erchfelles auf seinen Ban und seine Kernverhältnisse. Pflüger's A rch. Bd. 139 S. 337. 
Tabelle XII.

Rana esculenta. Kernlänge, Maximum, Minimum, Kernvolumen, DK : LK.

\begin{tabular}{|c|c|c|c|c|c|}
\hline \multirow[b]{2}{*}{ Name des Muskels } & \multicolumn{3}{|c|}{ Kernlänge } & \multirow{2}{*}{$\begin{array}{c}\text { Kern- } \\
\text { volumen } \\
k \mu\end{array}$} & \multirow[b]{2}{*}{$\mathrm{DK}: \mathrm{LK}$} \\
\hline & $\begin{array}{l}\text { Durch- } \\
\text { schnitt } \\
\mu\end{array}$ & $\begin{array}{c}\text { Maxi- } \\
\operatorname{mum} \\
\mu\end{array}$ & $\begin{array}{c}\text { Mini- } \\
\mu\end{array}$ & & \\
\hline 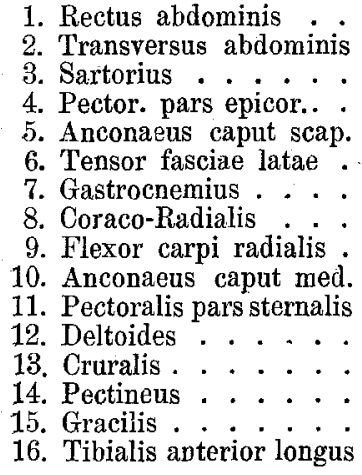 & $\begin{array}{l}20,64 \\
21,46 \\
21,56 \\
21,60 \\
22,44 \\
23,12 \\
23,44 \\
24,28 \\
25,44 \\
25,60 \\
26,00 \\
26,12 \\
26,32 \\
26,52 \\
28,68 \\
30,48\end{array}$ & $\begin{array}{l}30,00 \\
28,00 \\
28,00 \\
28,00 \\
30,00 \\
28,00 \\
32,00 \\
32,00 \\
38,00 \\
32,00 \\
36,00 \\
38,00 \\
36,00 \\
36,00 \\
38,00 \\
46,00\end{array}$ & $\begin{array}{l}14,00 \\
14,00 \\
16,00 \\
14,00 \\
16,00 \\
16,00 \\
18,00 \\
20,00 \\
18,00 \\
18,00 \\
20,00 \\
20,00 \\
18,00 \\
18,00 \\
20,00 \\
20,00\end{array}$ & $\begin{array}{l}114 \\
189 \\
202 \\
208 \\
143 \\
133 \\
104 \\
250 \\
206 \\
172 \\
190 \\
230 \\
206 \\
150 \\
137 \\
234\end{array}$ & $\begin{array}{l}1: 7,8 \\
1: 6,4 \\
1: 6,2 \\
1: 6,2 \\
1: 7,9 \\
1: 7,2 \\
1: 9,8 \\
1: 6,7 \\
1: 7,9 \\
1: 8,8 \\
1: 8,7 \\
1: 7,7 \\
1: 8,2 \\
1: 9,8 \\
1: 11,5 \\
1: 9,8\end{array}$ \\
\hline
\end{tabular}

Tibialis anterior longus, $30,48 \mu$, der Unterschied beträgt also $50 \%$, das ist für ein so konstantes und wichtiges Maass ein sehr bedeutender Unterschied, der auf eine starke Differenzierung der Muskeln hinweist. Vergleicht man die Reihe der Maxima, so sieht man, dass diese im allgemeinen auch eine ansteigende ist, dass aber immerhin dieses Ansteigen nicht gleichmässig vor sich geht; dasselbe gilt für die Minima. Es darf dies auch nicht wundernehmen, da sowohl die Zahlen für die Maxima wie die für die Minima doch recht zufällige sind, je nachdem man zufällig das Glück hat, bei dem Durchsehen der Präparate besonders grosse oder besonders kleine Kerne anzutreffen. Die eigentlich wichtigen Zahlen sind natürlich nur die Durchschnittszahlen. Auch aus dieser Tabelle erkennt man wieder, dass die beiden Teile des Pectoralis ganz verschiedene Muskeln sein müssen, da ihre Kernlängen deutlich voneinander verschieden sind $(21,60 \mu$ und $26,00 \mu)$; dasselbe gilt für die beiden Köpfe des Anconaeus $(22,44 \mu$ und $25,60 \mu)$, die beiden Bauchmuskeln liegen hier allerdings ganz dicht zusammen: 20,64 $\mu$ und $21,46 \mu$. Vergleicht man mit den Durchschnittszahlen für die Kernlänge die Zahlen für DK:LK in der letzten Kolumne der Tabelle, so sieht man, dass die längsten Kerne im allgemeinen wohl auch die schlanksten sind; doch finden sich auch 
A usnahmen. Es scheint danach aber doch, dass im allgemeinen die Querschnittsgrösse der Kerne weniger stark verschieden ist als die Länge. Die Bedeutung der Kernlänge für die Funktion der Muskeln ist bis jetzt noch durchaus dunkel. Ich werde am Schlusse dieser Arbeit versuchen, die sämtlichen hier untersuchten Muskeln in bezug auf ihre Kern- und Faserverbältnisse zu charakterisieren. Ich hoffe, dass es dann verhältnismässig leicht sein wird, bei Untersuchungen über das physiologische Verhalten der Muskeln Schlüsse auf die Bedeutung der hier besprochenen Kern- und Faserverhältnisse $\mathrm{zu}$ ziehen und so allmählich über den Aufbau der Muskeln ins Klare zu kommen.

Vergleicht man die hier bei dem Frosche gefundenen Zahlen für die Kernlänge mit denen, die für die anderen bisher von mir untersuchten Muskeln gefunden worden sind, so sieht man, dass der Frosch ganz ausserordentlich lange Kerne besitzt. Die Zahlen für die menschlichen Augenmuskeln schwankten bei den Erwachsenen zwischen 10,68 und $12,30 \mu$, die für die menschlichen Skelettmuskeln zwischen 11,90 und $15,60 \mu^{1}$ ) (S. 282 und 283, Tab. LX). Bei dem Kaninchen schwankten sie, bei den Muskeln des Formoltieres, bei dell weissen zwisehen 13,77 und 17,67 , bei den roten zwischen 11,23 und 14,92 $\mu^{3}$ ) (S. 282 und 283, Tab. LX). Die- Kerne für das $\mathrm{Z}$ werchfell des Menschen hatten etwa eine Länge von 13-14 $\mu^{2}$ ) (S. 402, Tab. VIII) und die des Sartorius des Hundes eine solche von 11-12 $\mu^{1}$ ) (S. 282 und 283, Tab. LX). Bei weitem die kürzesten Kerne besass die $\mathrm{K}$ arausche in den roten Muskeln, bei denen die Zahlen zwischen 5,50 und $8,25 \mu$ lagen, während die weissen Karauschenmuskeln Kerne von 12,80 und $14,10 \mu$ Länge besassen ${ }^{1}$ ) (S. 282 und 283 , Tab. LX). Alle diese Zahlen bleiben ganz erbeblich zurück hinter denen des Frosches, die ja zwischen 20 und $30 \mu$ liegen. Ähnlich lange Kerne habe ich bis jetzt nur gefunden in den zentralen Muskelfasern der Rumpfmuskulatur des Flussneunauges, bei denen die Durchschnittszahl 19,50 $\mu$ betrug, das Maximum $30,00 \mu$ und das Minimum $10,00 \mu$. Weit kürzer waren die Kerne der

1) P. Schiefferdecker, Muskeln und Muskelkene. 317 Seiten mit 20 Abbildungen im Text. Joh. Ambros. Barth, Leipzig 1909.

2) P. Schiefferdecker, Untersuchung des Zwechfelles auf seinen Bau and seine Kernverhältnisse. Pflüger's Arch. Bd. 139 S. 337. 
parietalen Rumpfmuskulatur desselben Tieres mit 9,18 $\mu$ im Durehschnitte, $14,00 \mu \mathrm{im}$ Maximum und $6,00 \mu$ im Minimum. Auch hier war dann wieder bei den langen Kernen der Querschnitt verbältnismässig klein, so dass DK:LK sich verhielt wie 1:9,37, während die kurzen Kerne verhältnismässig dick waren: DK:LK wie 1:2,50. Auch bei diesen Zahlen tritt es also wieder deutlich hervor, dass die Kernmasse augenscheinlich ganz spezifisch für den betreffenden Muskel sind und wenigstens nicht ohne weiteres von der Stellung des Tieres in der Tierreihe abhängen. Die bedeutende Kernlänge der Froschmuskeln fällt auch bei der Betrachtung des mikroskopischen Bildes sofort auf; ebenso sieht man leicht, dass diese langen Kerne, falls die Kernkörperchen überhaupt deutlich hervortreten, gewöhnlich mehrere solche enthalten. Es wird dieses wohl mit der bedeưtenden Länge der Kerne zusammenhängen.

Wie aus Tabelle XII weiter hervorgeht, schwanken auch die Zahlen für das "Kernvolumen" bei den Froschmuskeln recht wesentlich. Ich habe, um dieses Verhalten noch deutlicher hervortreten zu lassen, in Tabelle XIII (S. 426) die Muskeln wieder nach der Grösse ihres Kernvolumens geordnet. Während der Gastrocnemius ein Kernvolumen von $104 \mathrm{k} \mu$ besitzt, hat der Coraco-Radialis ein solches von $250 \mathrm{k} \mu$, also das $2^{1 / 2}$ fache des ersteren. Die beiden Bauchmuskeln, die ihrer Kernlänge nach dicht zusammen lagen, unterscheiden sich ihrem Kernvolumen nach recht bedeutend (114:189 k $\mu$ ), was natürlich zurückzuführen ist auf die Verschiedenheit des Kernquerschnittes bei den beiden Muskeln; betrug doch DK: LK bei dem einen $1: 7,8$, bei dem anderen $1: 6,4$. Man sieht, dieses Zahlenverhältnis prägt sich, wie es ja auch selbstverständlich ist, im Kernvolumen wieder deutlich aus. Auch in dieser Tabelle finden sich wieder einige Muskeln, die in bezug auf die Grösse ikres Kernvolumens einander nahe stehen; im ganzen bandelt es sich aber doch um eine allmählich aufsteigende Reihe. Tch habe in meinen früheren Muskelarbeiten zeigen können, dass das Kernvolumen bei dem Erwachsenen im ganzen auch als eine spezifische Zahl anzusehen ist. So lagen die Kernvolumina des menschlichen Rectus oculi superior in den vier untersuchten Fällen etwa um $100 \mathrm{k} \mu$ herum, bei den beiden Deltoidei zwischen 93 und $96 \mathrm{k} \mu$, fast ebenso hoch bei Pectoralis major 
(93) und Biceps (97), während der Serratus mit $106 \mathrm{k} \mu$ etwas höher stand ${ }^{1}$ ) (S. 282 und 283, Tab. LX). Das Kernvolumen des Levator betrug nur 54-68 $\mathrm{k} \mu^{1}$ ) (S. 282 und 283, Tab. LX). Beim $\mathrm{Z}$ werchfelle lagen die Zahlen zwischen 66 und $92 \mathrm{k} \mu$; nur der Muskel des Kroaten stieg auf $143 \mathrm{k}^{2}{ }^{2}$ ) (S. 402, Tab. VIII). Bei den weissen Kaninchenmuskeln lagen die Zahlen zwischen 55 und $86 \mathrm{k} \mu$, bei den roten zwischen 88 und $129 \mathrm{k} \mu$. Bei den weissen Karauschenmuskeln zwischen 34 und $38 \mathrm{k} \mu$, bei den roten zwischen 18 und $39 \mathrm{k} \mu^{\mathrm{j}}$ ) (S. 282 und 283, Tab. LX). Beim Neunauge betrug, wie ich wieder vorgreifend bemerken will, das Kernvolumen der zentralen Rumpfmuskeln 66, das der parietalen $97 \mathrm{k} \mu$. Wir sehen also, dass das Kernvolumen bei den Froschmuskeln verhältnismässig recht hoch ist: Die niedrigsten Zahlen der Froschmuskeln entsprechen etwa den höchsten der Muskeln der von mir bisher untersuchten Wesen.

\section{Tabelle XIII.}

Rana esculenta. Muskeln, geordnet nach der Grösse des Kernvolumens.
1. Gastrocnemius . . . . . . . $104 \mathrm{k} \mu$
2. Rectus abdominis . . . . . . . 114 "
3. Tensor fasciae latae. . . . . . . 133 "
4. Gracilis . . . . . . . . 137 "
5. Anconaeus caput scapulare. . . . . 143 "
6. Pectineus . . . . . . . . . $150 "$
7. Anconaeus caput mediale ..... . 172 "
8. Transversus abdominis . . . . . . . $189 "$
9. Pectoralis pars sternalis ..... . . 190 "
10. Sartorius . . . . . . . . . 202"
11. Flexor carpi radialis. . . . . . . $206 "$
12. Cruralis . . . . . . . . . $206 "$
13. Pectoralis pars epicoracoidea. . . . 208."
14. Deltoides. . . . . . . . . $230 "$
15. Tibialis anterior longus ..... . $284 "$
16. Coraco-Radialis . . . . . . . 250 "

Wir finden also in den Froschmuskeln verbältnismäsig wenige und dabei grosse Kerne und eine ver-

1) P. Schiefferdecker, Muskeln und Muskelkerne. 317 Seiten mit 20 Abbildungen im Text. Joh. Ambros. Barth, Leipzig 1909.

2) P. Schiefferdecker, Untersuchung des Zwerchfelles auf seinen Bau und seine Kernverhältnisse. P flüg er's Arch. Bd. 139 S. 337. 
hältnismässig geringe Zahl für die relative Kernmasse: Die Froschmuskeln sind also anzusehen als verhältnismässig kernarme Muskeln, als Muskeln, die verhältnismässig wenig Kernmasse besitzen, und bei denen diese Kernmasse auf verhältnismässig grosse Kerne verteilt ist. Es spricht dies dafür, dass der Stoffwechsel in ihnen ein langsamer, ist und dass infolgedessen wohl auch die Energie der Muskeltätigkeit eine verhältnismässig geringe ist. Das ungünstige Moment, das in der Verteilung der an sich schon geringen Kernmasse auf wenige und verhältnismässig grosse Kerne liegt, wird allerdings zu einem Teile wieder gemildert dadurch, dass die Kerne im Verhältnisse zu ihrer Dicke recht lang sind; denn je weiter der Kern sich von der Kugelgestalt entfernt, um so grösser wird seine Oberfläche im Verhältnisse zu seinem Inhalte. Je stärker aber dieses Verbältnis ausgeprägt ist, um so leichter wird ein chemischer Austausch zwischen Kern und Faser stattfinden, um so grösser wird also der Einfluss des Kernes auf die Faser werden. Wir werden daher annehmenkönnen, dass diejenigen Muskeln, die verhältnismässig lange und schmale Kerne besitzen, einen stärkeren inneren Stoffwechsel aufweisen werden als diejenigen, welche verhältnismässig kurze und dicke Kerne besitzen. Auch dass die langen Kerne meist mehrere Kernkörperchen besitzen, darf man hierbei nicht unberücksichtigt lassen, denn nach den zurzeit vorliegenden Untersuchungen scheint es, dass a uch die Kernkörperchen für den Stoffwechsel des Kernes und der Zelle von nicht unwesentlicher Bedeutung sind. Daher fanden sich ja auch, wie ich das in meiner zweiten Muskelarbeit besonders hervorgehoben habe, stets Kernkörperchen in solchen Kernen, die durch ihre Lage in Kernreihen erkennen liessen, dass sie im Vermehrungsprozesse begriffen waren, oder dass sie wenigstens eben durch einen solchen entstanden waren, während in den sonstigen, mehr im ruhigen Gleichgewichte befindilichen Kernen die Kernkörperchen vielfach fehlten.

In Tabelle XIV (S. 428) sind die "modifizierten Kernzahlen" und die Zahlen für die "Gesamtkernmasse" zusammengestellt. Die Muskeln stehen wieder in der ursprünglichen Grundanordnung. Wie man im Vergleiche mit Tabelle VII erkennt, haben sich die Kernzahlen, zum Teil wenigstens, nicht unwesentlich ge- 
ändert. Es liegt das eben daran, dass die Kerne der versehiedenen Muskeln doch recht verschieden lang waren. Infolgedessen haben diejenigen Muskeln, welche sehr lange Kerne besassen, kleinere Zahien bekommen, und umgekehrt diejenigen, welche kurze Kerne besassen, grössere; am wenigsten sind natürlich die Zahlen derjenigen Muskeln verändert worden, deren Kerne eine mittlere Länge besassen. Im ganzen sind die Zahlen für die verschiedenen Muskeln nicht sehr . stark voneinander verschieden; auch bei der "absoluten Kernzahl" in Tabelle VII war das ähnlich. Die Grösse der Faserquerschnitte schwankte ja auch nicht sehr bedeutend, im Maximum um das Doppelte.

Tabelle XIV.

Rana esculenta. Modifizierte Kernzahlen und Gesamtkernmasse.

\begin{tabular}{|c|c|c|}
\hline Name des Muskels & $\begin{array}{l}\text { Modifizierte } \\
\text { Kernzablen }\end{array}$ & $\begin{array}{c}\text { Gesamt- } \\
\text { kernmasse }\end{array}$ \\
\hline 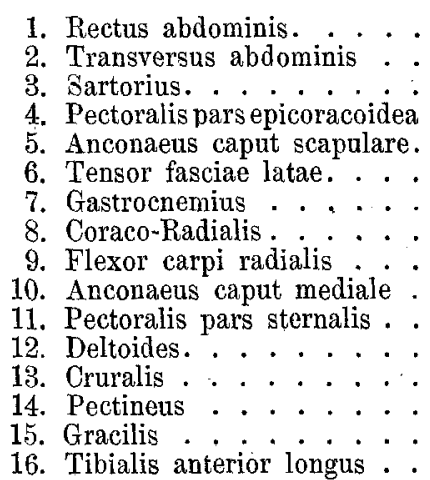 & $\begin{array}{l}3,53 \\
3,12 \\
3,53 \\
3,07 \\
3,50 \\
3,46 \\
5,86 \\
3,97 \\
3,63 \\
2,72 \\
3,61 \\
2,76 \\
4,52 \\
2,79 \\
3,65 \\
2,81\end{array}$ & $\begin{array}{l}402,42 \\
589,68 \\
713,06 \\
638,56 \\
500,50 \\
460,18 \\
609,44 \\
992,50 \\
747,78 \\
467,84 \\
685,90 \\
634,80 \\
931,12 \\
418,50 \\
500,05 \\
657,54\end{array}$ \\
\hline
\end{tabular}

Bei den Zahlen für die "Gesamtkernmasse" ist die Grösse des Kernvolumens berücksichtigt worden. Die Zahlen sind ja dadurch erhalten, dass das Kernvolumen mit der modifizierten Kernzahl multipliziert wurde. Diese Zahlen haben hier bei dem Vergleiche der verschiedenen Muskeln miteinander nur wenig Bedeutung; sie werden erst wichtig, wenn man verschiedene Exemplare desselben Muskels, die sich in versehiedenen Zuständen befinden, miteinander vergleicht. Ich habe sie hier nur der Vollständigkeit wegen aufgeführt.

Die Zahlen für die "modifizierten Kernzahlen" und für die „Gesamtkernmasse" sind relative Zahlen und gelten nur für die gerade miteinander verglichenen Muskeln. 


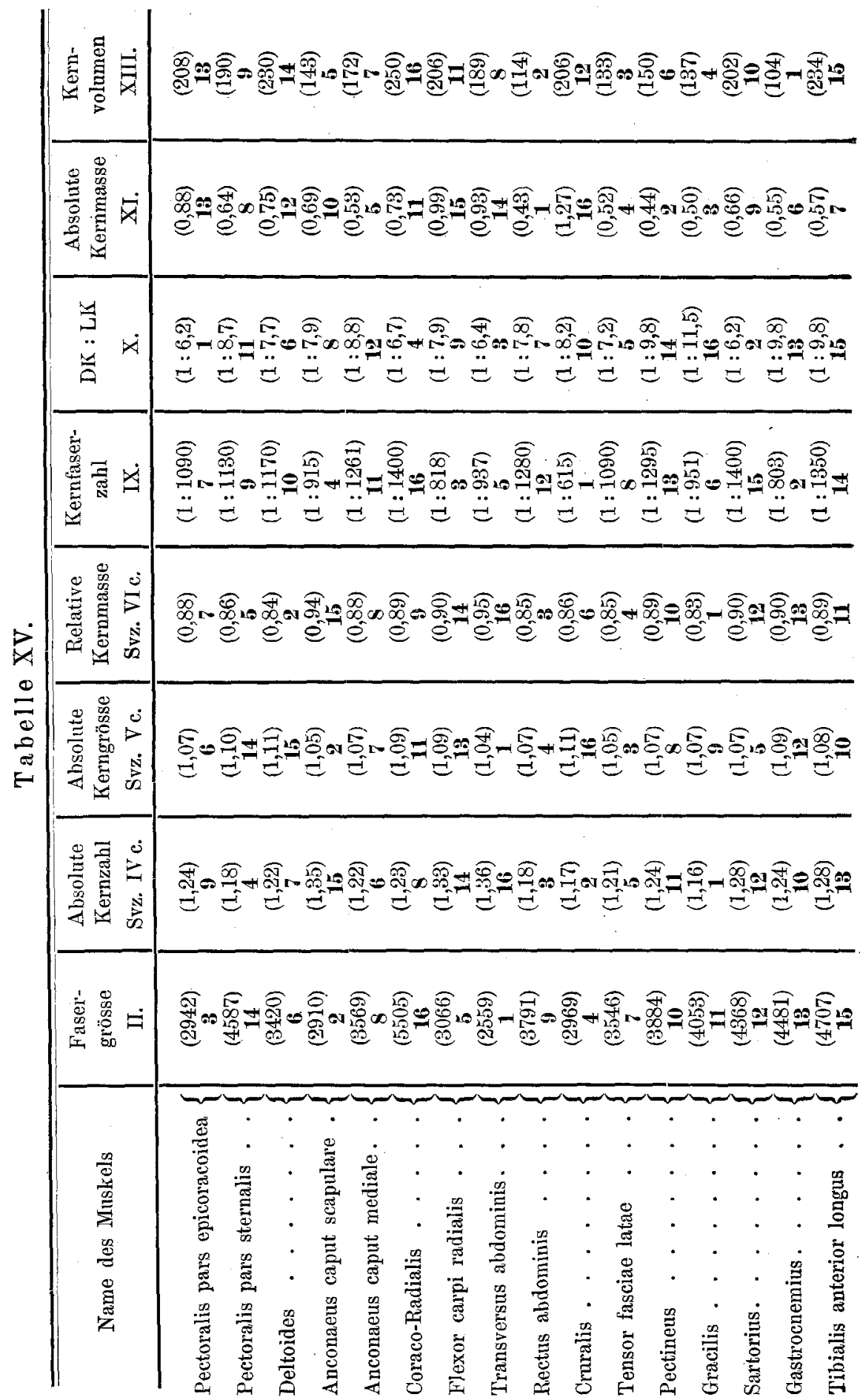


In Tabelle XV (S. 429) habe ich dann versucht, eine $\mathrm{Zu}$ sammenstellung der charakteristischen Eigentümlichkeiten der einzelnen Muskeln zu geben, um eben jeden Muskel kurz und doch deutlich allen andern gegenüber zu charakterisieren. Als charakteristische Grössen sind hierzu verwendet worden: 1. die "Fasergrösse" (Tab. II), 2. die „Schlussverhältniszahlen" (Svz.) der „absoluten Kern zahl", der "absoluten Kerngrösse", der "relativen Kernmasse" (in den Tab. IV e, V c, VIe), die „Kernfaserzabl" (Tab. IX), das Verhältnis DK:LK (Tab. X), die "relative Kernmasse" (Tab. XI), das „Kernvolumen" (Tab. XII).

In den einzelnen Kolumnen für diese Grössen sind dann jedesmal die Zablen eingetragen (die fett gedruckten Zahlen der unteren Reihe), welche die Stelle angeben; die der Muskel in der betreffenden Tabelle einnimmt. Man kann aus diesen Zahlen sofort erkennen, eine wie niedrige oder wie hohe Stellung der Muskel in der betreffenden Tabelle einnimmt, und man kann so, wenn man die in der gleichen Reihe stehenden Zahlen miteinander im Geiste verbindet, sich wenigstens ein ungefähres Bild von dem gesamten Aufbaue res Muskels schnell im Kopfe entwerfen. Diese Zablen würden nun dadurch eventuell zu einer Täuschung Veranlassung geben können, als mitunter, wie ich das bei den einzelnen Tabellen oben schon hervorgehoben habe, mehrere Muskeln dieselben Zahlen aufweisen und dabei dennoch eine andere Zahl für ihre Stellung erhalten müssen. Um eine solche Täuschung auszuschliessen, und um gleichzeitig es dem Leser zu ermöglichen, die Grösse des Unterschiedes zwischen den einzelnen Muskeln rasch festzustellen, sind die Zahlen aus den Tabellen in Klammern über die Hauptzahlen herübergeschrieben. So ist es erreicht worden, dass diese Tabelle eine schnelle Übersicht gibt und doch gleichzeitig auch für einen genaueren Vergleich ausreicht. Ich hoffe daher, dass diese Tabelle sich für jeden als praktisch erweisen wird, der z. B. bei physiologischer Untersuchung, sich schnell über den Charakter der einzelnen Muskeln orientieren will. Es wird nun aber auch darauf ankommen, diese hier anatomisch untersuchten Muskeln physiologisch genau zu untersuchen, um auf diese Weise die Bedeutung der hier gefundenen morphologischen Unterschiede für die Funktion des Muskels festzustellen. Ich habe schon in meiner ersten Muskelarbeit hervorgehoben, dass man sich die Zahlen für die einzelnen für den Muskelaufbau wichtigen Grössen auch als Farben denken könnte, die man ibrer Grösse entsprechend als Sektoren 
auf einen Farbenkreisel auftragen würde; dann würde durch die Mischung dieser Farben bei der Drehung des Kreisels ein bestimmter Farbenton entstehen, der für den betreffenden Muskel charakteristisch wäre. Diese Tabelle XV stellt uns gewissermaassen einen solchen Farbenkreisel dar, dessen Sektoren, deren Grösse dureh die Zahlen ausgedrückt wird, wir im Geiste zu einem Gesamtbilde vermischen können, zu einem Gesamtbilde, das eben für den betreffenden Muskel charakteristisch ist.

Ich habe oben bei der Besprechung des mikroskopischen Bildes auf S. $378 \mathrm{ff}$. (ich mache auf diese Besprechung hier noch besonders aufmerksam) darauf hingewiesen, dass das mikroskopische Bild für die sämtlichen hier untersuchten Muskeln so übereinstimmend war, dass man daraus den Schluss ziehen konnte, dass eine Differenzierung dieser Froschmuskeln kaum vorhanden war. Ich machte aber damals schon darauf aufmerksam, dass man erst die Resultate der Ausmessungen abwarten müsse, um hierüber ein einigermaassen sicheres Urteil gewinnen zu können. Wie wir nun aus den bisherigen Tabellen schon ersehen haben, und wie das hier in Tabelle $X V$, in dieser Schlusstabelle, sehr übersichtlich hervortritt, sind die hier untersuchten Froschmuskeln in bezug auf ihre Kern- und Faserverhältnisse sehr deutlich differenziert, wenn auch nicht so hochgradige Unterschiede zwischen den einzelnen Muskeln bestehen, wie ich sie bei mehreren der bisher untersuchten Wesen habe nachweisen können. Im ganzen kann man die Differenzierung bei den hier untersuchten Froschmuskeln doch wohl nur als eine mässig starke bezeichnen, so viel geht aber deutlich aus den Untersuchungen hervor, dass a uch beim Frosche schon jeder Muskel in bezug auf seine Kern-und Faserverhältnisse ein ganz spezifisches Verhalten zeigt. Die Erkenntnis dieser spezifischen Differenzierung war aber nur möglich mit der von mir angewandten Ausmessungsmethode. Die sonstigen histologischen Untersuchungsmethoden lassen uns hier völlig im Stiche. $\mathrm{Zu}$ diesem Resultate bin ich ja auch schion in meiner ersten Muskelarbeit gekommen, in der ich bei den dort untersuchten erkrankten menschlichen Muskeln Unterschiede in dem feineren Aufbaue nachweisen konnte, die durch die Erkrankungen bedingt waren, deren Nachweis mit den gewöhnlichen Untersuchungsmethoden ebenfalls völlig ausgesehlossen gewesen wäre. 


\section{Kurze Zusammenfassung der Resultate.}

1. Bei den hier untersuchten Froschmuskeln war zunächst auffallend die grosse Ähnlichkeit des mikroskopischen Bildes bei sämtlichen Muskeln.

2. Es fanden sich überall gut ausgebildete polygonale Muskelfaserquerschnitte mit im allgemeinen abgerundeten Ecken, die nur hin und wieder schärfer hervortraten. Zwischen diesen lagen in den meisten Muskeln, ganz unvermittelt, weit kleinere Querschnitte, die meist weit schärfere Ecken zeigten als die grossen. Die Bedeutung dieser Erscheinung ist unbekannt. Nach der Form zu schliessen, scheinen diese kleinen Querschnitte zu Muskelfasern zu gebören, die eine geringere "Protoplasmaspannung" besitzen als die, zu denen die grossen gehören. Die Spannung dieser muss im allgemeinen ziemlich gross sein, da sie meist ziemlich gut abgerundete Ecken zeigten, obgleich sie dicht aneinander lagen.

3. Die Muskelkerne lagen bei allen Muskeln binnenständig, nur hin und wieder fanden sich randständige Kerne in ganz geringer Anzahl. Die Binnenständigkeit der Kerne ist also jedenfalls für den Froschmuskel charakteristisch.

4. Die Menge des Bindegewebes war bei den hier untersuchten Froschmuskeln eine ganz ausserordentlich geringe, weit geringer, als bei den sonst bisher von mir untersuchten Muskeln.

5. Auch das elastische Gewebe war nur in ganz geringer Menge vorhanden.

6. Es scheint, dass der Grad der Ausbildung des elastischen Gewebes im Muskel bis zu einem gewissen Maasse abhängig ist von der Menge des vorhandenen Bindegewebes, sei es nun fulkrales oder nutritives. Hauptsächlich ist derselbe aber augenscheinlich abhängig von der "Spezifität des Bindegewebes“, und diese hängt beim Muskel wieder $a b$ von der "Spezifität des Muskels"

7. Die Querschnittsgrösse der Muskelfasern bei den hier untersuchten Muskeln war sehr bedeutend, bedeutender als bei all den bisher von mir untersuchten Muskeln.

Der Unterschied in der Grösse der Fasern der hier untersuchten Muskeln war verhältnismässig gering und betrug höchstens das Doppelte.

8. Die Querschnittsgrösse der Muskelfasern ist für jeden Muskel spezifisch, und es ist keine Beziehung vorhanden zwischen ihr und der Kernlänge. 
9. Bei allen hier untersuchten Muskeln nahmen sowohl die "Kernzahlen" wie die "Querschnittsgrösse des Kernes" in den einzelnen Muskeln mit der Zunahme der Fasergrösse in mehr oder weniger hohem Grade relativ ab. Die Querschnittsgrösse nahm dabei in höherem Grade ab als die Kernzahl. Diese Beobachtungen habe ich bei allen bisher untersuchten Muskeln mit wenigen Ausnahmen gemacht.

10. Infolge dieses Verhaltens der Kerne nimmt auch die Gesamtmasse der Kerne, in Prozenten der Fasermasse ausgedrückt, die "relative Kernmasse", bei zunehmender Fasergrösse ab. Die Grösse dieser Abnahme ist bei den einzelnen Muskeln verschieden.

11. Aus meiner Zwerchfellarbeit konnte ich den Schluss ziehen, dass die Schlussverhältniszahlen für die "absolute Kernzahl", für die „absolute Kerngrösse" und für die "relative Kernmasse" gerade für die "Qualität" der 'Tätigkeit eines Muskels von wesentlicher Bedeutung sind. Man würde demgemäss durch die Zusammenstellung dieser Zahlen für einen jeden Muskel eine Art von Formel für die qualitative Beschaffenheit dieses Muskels aufstellen können, wie ich das auf Seite 411 und 412 versucht habe.

12. Die Muskeln waren verhältnismässig arm an Kernen, doch schwankte die Menge dieser bei den einzelnen Muskeln nicht unwesentlich, so dass das Fasergebiet, welches der Kern in den einzelnen Muskeln zu beherrschen hat, verschieden gross war.

13. Die Kerne waren dabei im Verhältnisse zu denen bei den bisher von mir untersuchten Muskeln sehr lang. Die Kernlänge zeigte bei den einzelnen Muskeln ziemlich bedeutende Verschiedenheiten, und ebenso war auch das Verhältnis der Dicke zu der Länge bei den Kernen der einzelnen Muskeln nicht unwesentlich verschieden.

Je länger und schlanker ein Kern ist, um so mehr entfernt er sich von der Form der Kugel, welche im Verhältnisse zu ihrem Inhalte die kleinste Oberfläche besitzt, um so grösser wird also seine Oberfläche im Verbältnisse zu seinem Inhalte, was für den chemischen Stoffumsatz zwischen Kern und Zelle von Bedeutung sein muss.

14. Das "Volumen" der Froschkerne war sehr gross. Die "relative Kernmasse" war bei den einzelnen Muskeln recht verschieden gross, aber im ganzen verhältnismässig klein. Die hier untersuchten Froschmuskeln enthielten also im Verhältnisse zu den bisher von mir untersuchten Muskeln wenig Kernmasse. Da diese 
geringe Kernmasse auf verhältnismässig sehr grosse Kerne verteilt war, so war die Anzahl der Kerne eben im ganzen gering. Dieses alles war ungünstig für den inneren Stoffwechsel der Fasern, den Austausch zwischen Kern und Zelle. Günstig für den Stoffwechsel musste dabei die grosse Länge der Kerne wirken, wie das oben schon hervorgehoben wurde. Im allgemeinen waren die längsten Kerne auch die schlanksten.

15. Die Grösse der "relativen Kernmasse", d. h. der in Prozenten der Fasermasse ausgedrückten Kernmasse eines Muskels, hängt nach meinen bisherigen Beobachtungen augenscheinlich nur oder doch im wesentlichen von der spezifischen Beschaffenheit des betreffenden Muskels $a b$, nicht von der Stellung des Tieres in der Tierreihe.

16. Die "Kernkörperchen" waren nicht immer sichtbar, waren aber, wo sie hervortraten, häufig in der Mehrzahl vorhanden, was wohl mit der Länge der Kerne zusammenhängt.

17. Die "Kernverhältnisse" der Froschmuskeln sprechen dafür, dass der Stoffwechsel in diesen ein langsamer ist, und dass infolgedessen wohl auch die Energie der Muskeltätigkeit eine verhältnismässig geringe ist. Man wird annehmen können, dass diejenigen Muskeln, die verhältnismässig lange und schlanke Kerne besitzen, einen stärkeren inneren Stoffwechsel aufweisen als diejenigen, welche verhältnismässig kurze und dicke Kerne besitzen. Da nach unsern jetzigen Kenntnissen auch die "Kernkörperehen" an dem Stoffwechsel des Kernes und der Zelle nicht unwesentlich beteiligt sind, so wird der Umstand, dass in den langen Kernen auch mehrere Kernkörperchen vorkommen können, hierbei auch berücksichtigt werden müssen.

18. Während der histologische Aufbau bei den hier untersuchten Muskeln kaum annehmen liess, dass eine deutliche Differenzierung der einzelnen Muskeln vorhanden sei, ergab die Ausmessung, dass dieses doch durchaus der Fall war. Ein jeder Muskel zejgte sich völlig spezifisch differenziert. Die Zahlen für die einzelnen für den Muskelaufbau charakteristischen Grössen zeigten bei den hier untersuchten Muskeln allerdings nicht so grosse Unterschiede, wie ich sie bei manchen von den bisher untersuchten Wesen batte feststellen können, so dass man den Grad der Differenzierung wohl als "mằssig hoch" bezeichnen "konnte. In einer Schlusstabelle (Tabelle XV) 
habe ich versucht, durch eine kurze Zusammenstellung der für den Aufbau der Muskeln wichtigen Zahlen ein Übersichtsbild über die Differenzierung zu geben. Ich hoffe, dass diese Zusammenstellung wie überhaupt die in dieser Arbeit mitgeteilten Untersuchungen von Nutzen sein werden für eine genaue physiologische Untersuchung der Froschmuskeln und auch vielleicht $\mathrm{zu}$ einer solchen anregen werden. Die durch eine solche Untersuchung gewonnenen physiologischen Ergebnisse würden dann hoffentlich erjauben, den Wert der hier für die einzelnen Muskeln gefundenen Zahlen für die Funktion derselben festzustellen.

\section{Literatur.}

1) P. Schiefferdecker, Beiträge zur Kenntnis der Myotonia congenita, der Tetanie mit myotonischen Symptomen, der Paralysis agitans und einiger anderer Muskelkrankheiten, zur Kenntnis der Aktivitätshypertrophie und des normalen Muskelbaues. Mit klinischen Beiträgen von Prof. Fr. Schultze. Deutsche Zeitschr. f. Nervenheilk. Bd. 25 H. 1-4 S. 1-345 m. 15 Taf. 1903.

2). P. Schiefferdecker, Muskeln und Muskelkerne. 317 Seiten mit $20 \mathrm{Ab}-$ bildungen im Text. Joh. A mb. Barth, Leipzig 1909.

3) P. Schiefferdecker, Untersuchung des Zwerchfelles auf seinen Bau und seine Kernverhältnisse. Pflüger's Arch. Bd. 139 S. 337-427, mit 7 Textfiguren u. 4 Fahnentabellen.

4) L. Ha u ck, Untersuchungen zur normalen und pathologischen Histologie der quergestreiften Muskulatur. Inaug.-Diss., 18 Seiten. Leipzig 1900. Zugleich erschienen in: Deutsche Zeitschr. f. Nervenheilk. Bd. 17.

5) Ph. Knoll, Über protoplasmaarme und protoplasmareiche Muskulatur. Denkscbr. d. k. Akad. d. Wissensch. zu Wien, math.-naturwissensch. Kl. Bd. 58 S. $633 \rightarrow 700$ m. 9 Taf. 1891.

6) J. Schafter, Beiträge zur Histologie und Histogenese der quergestreiften Muskelfasern des Menschen und einiger Wirbeltiere. Sitzungsber. d. k. Akad. d. Wissensch. zu Wien, math.-naturwissensch. Kl. Bd. 102 Abt. 3 S. 7-148 m. 6 Taf. 1893.

7) R. Mayeda, Über die Kaliberverhältnisse der quergestreiften Muskelfaser. Zeitschr. f. Biol. Bd. 27 N. F. 1890; Bd. 9 S. 119-1ว2 m. 2 Taf.

8) K. B. Lehmann, Untersuchungen über den Hämoglobingehalt der Muskeln. Zeitschr. f. Biol. Bd. 45 S. 324-345. 1903. 